EFEITO DE SISTMMAS DE ROTAGÃO, SUCKS,SÃO F NIVIEIS, DE CATAGRM, SOBRIS CARACIIERISTICAS FISICAS F QUIMICAS DO SOLO IF NO DESIGNVOIVIMIRNTO DO SISTIGMA RADICULAR IF PRODURÃO DE GRÃOS DF MILHO (Zea maYe L)

ANTONIO CARLOS BARRETD

Engenheiro Agronomo, Mestre

Orientador: Prof. Dr. ANTONIO ROQUE DECHEN

Tese apresentada à Escola Superior de Agricultura "Luiz de Queiroz", da Universidade de Såo Paulo, para obtenção do título de Doutor em Agronomia, Area de Concentração : Solos e Nutrição de Plantas.

P I R A C I C A B A

Estado de Såo Paulo - Brasil

Março - 1991 
Ficha catalográfica preparada pela Seção de Livros da Divisão de Biblioteca e Documentação - PCAP/USP

Barreto, Antonio Carlos

B273e Efeito de sistemas de rotação, sucessão e níveis de calagem, sobre características físicas e químicas do solo e no desenvol vimento do sistema radicular e produção de grãos de milho (Zeá mays L.). Piracicaba, 1991.

154p. ilus.

Tese - ESALQ

Bibliografia.

1. Calagem 2. Milho - Calagem - Efeito 3. Milho - Grão Produção 4. Milho - Raiz - Desenvolvimento 5. Milho - Rotação 6. Rotação de cultura agrícola 7. Solo - Propriedade física 8. Solo - Propriedade química I. Escola Superior de Agricultu ra Luiz de Queiroz, Piracicaba

CDD 633.15 
EFETTO DE SISTHMAS DE ROTACÃO, SUCESSÃO E NIVEIS DE CALAGEM, SOBRE CARACIKRISTICAS FISICAS $E$ QUIMICAS DO SOLO $F$ NO DESENVOLVIMEATY DO SISTHMA RADICUILAR F PRODUGÃ̃ DE GRÃOS DE MIIHO (Zea maỸa L)

\author{
ANTÔNIO CARLOS BARRETO
}

Aprovada em:

Comissao julgadora:

Prof. Dr. Antonio Roque Dechen ESALQ/USP

Prof. Dr. Henrique Paulo Haag ESALQ/USP

Prof. Dr. Flávio Zanette UF do Paraná

Dra. Sonia Carmela Falci Dechen IAC

Dr. Pedro Roberto Furlani

IAC
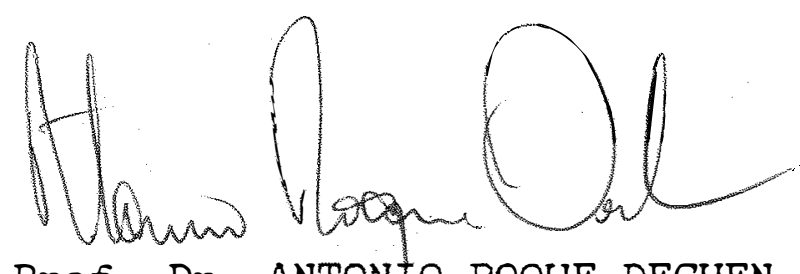

Prof. Dr. ANTONIO ROQUE DECHEN

Orientador 
Dedico este trabalho

Aos meus pais $\begin{gathered}\text { FRANiCISCO e } \\ \text { ALIETE } \\ e\end{gathered}$

Aos meus filhos FERNANDA e LUCAS 


\section{Agradecimentos}

- Ao Prof. Dr. Antonio Roque Dechen, pela segura orientação em todas as fases do trabalho, e pela relação de amizade e confiança.

- Á Dra. Sonia Carmela Falci Dechen, por ter permitido a utilização do experimento, e pela ajuda no trabalho de campo.

- Ao Dr. Francisco Lombardi Neto, chefe da Seção de Conservação do Solo do IAC.

- Ao Prof. Dr. Quirino Augusto de Camargo Carmello, pela ajuda na área de computação e sugestões na redação final do trabalho.

- Ao Prof. Dr. Cássio Roberto de Melo Godoi e Pósgraduanda Sônia Maria D Stefano Piedade, pela colaboração na área estatistica.

- 'A Empresa Brasileira de Pesquisa Agropecuária (EMBRAPA)

- À Escola Superior de Agricultura"Luiz de Queiroz"(ESALQ)

- Ao Conselho Nacional de Desenvolvimento Cientifico e Tecnológico ( $\mathrm{CNPq})$

- 'A Seção de Conservação do Solo do Instituto Agronômico 


\section{SUMÁR IO}

Página

RESUMO .......................... vi

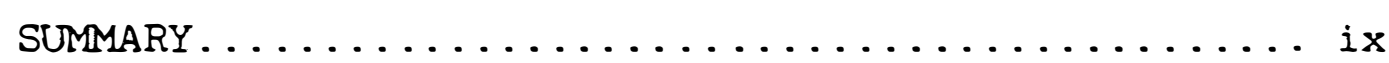

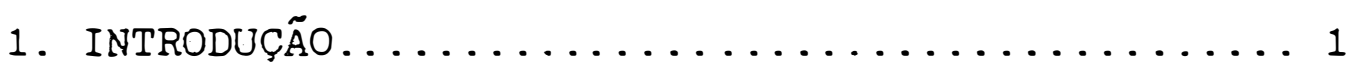

2. REVISÄO DE LITERATURA................... 7

2.1. Rotação de culturas e ou adubação verde... 8

2.1.1. Efeito sobre as caracteristicas quimicas do solo.............. 8

2.1.2. Efeito sobre as caracteristicas fisicas do solo..................13

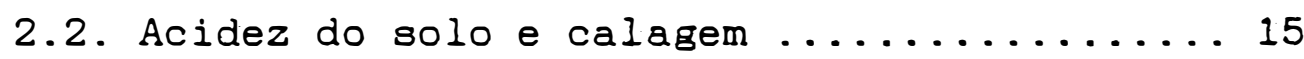

2.3. Sistema radicular ................ 20

2.3.1. Considerações gerais...........20

2.3.2. Crescimento de raizes em relação às caracteristicas quimicas e físi-

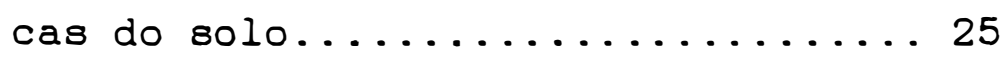

2.3.3. Avaliação do sistema radicular .... 31

2.3.3.1. Estudo descritivo $x$ estudo ecológico de raizes .......31

2.3.3.2. Métodos de avaliação do sistema radicular......... 33

3. MATERIAL E METODOS.................... 37

3.1. Caracteristicas da área experimental ..... 37

3.1 .1$. Clima .................. 37 
Página

3.1.2. Solo .................. 38

3.2. Caracteristicas do experimento ........ 39

3.2.1. Dimensões ................. 39

3.2.2. Tratamentos .............. 39

3.2.3. Culturas (Caracteristicas agronômicas $\ldots \ldots \ldots \ldots \ldots \ldots \ldots \ldots \ldots$

3.2.3.1. Amendoim............40 40

3.2.3.2. Milho.............4 41

3.2.3.3. Mucuna-preta.......... 41

3.2.4. Delineamento experimental .......4 42

3.3. Desenvolvimento do trabalho.......... 42

3.3.1. Avaliação do sistema radicular .... 42

3.3.1.1. Método do trado ........43

3.3.1.2. Método do perfil .......45

3.3.2. Avaliação de caracteristicas físicas do solo $\ldots \ldots \ldots \ldots \ldots \ldots \ldots \ldots$

3.3.3. Avaliação de caracteristicas químicas do solo................ 4 ?

3.3.4. Análise foliar ............4 48

3.3.5. Produção de graos ............49

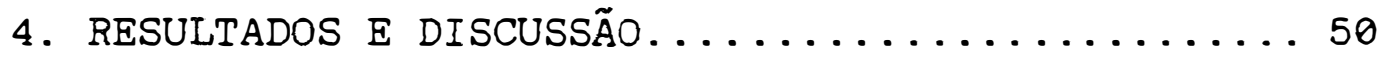

4.1. Caracteristicas químicas do solo........ 50

4.1.1. Efeito dos sistemas de produção.... 50

4.1.2. Efeito da calagem............6 61

4.1.2.1. Fósforo............6 63 
Página

4.1.2.2. Matéria orgânica.......66 63

$4.1 .2 .3 . \mathrm{pH} \ldots \ldots \ldots \ldots \ldots \ldots . \ldots . \ldots 64$

4.1.2.4. Potássio, cálcio e magnesio 66

4.1.2.5. H + Al e Alumínio trocável. 68

$4.1 .2 .6 . \mathrm{S}, \mathrm{CTC}$ e V\% ...........71

4.1.2.7. Cobre, Ferro, Manganês e

Zinco..............73

4.1.3. Efeito da profundidade......... 79

4.2. Caracteristicas físicas do solo........ 85

4.3. Avaliação do sistema radicular..........93

4.3.1. Método do trado..............93

4.3.2. Método do perfil............. 103

4.4. Nutrientes absorvidos............... 118

4.5. Produção de gräos................. 121

4.6. Métodos de avaliação do sistema radicular.. 123

5. CONCLUSÕES. . . . . . . . . . . . . . . . . . 127

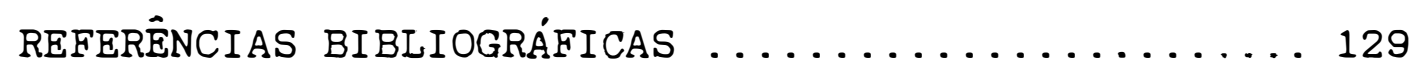


FERITIO DE STISTEMAS DE ROTAQÃO, SUCBSSÃO $F$ NIUVEIS DE CAKAGEM, SOBRE CARACIERISTICAS FISICAS F QUTIMICAS DO SOLO $\mathrm{F}$ NO DESENVOLVIMFNTO DO SISTFMA RADICUIAR I PRODUCẼOA DE GRÁOS DE MILHO (Zea maye I.-)

Autor: ANTÔNIO CARLOS BARRETO Orientador: PROF. DR. ANTONIO ROQUE DECHEN

RESUMO

Avaliou-se o efeito da rotação e sucessão de amendoim e mucuna-preta sobre a cultura de milho, em comparação com o seu cultivo contínuo, bem como a ação de três níveis de calagem, tentando-se associar os resultados às mudanças ocorridas em características físicas e químicas do solo, e de que forma estas afetariam o desenvolvimento do sistema radicular, os nutrientes absorvidos, e a produção de grãos.

O trabalho foi desenvolvido no Centro Experimental de Campinas, do Instituto Agronômico, em Campinas - SP, em um experimento instalado em Latossolo Vermelho-Escuro, no oitavo ano de sua condução. 0 experimento, em blocos ao acaso com parcelas subdivididas e três repetições, tinha nas parcelas os seguintes tratamentos : milho contínuo (Mi-cont.); rotação de milho 
com amendoim e este com amendoim em sucessāo ( $\mathrm{Mi}-\mathrm{Aa} / \mathrm{As}$ ); e rotação de milho com amendoim e este com mucuna-preta em sucessão (Mi-Aa/Mu), e nas subparcelas os níveis de calagem: 0,3 e 6 t/ha. A profundidade de amostragem do solo foi considerada como um fator de estudo e tratada como subsubparcela.

Amostras de solo foram retiradas das profundidades 0 a 20,20 a 40 e 40 a $60 \mathrm{~cm}$ e avaliadas quanto às características químicas; Mat. Org., pH, P, K, $\mathrm{Ca}, \mathrm{Mg}, \mathrm{Al}$ troc., $\mathrm{H}+\mathrm{Al}$, Cu, Fe, $\mathrm{Mn}$ e $\mathrm{Zn}$, soma de bases, saturação por bases e capacidade de troca de cátions.

A avaliação do sistema radicular foi feita através do método do trado, o qual constou da retirada de amostras volumétricas de solo + raizes de 10 em $10 \mathrm{~cm}$ até à profundidade de $50 \mathrm{~cm}$, utilizando-se um trado tipo caneca com $7 \mathrm{~cm}$ de diâmetro. Após a separação das raizes, elas foram secas e pesadas. Utilizou-se também o método do perfil, através do qual fez-se uma avaliação da quantidade de raizes em um perfil transversal à linha de plantio central da parcela.

Das trincheiras abertas para a execução desse método, foram retiradas amostras indeformadas de solo, usadas na determinação da porosidade total, macroporosidade, densidade aparente e curva característica de umidade para as profundidades 0 a $20 ; 20$ a 40 e 40 a 60 cm. 
Determinaram-se os teores de N, P, K, Ca, $\mathrm{Mg}, \mathrm{S}, \mathrm{B}, \mathrm{Cu}, \mathrm{Fe}, \mathrm{Mn}$ e $\mathrm{Zn}$, em uma amostra composta do terço central de folhas +4 de quinze plantas de milho e avaliouse a produção de grãos de toda a parcela.

Os resultados mostraram que os sistemas de rotação e sucessão não afetaram as caracteristicas fisicas e químicas do solo e estas, por sua vez, não alteraram o desenvolvimento do sistema radicular e nem a produção do milho, quando comparados com o cultivo contínuo.

Já a calagem, mesmo após quatro anos e meio da última aplicação, ainda foi capaz de manter seu efeito principalmente, sobre a neutralização do aluminio trocável e sobre os teores de cálcio e magnésio, o que promoveu maior desenvolvimento do sistema radicular e maior produção de grãos, não alterando porêm, as caracteristicas físicas do solo. A calagem atuou também em profundidade, mas foi na camada $\theta$ a $20 \mathrm{~cm}$ que as caracteristicas químicas apresentaram maior variação.

O método do perfil se mostrou mais adequado para o estudo do sistema radicular, que o método do trado. O desenvolvimento do sistema radicular mostrou uma relação direta com a produção de grãos e com os efeitos resultantes da ação dos fatores em estudo. 
CROP ROTATION, CROP SUCCBSSIDN AND LIME RATES ON THE SOII CHFAI MAI AND PHISICAL CHARACIFRISTICS AND MAIZE Clea maye L-) FOXI SYSTIM ANI YIELD

Author: ANTÔNIO CAFIOS BARRETO Adviser: PROF. DR. ANTONIO ROQUUE DECHEN

SUMMARY

The effects of both crop rotation and succession of peanut or velvet bean on the corn plants were evaluated in comparison with a continuous maize crop. Also, the effects of three lime rates were studied in relation to the changes in some soil chemical and physical characteristics. The root system distributior nutrients concentrations and grain yield of corn were also determined.

A field experiment was carried out at the Experimental Center of the Instituto Agronômico in Campinas, State of Sao Paulo. The soil is classified as a Dark-Red Latosol and the samples were taken in the 8 th year of experimentation. A randomized complete block design was used in a split-plot arrangement, with three replications. Three cropping systems, as the plots, were as follows: 
continuous maize cropping (Mi-cont.); maize and wet-season peanut in rotation ( $\mathrm{Mi}-\mathrm{Aa} / \mathrm{As})$; and this one with dry-season peanut in succession, and maize and wet-season peanut in rotation, and this one with velvet bean in succession (Mi$\mathrm{Aa} / \mathrm{Mu})$. Lime rates $(0,3$ and $6 \mathrm{t} / \mathrm{ha})$ constituted the subplots. Soil sampling depths $(0$ to $20 \mathrm{~cm} ; 20$ to $40 \mathrm{~cm}$ and 40 to $60 \mathrm{~cm}$ ) were considered as sub-sub-plots.

Soil organic matter, $\mathrm{pH}$, phosphorus, exchangeable cations (potassium, calcium, magnesium and aluminum plus hydrogen), extractable copper, iron, zinc, manganese, percentage of basis saturation and cation exchangeable capacity were calculated.

The root system was evaluated by through the auger method, using an auger with $7 \mathrm{~cm}$ in diameter. In such evaluation samples were taken containing soil plus root down to $50 \mathrm{~cm}$ depth by a $10 \mathrm{~cm}$ interval. Roots were separated from the soil, were dried and weighed. Also a profile wall method was used to estimate the amount of roots in a transverse profile to the middle row. After a 5 $\mathrm{mm}$ of soil removal, from the whole profile a counting was done through the utilization of a "string-crossline" $60 \mathrm{x}$ $90 \mathrm{~cm}$, with $5 \mathrm{~cm} \times 5 \mathrm{~cm}$ meshes. From the same trenches, undeformed soil sampling were taken in the three depths to determine total porosity, macroporosity, bulk density, and moisture characteristic curve. 
Crop grain yields were recorded and +4 maize leaves collected at the bloom stage were analysed, for nitrogen, phosphorus, potassium, calcium, magnesium, sulfur, boron, copper, iron, manganese and zinc.

The results showed that both crop rotation and succession did not cause any change on the soil chemical and physical characteristics studied. There were no changes in the development of the root system nor the maize yield, when compared to the continuous cropping.

The effects of liming on the exchangeable aluminum and on the exchangeable calcium and magnesium were verified even though it was applied for the last time in the experimental area four and half years before. As a consequence of those changes, a better growth of the root system and higher grain yield were found out. Liming did not change any of the physical characteristic determined in the soil properties related to soil depth. Most soil chemical characteristics changed with lime in the $\theta$ to 20 cm soil layer.

The profile wall method proved to be better than the auger method to evaluate the root system.

The growth of the root system showed to be related directly the grain yield and also to the effects of the other studied variables. 


\section{INTRODUÇÃO}

Como regra geral, quando se destrói a vegetação natural e se cultiva.os solos, sua estrutura sofre deterioração, e ainda que esta deterioração esteja relacionada com a diminuição do conteúdo de matéria orgânica (BAVER et alii, 1972), talvez nao seja esta sua única causa, sendo o impacto das gotas de chuva sobre o solo descoberto e o uso de implementos agricolas, sem dúvida, também em parte responsáveis (BLACK, 1975).

Alguns autores, tais como (YAALON \& YARON, 1966), chegaram a propor que o estudo das mudanças provocadas pelo homem no solo fosse efetuado independentemente da pedogênese histórica e ambiental, denominando esse estudo de "metapedogênese", e considerando - solo natural, como sendo o material de origem e o estádio inicial das modificações que o homem acarreta. Enquanto nos processos naturais de formação de solos, os fatores pedogênicos agem em um prolongado periodo de tempo, os fatores metapedogênicos atuam, nas propriedades do solo, intensa e rapidamente.

A medida que a exploração agricola se intensifica, a capacidade produtiva dos solos naturalmemte 
tende a diminuir, o que pode variar de acoivo com as características de cada solo.

Os desgastes prematuros dos solos, quando nao irreversiveis, crescentes e ameaçadores, aliados aos altos custos dos fertilizantes químicos e outros insumos, têm provocado, nos últimos tempos, uma certa revitalizaçao de antigas práticas de cultivo, tais como a rotação de culturas e a adubação verde.

A rotação de culturas e a aduíação verde são práticas consideradas como melhoradoras do solo, conferindo-lhe boas caracteristicas do ponto de vista físico, quimico e biológico, desejáveis para um desenvolvimento satisfatório das plantas.

No Estado de Sao Paulo, pioneiro no Brasil na realização de pesquisas sobre o assunto, MIYASAKA (1984), cita que a prática da adubação verde já era recomendada, desde 1919, por D' UTRA, quando na ocasião publicou o trabalho "Adubos Verdes", onde destacava suas qualidades como melhoradores das características do solo. Esse trabalho foi o ponto de partida para a realização, pelo Instituto Agronômico e depois pela Escola Superior de Agricultura "Luiz de Queiroz", de uma série de outros estu-

D'UTRA, G.R.D. Adubos verdes: sua produção e modo de emprego. Campinas, Instituto Agronômico de Campinas, 1919. 76p. (Relatório). 
dos abrangendo diversas culturas (NEME, 1934; KIEHL \& GALLI, 1951; VIÉGAS et alii, 1960 e CAVALERI el alii, $1963)$.

Segundo SILVA (1984), os estudos sobre rotação de culturas envolvendo algodão, milho, leguminosas e outras plantas, iniciaram-se com a instalação de ensaios permanentes no municipio de Campinas, em 1936, que mais tarde estenderam-se para outros municípios (YATES, 1952; CORRÊA et alii, 1961; FERRAZ et alii, 1977 e MIYASAKA et alii, 1983).

Diversos trabalhos também tiveram inficio e vêm sendo desenvolvidos em outros Estados (FUNDAÇÃO CARGILL, 1984).

Muitos resultados têm sido obtidos, e em geral, os efeitos benéficos destas práticas estão relacionados com as diferenças quanto às necessidades nutricionais dentre as espécies cultivadas, à fixação de nitrogênio e à adição de outros nutrientes ao solo, bem como, à melhoria de suas características químicas, físicas e biológicas, o controle de nematóides, de algumas doenças e ervas daninhas, e ainda, à redução das perdas de solo pela erosão, além de proporcionarem maior eficiência com relação ao aspecto prático no manejo das culturas na propriedade.

Existem casos, no entanto, em que não se observam, mudanças favoráveis, como por exemplo em 
características do solo, (NASCIMENTO et alli, 1988 e UCHIKAWA, 1989), e em algumas situaçōes, podem até ocorrer resultados negativos, como alerta (BRAGA, 1984).

Uma avaliação crítica feita por BRAGA (1984), sobre o conjunto de resultados disponiveis no Estado de São Paulo, indica que a aferição dos efeitos da adubação verde, pelo desempenho de culturas econômicas consecutivas, apresenta um caráter empírico, porque não proporciona, na maioria dos casos, elementos para um entendimento seguro dos mecanismos responsáveis pelos resultados obtidos.

Através de uma análise mais abrangente, CANNELL (1981), admite que o efeito de cultivos sobre o crescimento das culturas tem sido examinado em multos experimentos. No entanto, ele também salienta que a maioria desses experimentos tem sido de natureza empírica, nos quais somente se mede a produção, ou quando muito, apenas parte das características do meio, as quais estão envolvidas no estudo e as razões das diferenças observadas nem sempre são esclarecidas. Sugere que os dados de produção das culturas podem ser suplementados por informações adicionais sobre $\circ$ crescimento das plantas entre o plantio e a colheita, as condicões do solo, além do crescimento e da função das raízes, o que ele denomina de estudo intensivo. 
O presente trabalho, teve como objetivo avaliar o comportamento da cultura de milho em sistemas de rotação e sucessão com amendoim e mucuna preta, em comparação com o cultivo continuo desse cereal, em diferentes niveis de calagem, após oito anos de condução do ensaio.

A avaliação foi feita através da determinação, nos diversos tratamentos, de caracteristicas físicas e químicas do solo, dos teores de nutrientes absorvidos e da produção da cultura de milho, e especialmente por meio do estudo do comportamento do sistema radicular da cultura, através de dois métodos. Verificou-se até que ponto o sistema radicular manifestava mudanças no seu desenvolvimento; se estas estavam associadas às variações nas caracteristicas físicas e quimicas do solo provocadas pelos tratamentos e se as mudanças no desenvolvimento do sistema radicular estavam relacionadas com os teores dos nutrientes e a produção de milho.

Como hipóteses, admitiu-se que:

- A rotação de culturas e ou a adubação verde alteram as caracteristicas físicas e químicas do solo, afetando o desenvolvimento das raízes e, consequentemente, a produção de milho.

- A prática da calagem, ao corrigir a acidez, neutraliza a ação de elementos tóxicos, otimizando a disponibilidade 
de nutrientes, além de promover outros beneficios, tais como a adição de cálcio e magnésio ao solo, afetando também, o desenvolvimento das raizes e a produção. 


\section{REVISÃo DE LITERATURA}

A distribuicão de raízes no solo resulta de uma série de processos complexos e dinâmicos, os quais incluem as interações entre 0 ambiente, 0 solo e as plantas em pleno crescimento. Uma vez que a água e os nutrientes são absorvidos pelas raízes, sua concentração, distribuição e atividade (taxa de crescimento e longevidade) dentro do perfil do solo, é em grande parte que determinará a produção das culturas (BROWN \& SCOTT, 1984). $\&$

Segundo os mesmos autores, as condições do solo que mais frequentemente determinam o crescimento das raízes e seu modelo de distribuicão são: 1) profundidade da zona de raízes; 2) características da zona de raízes que se referem à densidade do solo, aeração, movimento de água, nutrientes, pH e a presença de elementos tóxicos; e 3) grau de competicão intra e interespecifica das raízes resultante da alta população de plantas ou da infestação de ervas daninhas.

Assim sendo, as diversas práticas de cultivo ou manejo das culturas, ao afetarem as caracteristicas do solo, indiretamente alteram as condições 
de desenvolvimento das raizes, o que por sua vez, refletese na produção.

\subsection{Rotação de culturas e ou adubação verde}

\subsubsection{Efeitos sobre as caracteristicas quimicas do solo}

o desenvolvimento gradativo dos vegetais, fixando o carbono a partir do dióxido de carbono $\left(\mathrm{CO}_{2}\right)$ atmosférico e incorporando nitrogênio em pequenas adições anuais, proveniente, em parte, das águas da chuva e da fixação do nitrogênio do ar por microrganismos, além de outras contribuições, permite o acúmulo progressivo de grande parte da matéria organica dos 80108.

A matéria orgânica constitui-se em um dos fatores de maior importância no condicionamento da produtividade dos solos, e sua presença produz sensiveis alterações nas propriedades físicas, químicas e biológicas dos 80108 .

Do ponto de vista químico, o objetivo da introdução da rotação de culturas e a inclusão de leguminosas é, a longo prazo, estabilizar a produção com o uso de pouca ou nenhuma prática de pousio, e tal estabilização depende criticamente da habilidade de se preservar o nitrogênio fixado e outros nutrientes na 
matéria orgânica do solo, e construir uma ativa reserva de nutrientes organicamente retidos (DORAN \& SMITH, 1987 e TIESSEN, 1988).

A maior ou menor quantidade de húmus proveniente da decomposição da matéria orgânica, apresenta influência acentuada na capacidade de troca de cátions do solo (CTC) e, em geral, essa capacidade aumenta em função do conteúdo de matéria orgânica.

Estudos efetuados por LOPES \& COX (1977), sobre as caracteristicas dos solos de cerrados brasileiros, mostraram que na CTC efetiva há forte contribuicão da matéria orgânica em 80108 com pH acima de 5,5 , sendo que esta aumenta à medida que aumenta o teor de matéria orgânica, contribuindo pouco entre $\mathrm{pH} 5,0$ e 5,5 e tendo efeito negativo para $\mathrm{pH}$ menor que 5,0 .

Outro aspecto importante da matéria orgânica é a formação de complexos organometálicos, solúveis e insolúveis, quando ions como $\mathrm{Cu}^{+2}, \mathrm{Zn}^{+2}, \mathrm{Mn}^{+2}$, Co+2 e outros têm o potencial de formar ligações de coordenação com moléculas orgânicas, participando do transporte de metais nos processos de pedogêneselixiviaçao, da disponibilidade de micronutrientes para plantas e microorganismos, da diminuição da toxicidade de alguns metais e aumentando a resistência do húmus à decomposição ( IGUE, 1984). 
Segundo DORAN \& SMITH (1987), om muitos 80108 dos Estados Unidos, onde a vegetação natural foi retirada para o plantio e produção de graős, a fertilidade natural declinou significativamente, sendo a matéria orgânica do solo consumida pela retirada das colneitas, sem que se fizesse reposição subsequente, através de resíduos vegetais ou animais. Com o decréscimo de 40 a $60 \%$ no teor de matéria orgânica original dos solos, a produtividade diminuiu, as perdas por erosão superficial aumentaram e a mineralização liquida do nitrogênio orgânico do solo ficou abaixo das necessidades das plantas.

Com a rotação de culturas procura-se combinar uma alternância de espécies que se complementem em diversos aspectos. Do ponto de vista químico, as culturas podem, por exemplo, influenciar na reação do solo diretamente, por meio da retirada diferencial de nutrientes pelas raízes ou pela adição de outros nutrientes através da decomposição (PEEVY \& NORMAN, 1948; BARBER, 1974). BARBER (1974), verificou uma maior absorção de ânions do que de cátions pelo sistema radicular da soja, causando uma maior liberação de ânions $\mathrm{OH}^{-}$e $\mathrm{HCO}_{3}^{-}$, para a manutenção do balanço de cargas. RILEY \& BARBER (1969), observaram que a soja também é capaz de aumentar o pH em uma unidade, quando comparado com o nivel original.

A fixaçao simbiótica faz das leguminosas culturas indispensáveis nas rotações, visto os beneficios 
que promovem às culturas subseqüentes, e especialmente às gramíneas que são exigentes em nitrogênio. Até certo ponto, a adubação verde pode ser vista como parte de um esquema mais amplo de rotação.

Os resultados dessas práticas, entretanto, são um tanto contraditórios, pois nem sempre são obtidos resultados favoráveis, o que pode estar relacionado com a escolha das espécies e a sequência seguida (PRIMAVESI, 1979), e com fatores climáticos, uma vez que as propriedades do solo se manifestam em função dos teores de umidade variáveis, da temperatura do solo e da radiação solar, as quais podem modificar o efeito de tratamentos no mesmo local, em ocasiões diferentes (BAEUMER, 1981).

VIEIRA (1961), avaliou, por cinco anos, o uso de diferentés leguminosas, sobre a produção de grãos de milho e os resultados médios indicaram que a mucuna intercalada ao milho promoveu um aumento de $21 \%$ em relação à testemunha, seguindo-se o feijão-de-porco e a ervilha-devaca, enquanto o guandu apresentou resultado idêntico à testemunha, sendo que este resultado foi dependente do ano.

MUZILLI (1983) verificou, entre outras coisas, que a inclusão de soja no esquema de rotação de culturas contribui para a diminuição da intensidade de ocorrência da deficiência de nitrogênio, a qual se manifesta principalmente em milho e trigo cultivados sob 
plantio direto. Constatou também, que houve aumento no teor de matéria orgânica no decorrer do tempo.

HALLAN \& BARTHOLOMEU (1953) demonstraram que, em três diferentes solos, a adição de resíduos de soja e de milho proporcionou uma maior perda da matéria orgânica nativa do 8010 .

VASCONCELLOS et alii (1986), verificaram que a rotação soja-milho propiciou uma melhor distribuição de bases nas camadas mais profundas do solo, aumentando a saturação por cálcio. Houve, nas áreas comi rotação mucunamilho maiores teores de potássio, de cálcio e de magnésio, quando relacionados com os demais sistemas (soja-milho, milho contínuo e milho após milho + mucuna intercalar).

$$
\text { NASCIMENTO et alii (1988), em estudo }
$$

conduzido durante três anos, em um latossolo sob vegetaçao de cerrado, com diferentes rotações com milho, arroz, soja e lablab, mostraram que, nas frações ácidos fúlvicos, ácidos húmicos e humina, a rotação de culturas, em geral, não afetou de modo significativo a distribuição de carbono.

VIÉGAS et alii (1960), avaliaram, em diferentes localidades do Estado de Säo Paulo, o efeito fertilizante da mucuna-preta intercalada na cultura do milho. Concluiram que, embora a mucuna tenha provocado consideráveis aumentos na produção do milho, não afetou o 
teor de matéria orgânica dos solos e praticamente não modificou as suas caracteristicas químicas estudadas.

UCHIKAWA (1989), conduzindo experimento em um Latossolo Roxo Eutrófico, com as culturas de milho e soja em cultivo contínuo e em diferentes combinacões de rotaçã, verificou, através da análise de amostras retiradas de três profundidades $(\theta-10,10-20$ e 20 $30 \mathrm{~cm}$ ), que os diversos tratamentos nao afetaram os teores de carbono orgânico total do solo e que a rotação de culturas nao foi eficiente para a melhoria das caracteristicas químicas ( $\mathrm{pH}, \mathrm{P}, \mathrm{K}, \mathrm{Ca}, \mathrm{Mg}, \mathrm{Al}$ e acidez trocável), quando comparada com as parcelas que envolveram as monoculturas de milho e soja. Inclusive a monocultura de soja apresentou maiores valores de $\mathrm{pH}$, Ca e Mg no solo.

\subsubsection{Efeito sobre as caracteristicas fisicas do 5010}

A rotação de culturas tem sido indicada como meio de restaurar as propriedades fisicas do solo e aumentar seu potencial de produção, o que foi demonstrado por trabalhos como os de HAAS (1958) e de SPRATT (1966). As raizes profundas das leguminosas, por exemplo, têm um efeito particularmente benéfico sobre as culturas subseqüentes (SPRATT \& McCURDY, 1966). Na India, as culturas que se seguem ao guandu, uma leguminosa com 
sistema radicular profundo e vigoroso, apresentam, frequentemente, melhor comportamento, por duas razões: 1) residuo da raiz e nitrogênio fixado e 2) melhoria das condições do subsolo, o que possibilita melhor infiltração da água. As raizes dessa leguminosa podem penetrar através da rigida textura encontrada nos solos vermelhos e lateriticos, o que outras culturas, tais como os cereais, nao conseguem (HURD \& SPRATT, 1982).

A formação de agregados e sua estabilidade são determinadas pelo suprimento contínuo de residuos orgânicos (raizes, folhas e caules) e por sua decomposição no solo, pela atividade microbiana. Um método eficiente para se favorecer a estruturação do solo é a combinação de gramineas que possuam um sistema radicular abundante e em constante renovação, com leguminosas que fixem nitrogênio, o que acelera a decomposição (HARRIS et alii, 1966), tornando-os mais resistentes à ação do impacto das gotas de chuva e ao transporte através da enxurrada (DECHEN et alii, 1981). Também devido à relação $\mathrm{C} / \mathrm{N}$ elevada, as raízes das gramineas sao decompostas mais lentamente, e portanto, atuam como agentes estabilizadores importantes dos macroagregados, e por conseguinte, contribuem para a melhoria da estruturação do solo (TISDALL \& OADES, 1980).

A instabilidade estrutural é frequentemente encontrada na superficie de solos cultivados, e isso permite a formação de crostas e a translocação da argila 
para o subsolo, sendo que as crostas podem reduzir a taxa de infiltração. A acumulação de matéria orgânica na superficie, através de práticas de cultivo conservacionistas, é a mais viável solução para o problema (HAMBLIN, 1985).

Os adubos verdes, segundo IGUE (1984), em função da espécie que é cultivada, do espaçamento e da densidade de plantas, podem ter efeitos fisicos diretos sobre 0 solo, pois sendo uma cobertura natural, eles diminuem a intensidade de radiação solar e, portanto, a temperatura do solo, protegendo-o contra o impacto direto das chuvas, diminuindo a erosão e possibilitando uma maior infiltração.

Para KIEHL (1979), a matéria orgânica é um dos principais fatores que favorecem a estruturação do solo, sendo que o sistema de manejo é outro fator relacionado com a estrutura, assim, entre outras condições, os cultivos continuados e sem rotação de culturas provocam a destruição da estrutura do solo.

\subsection{Acidez do solo e calagem}

Os solos naturais diferem entre si, consideravelmente em sua reação, que é caracterizada pelo $\mathrm{pH}$, e estas diferenças se refletem na vegetação natural ou nos cultivos praticados. 
No Brasil, a condição de reação do solo mais comum é a de acidez excessiva, ou de baixo pH, o qual se apresenta noçivo às plantas, devido, quase que exclusivamente, aos seus efeitos secundários, os quais são, principalmente, excesso de aluminio e manganês solúveis, escassez de cálcio e, algumas vezes, escassez de fósforo ou molibdênio.

A importância relativa desses fatores depende da composição do solo, e da magnitude com que o efeito sobre a proporção de cálcio, fósforo, alumínio e manganês assimiláveis que 0 solo contém ocorre, e da susceptibilidade das culturas à uma deficiência de cálcio ou a um excesso de alumínio ou manganês (RUSSELL \& RUSSELL, $1968)$.

Dentre esses fatores, a toxidez de aluminio é considerada $\circ$ fator limitante mais importante para $\circ$ crescimento e desenvolvimento de plantas, em solos com elevada acidez.

Os efeitos mais drásticos da fitotoxidez de aluminio ocorrem nas raizes, e as plantas afetadas apresentam os seguintes sintomas: início da emissão de raizes próximas ao ponto de crescimento da raiz principal e inibição do crescimento de raízes laterais, tendo como consequência, um sistema radicular desprovido de raízes finas, reduzido em tamanho e com aparência coralóide (FOY, $1984)$ 
Em decorrência das altewações no desenvolvimento das raizes, o sistema radicular é pouco desenvolvido, e em condições de campo, pode prejudicar a capacidade de exploração de água e nutrientes, sendo que as plantas tornam-se mais susceptiveis a déficits hidricos e nutricionais, o que geralmente ocorre nos periodos de estiagem curtos, podendo afetar, consideravelmente, a produtividade.

As tentativas para especificar as razões das mudanças no comportamento de plantas quando os solos são submetidos à variaçoes na acidez, devem considerar um grande número de características do solo, que são simultaneamente alteradas, além da sensibilidade das espécies e variedades de plantas a tais alterações ser excessivamente diversa (JACKSON, 1967).

Segundo FURLANI (1989), embora esteja sendo considerável o esforço direcionado para o entendimento de aspectos básicos e aplicados envolvidos na fitotoxidez de aluminio, nao existe, ainda, o conhecimento pleno dos efeitos fisiológicos e bioquímicos acarretados por esse elemento em plantas, e dentre as dificuldades existentes destacam-se: a) a complexidade de se entender a físicoquímica do alumínio; b) a ausência de radioisótopo adequado; c) a ausência de método confiável e sensível para a sua deteção em amostra biológica e d) os problemas de contaminação nas análises químicas. 
Apesar do refinamento dos estudos, como os que têm sido feitos tentando relacionar a toxidez de alumínio com a especiação na solução do solo, a concentração total do aluminio ainda é um importante indicativo da sua toxidez (CAMARGO \& FURLANI, 1989).

A caracterização da acidez é feita hoje de forma segura e em geral, por um dos três métodos seguintes: SMP, alumínio trocável e através da correlação entre pH e saturação por bases, todos visando à recomendação de calagem para uma correção racional da acidez.

O efeito da calagem em culturas varia nao só com o tipo de solo, mas com a espécie vegetal ou o cultivar utilizado, bem como com o nivel de manejo geral, e, às vezes, por causa de fatores nao determinados. Não obstante os diversos beneficios desta prática, tais como a neutralização do alumínio e do manganês tóxicos, 0 aumento nos teores de cálcio e magnésio, 0 aumento na disponibilidade de fósforo e ou molibdênio, o aumento da nitrificação ou da fixação de nitrogenio e até pela melhoria das propriedades físicas de alguns solos, ela pode apresentar efeitos desfavoráveis, entre outros, a diminuição da disponibilidade de alguns micronutrientes ou de potássio, sendo muito difícil estabelecer-se exatamente - que está em jogo (RAIJ, 1983).

O efeito da calagem sobre a disponibilidade de fósforo, por exemplo, é perfeitamente comprovado por 
dados experimentais, e inclusive, podem ser estabelecidas relações de substituição entre o fósforo e calagem como mostram os dados de VIDOR \& FREIRE (1972).

(No efeito da calagem também se manifesta sobre algumas propriedades fisicas do solo, como foi observado por BOLTON et alii (1979b), em experimento com milho continuo e em rotação com alfafa e aveia, durante 13 anos, onde a calagem esteve associada ac aumento médio no espaço poroso, sendo maior nos sistemas de rotação, do que no milho continuo.

Mas como MARSCHNER (1986) salienta, aliado à aeração deficiente e à resistência mecânica, o baixo pH do subsolo é um importante fator para restringir o crescimento das raizes, nessa região. Sendo imóvel no floema, o cálcio necessário para o crescimento das raizes deve ser obtido da solução externa pelas suas zonas apicais. As raizes são, portanto, severamente inibidas em sua capacidade de penetrar em subsolos ácidos, mesmo quando uma quantidace adequada de calcário for adicionada à camada superficial.

Para algumas espécies a exigência de cálcio para o crescimento das raizes nao tem um valor fixo, mas sim varia em função do $\mathrm{pH}$ e da concentração de outros cátions, inclusive alumínio. Em algodão, por exemplo, em pH 5,6, - 1 uM de cálcio na solução externa é suficiente para - crescimento máximo das raízes, quando comparado com os 50 
UM, para pH 4,5 (IUND, 1970). Em geral, é necessário para o máximo crescimento, $15 \%$ de saturação por cálcio na solução do solo, mas como em solos minerais ácidos a taxa encontrada é, em geral, menor, a calagem nesses solos tende, portanto, a aumentar a extensão das raízes e 0 comprimento dos pelos radiculares (HAYNES \& LUDECKE, 1981). Comentando resultados obtidos no Estado de São Paulo sobre as respostas de algumas culturas a doses de calcário, QUAGGIO (1986), apresenta o amendoim como uma planta tolerante à acidez, com pequena resposta à calagem, cerca de apenas $10 \%$ da produção, 0 que deve estar associado ainda a um melhor suprimento de cálcio para os frutos; já a soja, 0 milho, 0 algodão e 0 girassol são plantas mais susceptiveis à acidez, com respostas - diferenciadas à calagem, e que chegam a ultrapassar em $300 \%$ a produção da testemunha.

\subsection{Sistema radicular}

\section{$2 \cdot 3 \cdot 1$. Considerações gerais}

A interdependência entre raiz e parte aérea é a mais óbvia caracteristica das plantas - a raiz obtém água e nutrientes, enquanto a parte aérea é a fonte inicial de todos os metabólitos orgânicos. Entretanto, esse fato, por si só nao explica a estreita correlaçăo que existe 
entre o crescimento da raiz e da parte aérea durante a fase vegetativa. Por exemplo, se uma parte da raiz ou da parte aérea é removida, alguns meristemas recuperam a relação original rapidamente, sem afetar o crescimento contínuo. As raizes sao o principal local de sintese de algurs hormônios que regulam o crescimento, tais como citoguininas e giberelinas. O etileno, que é produzido tanto na raiz como na parte aérea, também é um regulador de crescimerto. Esses conhecimentos têm dado uma nova dimensão ao sstudo do sistema radicular: ele nao é meramente ùm orgão de absorção. As raízes e a parte aérea devem, portanto, ser consideradas conjuntamente quando se deseja um adequado entendimento sobre a performance das plantas (RUSSELL, $1981)$

A prática da rotação e ou adubação verde, assim como a da calagem, têm se mostrado capazes de melhorar diversas caracteristicas físicas e quimicas do solo (SCHUURMAN, 1965; BARBER, 1971; BARBER et alii, 1988). Como consequência, o sistema radicular é favorecido indiretamente.

No entanto, nem sempre a raiz se comporta de maneira previsivel frente aos diversos fatores, tanto em condições favoráveis, como em situações adversas.

Nenhum dos fatores adversos do solo afeta todo o sistema de raizes na mesma intensidade. A deficiência de água é comumente mais severa próximo à 
superficie do solo, e assim também são os efeitos das mudanças bruscas de temperatura. A Anaerobiose é mais provável ocorrer em camadas mais profundas, e impedimentos mecânicos podem ser largamente confinados à estreitas zonas compactadas. Mesmo quando o suprimento de nutrientes é inadequado, eles podem ser relativamente abundantes em regiões localizadas (RUSSELL, 1981).

Conforme esse mesmo autor, em todas essas situações, independente de sua causa, ocorre o que ele chama de crescimento compensatório, fenômeno por sinal apenas parcialmente compreendido. Assim, por exemplo, se a diminuição do potencial de água restringe o crescimento próximo à superficie do solo, as raizes mais profundas recebem continuamente um suprimento de água favorável e elas podem se estender e ramificar muito mais do que quando o ambiente é favorável para todo o sistema radicular.

KLEPPER et alii (1973), por exemplo, em um estudo com algodão usando o rizotron, verificaram que com um $\mathrm{Fm}$ de $-0,9 \mathrm{MPa}$, ocorreu um decréscimo na densidade do comprimento de raizes, na profundidade $\theta-30 \mathrm{~cm}$, de 2,7 $\mathrm{cm} / \mathrm{cm}^{3}$ para $0,9 \mathrm{~cm} / \mathrm{cm}^{3}$ indicando a morte anterior de raizes. Entretanto, houve um correspondente aumento na densidade de raizes a $1,8 \mathrm{~m}$ de profundidade, que foi de 0,3 $\mathrm{cm} / \mathrm{cm}^{3}$ para $2,4 \mathrm{~cm} / \mathrm{cm}^{3}$, indicando a ocorrência de crescimento compensatório. 
Os principais fatores que determinam 0 crescimento das raizes no solo são: idade da planta, suprimento de oxigênio, umidade, temperatura, disponibilidade de nutrientes, pressão osmótica da solução do solo, cultivar e os métodos de cultivo (WIERSMA, 1959).

No solo ocorre, geralmente, a interação entre alguns desses fatores, e em consequencia, o efeito prejudicial de um dos fatores pode diminuir ou até melhorar os outros (RUSSELI \& RUSSELL, 1968).

- número de raízes primárias, as quais se desenvolvem da germinação das sementes ou da base do caule pode variar grandemente entre as espécies. Destas raízes partem ramificações laterais que funcionalmente, se assemelham às principais, mas diferem em dois importantes aspectos: são menores em diâmetro e em comprimento e, enquanto as raizes principais apresentam geotropismo positivo, as laterais, inicialmente, crescem horizontalmente ou através da superficie do solo, embora posteriurmente também cresçam para baixo. Esta estrutura básica causa a grande concentração de raízes próximo à superfície do solo em relação às profundidades maiores, mesmo quando os fatores do solo nao restringem a sua extensão. E raro que rafzes de culturas anuais ou bianuais, na profundidade $10-15 \mathrm{~cm}$, ocupem mais que $5 \%$ do volume do solo, sendo que, usualmente, ocupam bem menos e na 
profundidade 0,5 a $1,0 \mathrm{~m}$, elas frequentemente representam tão pouco quanto $0,1 \%$ (RUSSELL, 1981).

O crescimento do sistema radicular das culturas anuais raramente continua em todo o ciclo de desenvolvimento. Existem vários trabalhos na literatura mostrando que, no caso dos cerais, esse crescimento continua até à floração e depois cessa (MENGEL \& BARBER, 1974; EVANS \& WARDLAW, 1976). Por outro lado, MCCLURE \& HARVEY (1962) e HURD (1968) relatam que, sob condições favoráveis, o crescimento das raízes continua até o estádio de maturaçao.

FOTH (1962), enfatizou a necessidade de um melhor conhecimento do desenvolvimento radicular, e fez um estudo tentando associar o crescimento da raiz com o da parte aérea, na cultura do milho. Ele descreve que, inicialmente, o crescimento das raízes ocorre largamente em um sentido diagonal, seguido por um crescimento lateral extensivo. O crescimento lateral foi completado uma a duas semanas antes da emergência da espiga e causou uma marcante uniformidade na densidade de raizes entre 30 e $45 \mathrm{~cm}$ de profundidade. O aparecimento de raízes mais grossas, de sustentação, ocorreu próximo ao crescimento completo das raízes laterais. O crescimento extensivo de raízes abaixo de $45 \mathrm{~cm}$ ocorreu próximo ao embonecamento, sendo que no estádio de espiga o crescimento de raízes foi completado. O desenvolvimento inicial das plantas foi caracterizado por 
um rápido crescimento de raízes e parte aérea. Este último aumentou mais rapidamente, causando um aumento na relaça parte aérea/raiz. Esse período foi seguituo por um desenvolvimento das raízes mais grossas, o que causou um declínio da relação. O desenvolvimento dos grä́os ocorreu grandemente, após o crescimento de raízes ter cessado e foi associado a um aumento da relação.

\subsubsection{Crescimento de raizes em relậão a caracteristicas fisicas e guimicas do 5010}

O cultivo do solo, inevitavelmente, afeta suas caracteristicas físicas e químicas, as quais, com o tempo, apresentam mudanças que, consequentemente, interferem no desenvolvimento das plantas e, mais diretamente, refletem-se sobre o sistema radicular.

Em um grande número de trabalhos que tratam dos efeitos das condições do solo sobre o desenvolvimento de raizes, uma conclusão geralmente aceita, segundo REICHARDT (1981), é o problema do pequeno crescimento de raízes nos solos extremamente intemperizados dos trópicos e subtrópicos, sendo esse crescimento de raizes, em geral, muito menor nos trópicos do que nas regiões temperadas, para quase todas as culturas. 
Os principais fatores responsáveis atribuem-se que sejam: a) baixo $\mathrm{pH}$ do solo; b) alto $\mathrm{Al}+3$ trocável; c) compactação do solo; d) inadequada aeração; e) baixa retenção e transmissão de água.

Quando os solos, por exemplo, são compactados, a densidade aumenta e o número de macroporos é diminuido, as raizes nao podem reduzir seu diâmetro para entrar nos poros menores que o diâmetro de sua extremidade (WIERSUM, 1957), e assim, as raizes, para crescer em solos compactados, têm que deslocar as particulas do solo. Segundo BLACK (1975), o fato de as raizes penetrarem em espessuras reduzidas, de materiais nao porosos, como por exemplo, algumas ceras, demonstra que o tamanho dos poros do substrato, por si só, nao é um fator decisivo. O tamanho dos poros é importante se suas paredes nao cederem à pressão das raizes em crescimento.

Alguns; trabalhos têm evidenciado que a diminuição na penetração radicular está relacionada, principalmente, com a resistência que o solo compactado oferece a ser deslocado pelas raizes, e nao às diferenças na densidade aparente, conteúdo de água ou de ar (BLACK, 1975; TACKETT \& PEARSON, 1964).

Em certos casos, a aeração pode chegar a ser tão pobre e a resistência tão alta, que quaisquer destes fatores, em separado, podem impedir a penetração (TACKETT \& PEARSON, 1964; GRABLE, 1966). ROSSI \& MUNDSTOCK 
(1980), ao estudarem o desenvolvimento de raizes de milho em função dos níveis de drenagem do solo, observaram que, com a elevação do lençol freático até à superficie, portanto, com severas restrições de aeração, $90 \%$ do peso e $85 \%$ do comprimento das raizes se concentraram na profundidade $\theta-15 \mathrm{~cm}$.

$$
\text { HATANO et alii (1988), estudando o papel }
$$

dos macroporos do solo na promoção do alongamento das raizes, constataram que a distribuição de raizes correspondeu proporcionalmente à distribuição de macroporos, mas a proporção de raizes que se alongaram dentro dos macroporos foi maior nos solos com abundância de grupamentos de poros ou poros ligados.

BACCHI (1976), em um trabalho no qual o solo foi compactado artificialmente, concluiu que as camadas compactadas dentro do perfil causam mais distúrbios ao crescimento de raizes, do que nos perfis homogêneos com maior densidade. A camada compactada provocou a concentração das raízes na superficie, mas como as condições de umidade do solo eram satisfatórias, as restrições ao crescimento das raizes nao teveram efeito na produção, o que demonstra que nem sempre existe uma relação direta entre produção e crescimento de raizes, aspecto também observado por BARBER (1971).

$E$ opinião geral que 0 crescimento das raizes é impedido pelo aumento da densidade do solo, no 
entanto, existe uma certa variabilidade de dados em relação ao grau de densidade no qual o crescimento é totalmente impedido. SCHUURMAN (1965), tomando por base trabalhos desenvolvidos por vários autores, cita como densidade critica média, 1,65 para solos arenosos e 1,5 para solos de textura média.

Com relação ao efeito da água, considera-se que, em geral, a taxa de crescimento de raizes é máxima no teor de água volumétrica da capacidade de campo ( $33 \mathrm{kPa}$ ), e cessa o crescimento no ponto de murcha (1500 kPa) (MACKAY \& BARBER, 1985; TAYLOR \& KLEPPER, 1974). Quando a água disponivel, ou seja, aquela que está entre 33 e $1500 \mathrm{kPa}$, era $60 \%$ da capacidade de campo, a taxa de crescimento de raizes foi $70 \%$ do máximo e quando a unidade era maior nas camadas mais profundas, também foi maior o crescimento das raízes nessas camadas (MACKAY \& BARBER, 1985).

Tem sido mostrado que o teor de água no solo é o principal fator que afeta a taxa de crescimento de raizes (BARBER et alii, 1988).

Para se ter um suprimento adequado de água para as plantas é importante que: a) a zona de raizes do solo seja grande o suficiente para suprir as necessidades das plantas entre as adições por precipitação ou irrigação; b) as raizes desenvolvam-se livremente no solo; c) o suprimento de água do solo seja frequentemente reposto para evitar deficiencia hídrica nas plantas; d) a água 
adicionada se infiltre no solo, sem no entanto promover lixiviação de nutrientes para fora da zona de rézes; e e) um sistema de raizes efetivamente absorvedor de água seja mantido durante o ciclo de vida da planta. Essa última condição é influenciada não somente pelo suprimento de água, mas também pelos nutrientes do solo, pela aeração, patógenos, temperatura e presença de elementos tóxicos (UNGER et alii, 1981).

As plantas absorvem a maioria dos nutrientes diretamente da solução do solo que, em geral, é muito diluida. A solução do solo está sempre em equilíbrio dinâmico com a fase sólida, na qual se encontra a maior parte dos nutrientes na forma disponivel. Como a quantidade total de nutrientes na solucão é muito baixa, o ritmo de absorção depende da taxa de reposição da concentração da solução do solo através da fase sólida (FRIED \& BROESHART, 1967 ).

A concentração dos nutrientes na solução do solo é apenas parte do problema, pois eles têm que ser supridos à superfície das raizes, a uma taxa que satisfaça as necessidads da planta, e isso ocorre através dos seguintes mecanismos: fluxo de massa, difusão e intercepção radicular (BARBER, 1962; BARBER et alii, 1963).

O tamanho e a morfologia do sistema de raizes podem ter um profundo efeito sobre a extração de nutrientes do solo. Uma dada massa de raizes finas e longas 
tem una superfície de exploração de volume de solo maior do que a mesma massa de raízes curtas e grossas, pois diminui os caminhos da difusão dos nutrientes através do solo (SUMNER \& BOSWELL, 1981).

Para modificar a zona de rafzes, visando a melhorar o suprimento e a disponibilidade de nutrientes para as plantas, pode-se lançar mão de diversos meios: 1) aplicação de calagem e fertilizantes nas suas diversas formas; 2) seleção de culturas, visando à maior penetração de raízes; espécies e cultivares mais adaptados, rotação e cultivos múltiplos; e 3 ) através do uso de equipamentos, método convencional, subsolador, plantio direto ou cultivo mínimo (SUMNER \& BOSWELI, 1981).

Tanto a adição de fertilizantes ou resíduo de culturas, como a remoção de nutrientes pelas colheitas ou lixiviação, resultam em distúrbios no equilíbrio dinâmico do suprimento de nutrientes para as raizes das plantas. Para manter-se o sistema eletricamente neutro, as plantas absorvem ou excretam quantidades estequiometricamente equivalentes de cátions e ânions, na forma de $\mathrm{H}_{3} \mathrm{O}^{+}, \mathrm{HCO}_{3}^{-}$ou $\mathrm{OH}^{-}$, sendo que em função da maior absorção de cátions, os solos sob cultivo tendem a acidificar-se com 0 tempo (SUMNER \& BOSWELL, 1981).

Embora $\circ$ solo seja a fonte primária dos nutrientes, em geral, seu suprimento é inadequado, sendo necessária a aplicação, tanto de corretivos como de 
fertilizantes para que se tenha um satisfatório desenvolvimento das plantas.

\title{
2.3.3. Avaliação do sistema radicular
}

\subsubsection{Estudo descritivo $x$ estudo ecológico de raizes}

\begin{abstract}
Como
assinala

PEARSON

$(1974)$,

aproximadamente 50 anos antes, em 1922, WEAVER et alii, escreveram que: "Um exato conhecimento do desenvolvimento de raízes das culturas, sua posição, extensão e atividade como absorvedoras de água e nutrientes em vários estádios de crescimento, é de suprema importância para o entendimento científico da produção de plantas. Além disso, um conhecimento de modificações produzidas por variações no ambiente subterrâneo, devido às condições naturais ou às práticas de cultivo ou uso de fertilizantes, é também de grande valia".
\end{abstract}

Embora uns poucos trabalhos tenham sido realizados com essa finalidade, o progresso nessa área foi consideravelmente retardado. No caso do estudo de raízes, o

WEAVER, J.E.; JEAN, F.C. \& CRIST, J.W. Development and activities of roots of crop plants. Carnegie Inst. Wash. Publ. $\mathrm{n}^{\circ} .316,1922$. 
principal fator limitante é a metodologia, pois métodos de campo, para estudos "in situ", sao trabalhosos e demorados, e a sua precisão é baixa (KठPKE, 1981). Uma maior familiarização com as metodologias disponíveis e a instalação de estruturas adequadas a trabalhos dessa natureza, é possivel que, até certo ponto, permita a superação desse obstáculo.

BOHM (1979), afirma que, nas duas últimas décadas, ocorreu um rápido desenvolvimento nas pesquisas com raízes, e mesmo em meados dos anos setenta, já se delineava uma certa especialização nesse ramo da ciência, com sua divisão nos dois principais campos de pesquisa, ou seja, a ecologia e a fisiologia de raízes.

Em linhas gerais, o objetivo da ecologia de raizes, campo no qual o presente trabalho mais se enquadra, é investigar a influência dos fatores ambientais sobre o desenvolvimento do sistema radicular das plantas. O trabalho é feito através da avaliação de caracteristicas da raiz, como por exemplo, peso, comprimento e área, no tempo e no espaço, e de fatores do ambiente que influenciam o crescimento de raízes, como resistência do solo, densidade, água, ar e nutrientes (BOHM, 1979).

No Estado de São Paulo, por intermédio do Instituto Agronômico, desenvolveu-se uma considerável quantidade de trabalhos com avaliação do sistema radicular de uma série de culturas: arroz (GERMEK et alii, 1950; 
GROHMANN \& QUEIROZ NETO, 1966); amendoim (INFORZATO \& TELLA, 1960); fórmio, sisal e bambu imperial (MEDINA et alii, 1963); feijão (INFORZATO \& MIYASAKA, 1963); lablab ( INFORZATO \& MASCARENHAS, 1967); mamão (INFORZATO \& CARVALHO, 1967); abacaxí (INFORZATO et alii, 1968; soja (INFORZATO \& MASCARENHAS, 1969); tomate (INFORZATO et alii, 1970); morango (INFORZATO \& CAMARGO, 1973); ram1 (INFORZATO \& CASTRO, 1976); citros (RODRIGUES et alii, 1978).

Muitos desses trabalhos, apesar da grande contribuição que proporcionaram ao conhesimento do desenvolvimento do sistema radicular, apenas se propuseram a descrever a distribuição completa das raízes das diversas espécies. Do ponto de vista do estudo de ecologia de raizes, existe uma certa carência de informações. Em outras palavras, a avaliação do sistema radicular necessita ser contemplada nas mais diversas áreas de estudo, como um componente importante, auxiliando na compreensão e no melhor entendimento dos efeitos dos fatores em estudo.

\subsubsection{Métodos de avaliasão do sistema radicular}

De acordo com BOHM (1979); KOPKE (1981) e SCHUURMAN \& GOEDWAAGEN (1971), os principais métodos de campo para estudo do sistema radicular são: 
- Método de Escavação

- Método do Monolito

- Método do Trado

- Método do Perfil

- Método da Parede de Vidro

- Método do Elemento Marcado

No método de escavação, todo o sistema radicular é exposto, removendo-se o solo aderido. Depois de separadas do solo, as raízes podem ser fixadas em papel ou fotografadas para avaliação de suas caracteristicas. Este método é trabalhoso e demorado.

No método do monolito, retira-se o solo em blocos ou monolitos, de onde são extraídas as raízes através de lavagens, efetuando-se então pesagens e ou medidas.

O método do trado consiste em retirar amostras de um volume de solo com raiz, a diferentes distâncias e profundidades. A amostragem é feita com trados manuais ou mecânicos. Após proceder a lavagem do torrão, as raízes são separadas e feitas determinações de peso, volume e ou comprimento. Este é o método mais comum para se tirar amostras volumétricas de solo com raízes. Por sua simplicidade e rapidez, permite ampliar o número de repetições e realizar-se análise estatistica. 
No método do perfil abre-se uma trincheira, com o objetivo de expor parte do sistema radicular. A seguir, remove-se uma camada de cerca de $5 \mathrm{~mm}$ de espessura das paredes do perfil do solo e estima-se o comprimento das raízes expostas, ou então, procede-se à contagem das raízes que despontam. O registro dos dados pode ser feito através de desenho representando o perfil, onde se colocam pontos, de acordo com o número de raízes. Também apresenta, como vantagem, a possibilidude de se fazer paralelamente a descrição pedológica do perfil do solo.

No método da parede de vidro são construidas janelas de vidro ou outro material transparente, junto ao perfil do solo, de modo a permitir a visualização continua do desenvolvimento das raízes. Devese deixar o menor espaço possivel entre o vidro e o solo, para evitar a criação de condições especiais nesse local, as quais podem interferir no comportamento das raizes. uso do rizotron é a aplicação deste método da forma mais elaborada. Atualmente tem sido empregado o minirizotron, que usa tubos, sendo que as raízes ficam visiveis através de espelhos e técnicas de iluminação. Recente tecnologia usando microcâmaras tem aperfeiçoado o método e permitido estimar a atividade de raízes. E um método não destrutivo, em função do que apresenta inúmeras vantagens em relação aos demais, embora, seja relativamente sofisticado requerendo a participação de pessoal especializado. 
O método do elemento marcado consiste em colocar-se elementos marcados (isótopos) a distâncias determinadas do caule e depois testar sua presença na parte aérea, o que indica que as raízes estenderam-se até à posição em que o elemento foi colocado. O elemento mais usado é 0 32p, pois o fósforo possui pouca mobilidade no solo. O inverso também pode ser feito, injetando-se a solução na planta e fazendo-se a amostragem do solo.

o melhor método depende dos objetivos do estudo e também das características do solo. KOPKE (1981), comparou os métodos do monolito, do trado, do perfil e do tubo de vidro (parede de vidro) visando a estudar o sistema radicular da aveia (Avena sativa L.). A maior densidade de raizes ( $\mathrm{cm}$ de $\mathrm{raiz} / \mathrm{cm}^{3}$ de solo) foi determinada com o método do monolito, considerado portanto como método padrão, o qual apresenta maior exatidão mas uma baixa precisão. O método do perfil apresentou a relacão mais favorável entre o esforço gasto e a informação obtida, mas como esse método subestimou a medida de densidade de raízes comparado ao método padrão, os dados tiveram que ser multiplicados pelo fator 2,06. O método do trado requer pouco trabalho, permitindo um número maior de repetições a fim de avaliar as diferenças entre os tratamentos aumentando a precisão estatística. 


\section{MATERIAL E METOdOS}

O presente estudo foi desenvolvido em 1988/89, em um experimento instalado em 1981/82 sm área do Centro Experimental do Instituto Agronômico (IAC), em Campinas, sob coordenação da seção de Conservação do Solo e participação das seções de Fertilidade do Solo e Nutrição de Plantas e de Microbiologia do Solo do IAC (DECHEN, 1990).

\subsection{Caracteristicas da área experimental}

\subsubsection{CIima}

O Centro Experimental de Campinas está situado a $22^{\circ} 5321^{\prime \prime}$ de latitude sul, $47^{\circ} 0439^{\prime \prime}$ de longitude oeste, e a 693 m de altitude (FUNDAÇÃO INSTITUTO BRASILEIRO DE GEOGRAFIA E ESTATISTICA, 1957), sendo o clima da região quente, com inverno seco (SETZER, 1966).

Os dados pluviométricos apresentados na Tabela 1., foram obtidos através de pluviômetro instalado a $300 \mathrm{~m}$ do local do experimento. 
Tabela 1. Distribuiçio oluviosetrica (n) je 1988 a 1989 , no Centro Eroerioentai de Caspinas, ea Caspinas, sp

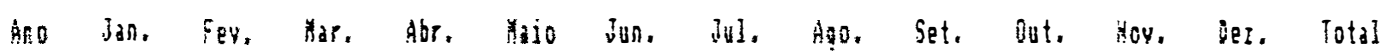

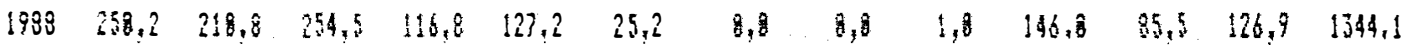

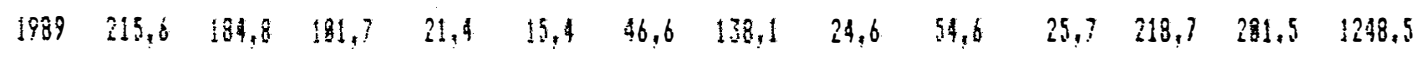

\section{1 .2 .5010}

O solo da área experimental foi classificado como Latossolo Vermelho-Escuro com $40 \%$ de argila, $3 \%$ de silte, $21 \%$ de areia fina e $36 \%$ de areia grossa (OLIVEIRA, s.d.). Em amostra coletada em 1981,

Tabela 2. Análise química do solo realizada em 1981, antes do início do ensaio.

\begin{tabular}{ccccccc}
\hline M.O. & pH & Al+3 & $\mathrm{Ca}+2$ & $\mathrm{Mg}+2$ & $\mathrm{~K}$ & $\mathrm{P}$ \\
\hline$-\%-1$ & & -- & e.mg/100 $\mathrm{ml}$ & $\mathrm{TFSA}--$ & $-\mu \mathrm{m} / \mathrm{ml}$ & $\mathrm{TFSA}-$ \\
2,4 & 4,7 & 0,9 & 0,5 & 0,2 & 20 & 2,0 \\
\hline
\end{tabular}

OLIVEIRA, J.B. de. Levantamento detalhado dos 80108 do Centro Experimental de Campinas do Instituto Agronômico. Dados da Seção de Pedologia do Instituto Agronômico (Nao publicados). 
apresentou as caracteristicas químicas constantes da Tabela 2, segundo metodologia descrita por RAIJ \& ZULLO (1977).

\subsection{Caracteristicas do experimento}

\subsubsection{Dimensões}

As parcelas tinham dimensões de $24,0 \mathrm{~m} x$ $5,0 \mathrm{~m}$, sendo que na maior dimensão foram subdivididas em três subparcelas de $6,0 \mathrm{~m} \times 5,0 \mathrm{~m}$. Desprezou-se uma faixa de 2 m entre as subparcelas e $1 \mathrm{~m}$ antes e ao final de cada parcela.

\subsubsection{Tratamentos}

Os tratamentos nas parcelas constaram de tres esquemas diferentes de cultivos, como são descritos a seguir e cujas seqüências de plantio durante os anos são apresentadas na Tabela 3. Nas subparcelas aplicaram-se as doses de calcário $(\theta, 3$ e 6 t/ha). Utilizou-se calcário dolomitico finamente moido, aplicado em agosto de 1982 e reaplicado em julho de 1984.

C - Milho contínuo, no periodo "das águas" (Mi).

F - Rotação da sucessão de amendoim ao amendoim com o milho - amendoim no período "das águas" e no "da seca" em rotação com milho $(\mathrm{F} \rightarrow \mathrm{Mi}-\mathrm{Am} / \mathrm{Am})$; 
H - Rotação da sucessão de mucuna-preta ao amendoim com o milho - amendoim no período "das águas" e mucuna-preta no "da seca" em rotação com milho $(\mathrm{H} \rightarrow \mathrm{Mi}-\mathrm{Am} / \mathrm{Mu})$.

Tabela 3. Seqüencias de plantio dos tratamentos

\begin{tabular}{ccccccccc}
\hline T. & $81 / 82$ & $82 / 83$ & $83 / 84$ & $84 / 85$ & $85 / 86$ & $86 / 87$ & $87 / 88$ & $88 / 89$ \\
\hline $\mathrm{C}$ & $\mathrm{Mi}$ & $\mathrm{Mi}$ & $\mathrm{Mi}$ & $\mathrm{Mi}$ & $\mathrm{Mi}$ & $\mathrm{Mi}$ & $\mathrm{Mi}$ & $\mathrm{Mi}$ \\
$\mathrm{F}$ & $\mathrm{Mi}$ & $\mathrm{Mi}$ & $\mathrm{Am} / \mathrm{Am}$ & $\mathrm{Mi}$ & $\mathrm{Am} / \mathrm{Am}$ & $\mathrm{Mi}$ & $\mathrm{Am} / \mathrm{Am}$ & $\mathrm{Mi}$ \\
$\mathrm{H}$ & $\mathrm{Mi}$ & $\mathrm{Mi}$ & $\mathrm{Am} / \mathrm{Mu}$ & $\mathrm{Mi}$ & $\mathrm{Am} / \mathrm{Mu}$ & $\mathrm{Mi}$ & $\mathrm{Am} / \mathrm{Mu}$ & $\mathrm{Mi}$ \\
\hline
\end{tabular}

\subsubsection{Culturas}

\subsubsection{Amendoim(Arachis hipogea. L.) \\ Utilizou-se o cultivar Tatu, 0 qual} apresenta sementes de película vermelha, 3 a 4 sementes por vagem e ciclo de 100 a 110 dias. O plantio "das águas" foi realizado de meados de setembro a fins de outubro, e o "da seca", de janeiro à primeira quinzena de fevereiro. Utilizou-se o espaçamento de $0,50 \mathrm{~m}$, e 18 plantas por metro linear de sulco. Como fonte de nitrogênio, 0 amendoim contou apenas com a fixação biológica, realizada com inoculação de uma mistura de três estirpes de Rhizobium e a 
aplicação de molibdênio na ordem de 100 g ie Mo/ha. A adubação anual foi feita utilizando-se a fórmula 0-20-20 + S (400 kg/ha): O plantio da seca nao foi acubado nem inoculado.

\subsubsection{Milho (Zea mays. L.)}

Utilizou-se o híbrido da Cargill C 111-S, sendo que o plantio foi realizado sempre no período "das águas", em outubro ou novembro, dependendo das condições climáticas. Na adubação empregou-se a fórmula 4-20-20 + S (400 kg/ha) realizando-se a adubação de cobertura com sulfato de amônio ( $40 \mathrm{~kg}$ de $\mathrm{N} / \mathrm{ha}$ ), 30 a 35 dias após a germinação. O espaçamento foi de 1,0 m entre linhas e a densidade de plantio foi de 5 plantas por metro linear de sulco.

\section{2 .3 .3 Mucuna-preta (5tizolobium. atterrinum Piper \& Tracy)}

Utilizada como adubo verde, em sucessão ao amendoim, plantada no período "da seca" (abril,maio), no espaçamento de $0,5 \mathrm{~m}$ entre linhas e sete sementes por metro linear. Nao recebeu adubação dispensando-se também o combate a pragas e moléstias. Com o surgimento das 
primeiras vagens a fitomassa foi roçada e deixada sobre o solo.

\title{
3.2.4. Delineamento experimental
}

o delineamento experimental empregado foi o de blocos casualizados com parcelas subdivididas e três repetições.

A análise estatistica dos resultados foi realizada utilizando-se o pacote estatistico SANEST (ZONTA et alii, s.d.).

\subsection{Desenvolvimento do trabaliho}

Avaliou-se por subparcela, o sistema radicular (através de dois métodos de estudo até à profundidade de $50 \mathrm{~cm}$ ), caracteristicas fisicas e quimicas do solo em três profundidades $(0$ a 20,20 a 40 e 40 a 60 cm), nutrientes absorvidos e a produção de grãos de milho.

\subsubsection{Avaliação do sistema radicular}

\begin{abstract}
Quinze dias antes da avaliação foi feita uma capina do experimento visando a eliminar raizes de outras plantas. A avaliação foi feita no inicio do periodo
\end{abstract}


de embonecamento, que MENGEI \& BARBER (1974), sugerem como melhor período de amostragem, no caso de se coletar em apenas uma época. Utilizaram-se os métodos do trado e do perfil (BOHM, 1979; SCHUURMAN \& GOEDEWAAGEN, 1971).

\subsubsection{Método do trado}

Consistiu na retirada de amostras nas profundidades de 0 a 10,10 a 20,20 a 30,30 a 40 e 40 a $50 \mathrm{~cm}$, utilizando-se um trado tipo canec:a com $7 \mathrm{~cm}$ de diâmetro, cujo modelo está apresentado na Figura 1.

As amostras, feitas por subparcela, foram coletadas em três pontos da linha, entre as plantas, e em três pontos escolhidos ao acaso nas entrelinhas. 0 resultado médio dos três pontos foi utilizado para as análises estatisticas e para as comparações entre os tratamentos. Após a coleta, as amostras foram secas em estufa, a aproximadamente $65^{\circ} \mathrm{C}$, visando à conservação das raizes. A conservação é necessária porque os métodos de lavagem e separação de raizes são muito lentos, e portanto, inviabilizam o processar de um grande número de amostras em tempo hábil para evitar sua deterioração, caso permaneçam úmidas.

Antes do processo de lavagem as amostras foram reidratadas e permaneceram submersas em água por um periodo de 24 horas para seu total esfacelamento, evitando 


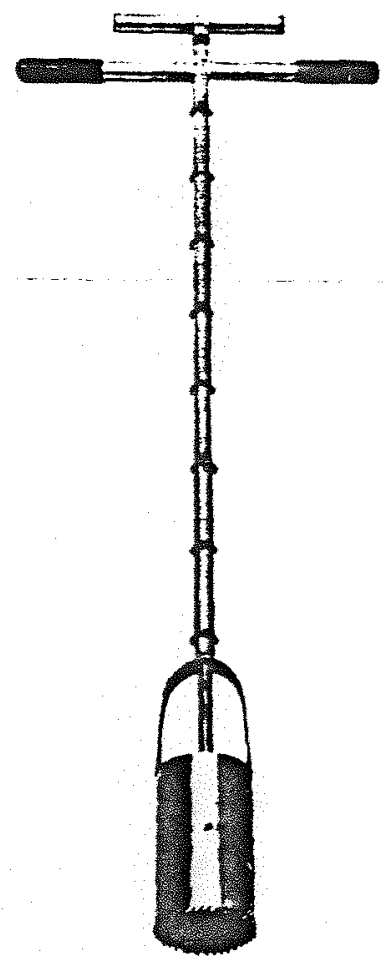

Figura 1 . Modelo do trado manual tipo "caneca", utilizado para a retirada de amostras de solo + raiz (Modelo adaptado de BOHM, 1979).

assim, a perda de raízes. Após esse período, as amostras, acondicionadas em vasos plásticos, eram revolvidas, e depois deixadas em repouso por aproximadamente um minuto, tempo suficiente para que o solo decantasse, quando então o liquido sobrenadante foi passado em uma peneira de 35 mesh onde as raizes ficavam retidas. Essa operaça foi repetida entre seis e dez vezes, dependendo da quantidade de raizes que a amostra continha. Após a lavagem as raízes eram levadas à estufa, onde permaneciam durante 48 h sob temperatura de $65^{\circ}$ a $70^{\circ} \mathrm{C}$, sendo depois determinado o peso de matéria seca. 
Em trinta e cinco amostras, tomadas ao acaso, determinou-se também o comprimento das mazes, pelo método de TENNANT (1975). Verificou-se um alto indice de correlação $(r=0,95)$ entre peso e comprimento de raizes, confirmando os resultados obtidos em outros trabalhos (BARBER, 1971; ROSSI \&. MUNDSTOCK, 1980). Em função desses resultados, determinou-se apenas o peso das raizes nas demais amostras.

\subsubsection{Metodo do perfil}

No inicio de cada subparcela abriu-se uma trincheira de aproximadamente $1 \mathrm{~m}^{3}$. A parede transversal à fileira central de plantas foi aplainada com o auxilio de uma pá reta, e depois removeu-se uma camada de solo de cerca de $5 \mathrm{~mm}$, utilizando-se um pequeno escarificador de jardinagem para que as raizes despontassem e pudesse ser feita a sua contagem.

Para facilitar o processo de contagem empregou-se um quadriculado de cordão com bordas de madeira, medindo $90 \mathrm{~cm}$ de largura e $60 \mathrm{~cm}$ de altura, e o quadriculo apresentando $5 \mathrm{~cm}$ de lado (Figura 2).

o quadriculado era encostado rente ao perfil, coincidindo seu centro com a fileira central de plantas. A seguir foi feita a contagem da quantidade de raizes em cada quadrículo. 


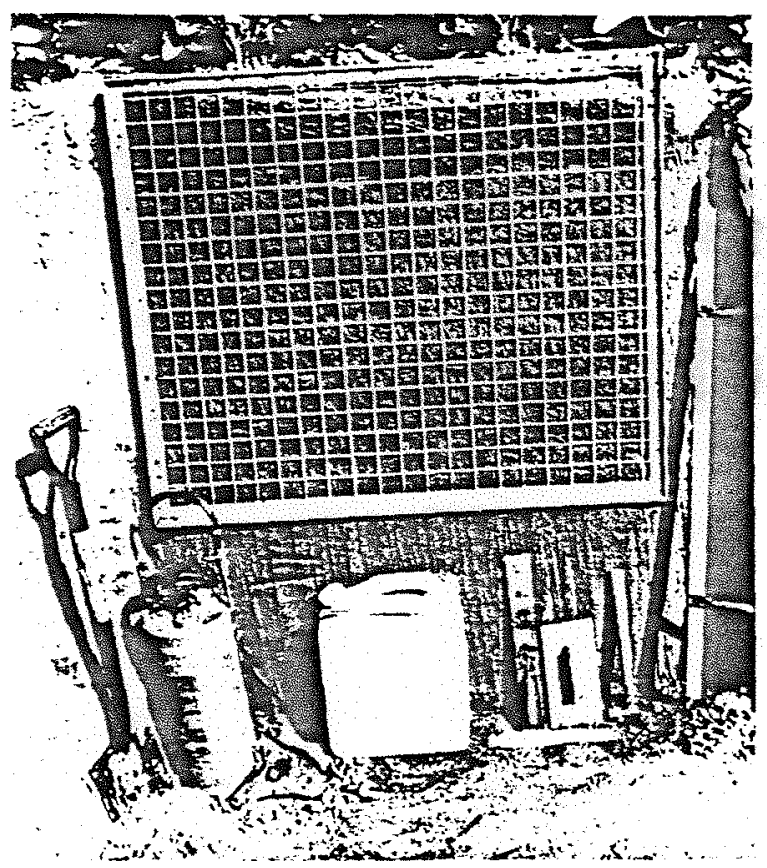

Figura 2 . Vista de uma trincheira ilustrando a utilização do quadriculado de madeira e outros utensilios, na contagem das raízes pelo método do perfil (Modelo adaptado de BOHM, 1979).

\subsubsection{Avaliação das caracteristicas fisicas do 5010}

Nas mesmas trincheiras utilizadas para avaliação do sistema radicular foram coletadas amostras indeformadas, com anéis volumétricos de $100 \mathrm{~cm}^{3}$, nas profundidades de $\theta$ a 20,20 a 40 e 40 a $60 \mathrm{~cm}$, em número de três amostras por profundidade. O valor médio foi utilizado na análise estatística.

Nessas amostras determinaram-se a densidade aparente, porosidade total, macroporosidade. ( 0.06 bar) e a 
curva de retençao de umidade até 2,00 bar, em extrator de Richards.

\subsubsection{Avaliação das caracteristicas quimicas do solo}

$\mathrm{Na}$ mesma época da amostragem de raízes, retiraram-se dez amostras simples de solo por subparcela, para constituir uma amostra composta representativa dos tratamentos. A amostragem foi feita nas profundidades de 0 a 20,20 a 40 e 40 a $60 \mathrm{~cm}$ usando-se trado tipo holandes.

Foram determinados: (RAIJ \& QUAGGIO, 1983) a) fósforo "disponível" extraido por resina trocadora de ânions; b) matéria orgânica pelo método de Walkley-Black; c) $\mathrm{pH}$ em solução centimolar de $\mathrm{CaCl}$ z utilizando-se relação solo:solução de $1: 2,5$; d) potássio trocável extraído por resina tracadora de cátions e determinado utilizando-se fotômetro de chama; e) cálcio e magnésio trocáveis extraidos juntamente com o potássio e determinados separadamente, utilizando-se espectrofotômetro de absorção atômica; f) acidez titulável ( $\mathrm{H}+\mathrm{Al}$ ), utilizando-se o tampão SMP de SHOEMAKER et alii (1961), aplicado à suspensao de determinaçao do $\mathrm{pH}$ em $\mathrm{Ca} \mathrm{Cl}_{2}$ na proporcão de $5 \mathrm{ml}$ por amostra; g) alumínio trocável ( $\mathrm{Al}+3$ ) extraido com $\mathrm{KCl} 1 \mathrm{~N}$ e determinado por volumetria (RAIJ \& ZULLO, 1977). 
A soma de bases (S), a CTC e a saturação por bases (V\%) foram calculadas a partir dos resultados analiticos.

\subsubsection{Análise foliar}

A amostragem de folhas foi feita coletandose o terço central da folha +4 de quinze plantas por Darcela, na época de amostragem de solo e raízes.

Para a determinação dos teores totais dos nutrientes presentes no material vegetal seco, utilizou-se a metodologia apresentada por SARRUGE \& HAAG (1974), utilizando-se a digestão nitrico-perclórica de $1 \mathrm{~g}$ de matéria seca e completando-se o volume a $50 \mathrm{ml}$, para a determinação de: a) fósforo total, pelo método colorimétrico do molibdato-vanadato; b) potássio, por fotometria de chama; c) cálcio e magnésio, por espectrofotometria de absorção atômica; d) enxofre, por método indireto, que utiliza cloreto de bário e determinação por espectrofotometria de absorção atômica; e) cobre, ferro, manganês e zinco, por espectrofotometria de absorçao atômica.

A determinação do nitrogênio foi feita utilizando-se a digestão sulfúrica de $100 \mathrm{mg}$ de matéria seca, com destilação em aparelho de Kjeldhal e titulação com $\mathrm{H}_{2} \mathrm{SO}_{4} 0,01 \mathrm{~N}$. A determinação de boro foi feita 
utilizando Azometina $H$, segundo metodologia descrita por BATAGLIA et alii (1983).

\subsubsection{Produção de grãos}

Efetuou-se a colheita da produção da área útil das subparcelas $(3,0 \times 5,0 \mathrm{~m})$. 


\section{RESULTADOS E DISCUSSÃa}

Partindo-se das hipóteses formuladas, os resultados serão apresentados e discutidos, tomando-se por base os efeitos dos sistemas de produção, dos niveis de calagem e das profundidades de amostragem, sobre as características químicas e físicas do solo.

Em seguida serão analisadas as variações das características do solo em função dos fatores de estudo, seu efeito sobre o comportamento da planta de milho através da avaliação do peso e quantidade de raízes, e o teor de nutrientes na planta e a produção de grãos.

A profundidade de amostragem foi considerada como um fator, em razão do interesse de se proceder a uma avaliação do comportamento das diversas variâveis entre as profundidades e registrar a ocorrência de possiveis interacões com os sistemas de produção e niveis de calagem.

4.1. Caracteristicas quimicas do solo 4.1.1. Efeitos dos sistemas de produção 
Os resultados sumarizados na Tabela 4 mostram que os diferentes sistemas de produção: Milho continuo, plantado no periodo "das águas" (Mi); Rotação da sucessão de amendoim ao amendoim com o milho (Mi-Aa/As) e Rotação da sucessão de mucuna-preta ao amendoim com o milho (Mi-Aa/Mu), nao causaram nenhuma alteração significativa nas caracteristicas quimicas do solo, pelo menos quando o seu efeito foi considerado isoladamente (Tabela 5). No entanto, a interação dos sistemas de produção com os níveis de calagem afetou os teores de fósforo, e a interação dos sistemas de produção com a profundidade de amostragem por sua vez, afetou os teores de fósforo e ferro, o que será comentado mais adiante.

O efeito esperado seria o beneficio da rotação do amendoim "das águas" e "da seca" com o milho (Mi- $\mathrm{Aa} / \mathrm{As})$, e os beneficios adicionais resultantes da inclusão da mucuna-preta como adubo verde na rotação (Mi$\mathrm{Aa} / \mathrm{Mu}$ ), em comparação com o cultivo de milho contínuo (Micont.), o que nao ocorreu.

Vale ressaltar, que a mucuna após o corte nao era logo incorporada e sim deixada sobre a superficie durante um periodo de cerca de dois meses, até o preparo do solo para o plantio do milho, quando srtao era efetuada a incorporação. Nesta ocasião ela já se apresentava em processo relativamente adiantado de decomposição. Na implantação do experimento prevaleceu o aspecto conserva- 


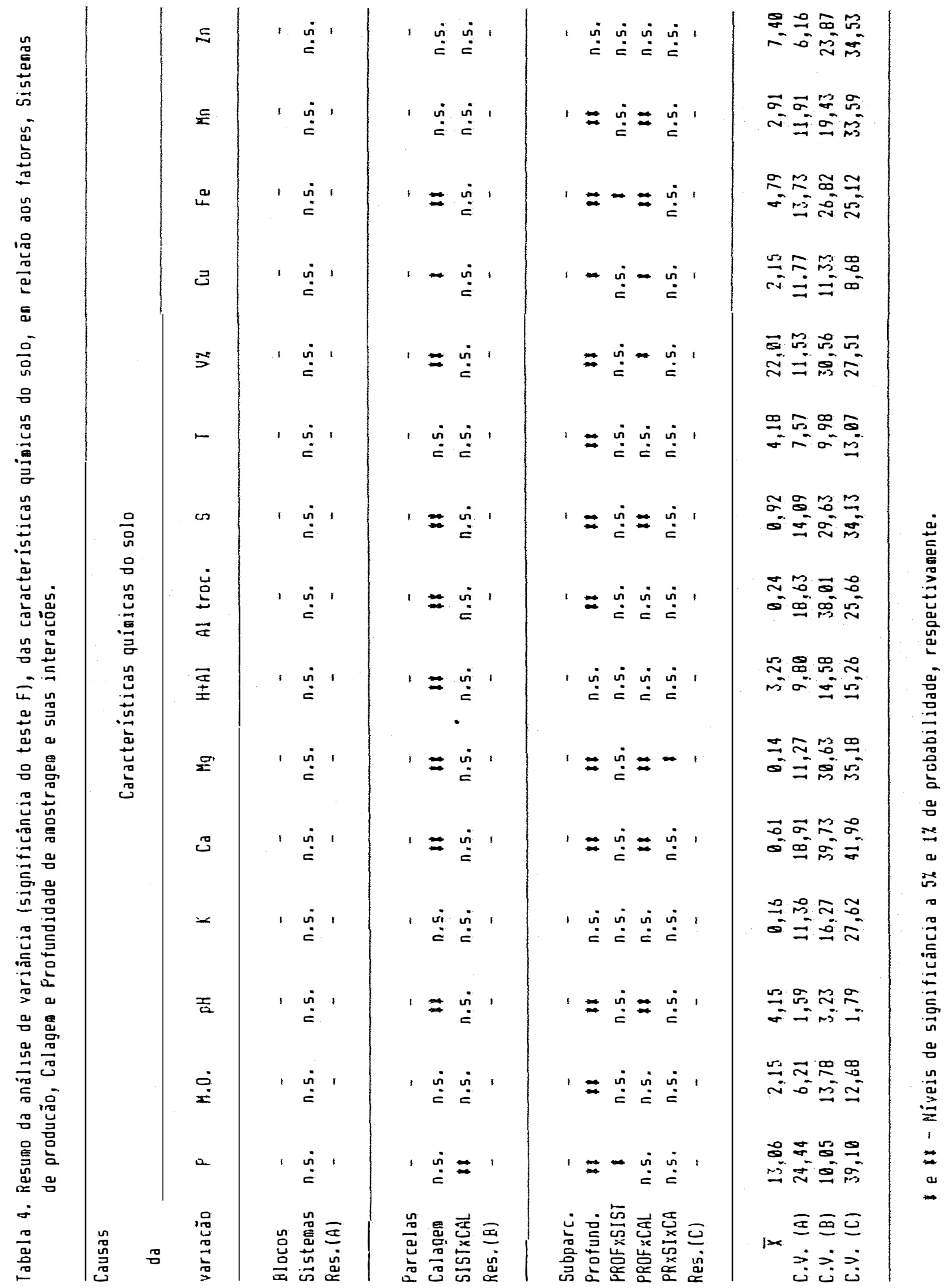




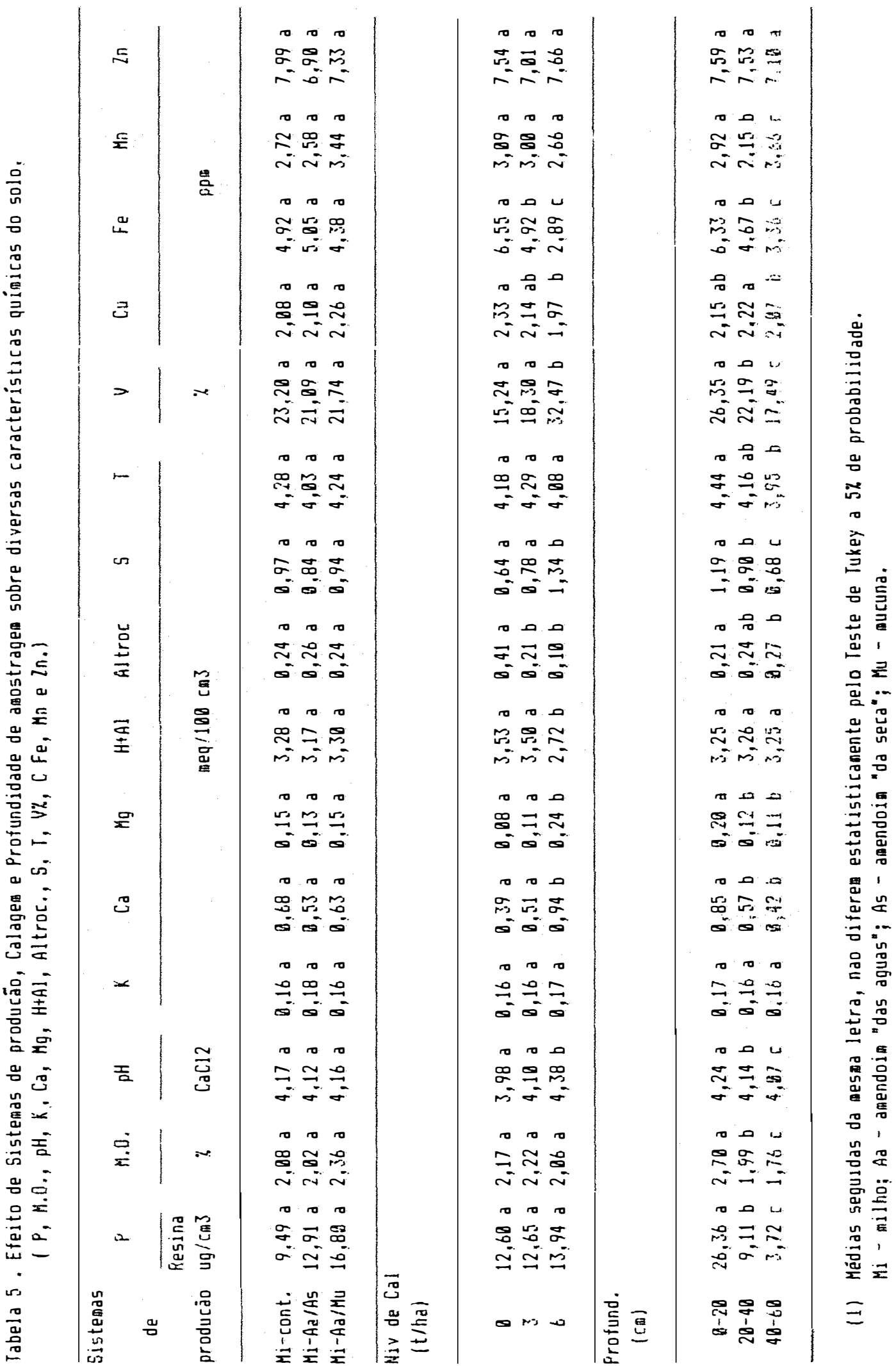


cionista, pois sabe-se que, deixando o material sobre a superficie, são menores as perdas de solo e de água (BERTONI et alii, 1972).

Por outro lado, levando-se em conta o aspecto nutricional, DE-POLLI \& CHADA (1989), demonstraram que a mucuna-preta, ao contrário do que ocorreu com a crotalária juncea e o feijão-de-porco, nao apresentou diferença de comportamento quando incorporada ou deixada na superficie, quando usada como adubo verde para a cultura do milho. Os autores admitem que as plantas menos fibrosas, como a mucuna, seriam indiferentes a estas formas de manejo, enquanto as mais fibrosas seriam beneficiadas pela incorporaçao.

Segundo RUSSELL \& RUSSELL (1968), as culturas podem influir sobre as que as seguem através da quantidade de água ou de nutrientes utilizáveis que deixam no solo, ou por intermédio de seus residuos, que podem ser benéficos ou prejudiciais.

Entre os objetivos da rotação de culturas está o de manter, ou mesmo melhorar, a fertilidade dos solos. De uma maneira geral considera-se que os cultivos continuos tendem a reduzir o conteúdo de matéria orgânica e nutrientes minerais do solo. Por outro lado, admite-se que numa boa rotação, culturas que apresentem exigências nutricionais diferentes, além de outras caracteristicas complementares, seriam capazes de proporcionar a obtenção 
de boas colheitas no decorrer dos anos, o que poderia estar relacionado com o aumento dos indices de fertilidade dos solos (BERTONI \& LOMBARDI NETO, 1990; PRIMAVESI, 1979; RUSSELL \& RUSSELL, 1968)

Vários trabalhos têm detectado niveis significativamente maiores de nitrogênio no solo em rotações, o que tem sido associado a meihores desempenhos das culturas (TIESSEN, 1988; SUTHERLAND et alii, 1961; BALDOCK et alii, 1981).

VASCONCELOS et alii (1986), encontraram maiores teores de potássio, cálcio e magnésio nas áreas de rotação mucuna-milho, em relação àos demais sistemas (sojamilho, milho continuo e milho após milho + mucuna intercalar).

MUZZILI et alii (1983), em um Latossolo Roxo Distrófico e em um Latossolo Vermelho-Escuro Distrófico, com cinco e quatro anos de uso, respectivamente, verificaram aumento no teor de matéria orgânica no decorrer do tempo. NASCIMENTO et alii (1988) nao observaram variação quando avaliaram o efeito de diversos sistemas de rotação incluindo ou não a adubação verde.

VIEAS et alii (1960), em experimento com dez anos de duração, constataram que a intercalação de mucuna-preta, embora tenha provocado considerável aumento na produção do milho, nao aumentou o teor de matéria 
organica dos solos e praticamente nao lhes modificou as caracteristicas quimicas estudadas. SANTOS \& ROMAN (1989) e JCHIKAWA (1989) obteveram resultados semelhantes com rotação de milho e soja, e NASCIMENTO et alli (1988), com milho, soja e arroz.

Em relaçăo ainda, ao efeito dos sistemas de produção sobre as características quimicas do solo, verifica-se que a interação entre sistemas e calagem foi significativa para os teores de fósforo. Na Tabela 6 observa-se que somente no nivel de calagem de 6 tiha é que - teor de fósforo foi significativamente maior para o sistema $\mathrm{Mi}-\mathrm{Aa} / \mathrm{Mu}$, em relação ao milho contínuo.

Quando se considera o efeito isolado dos fatores (Tabela 5), se observa essa tendência, o que atê certo ponto está correlacionado com o teor de matéria orgânica, que também foi maior no sistema Mi-Aa,Mu, provavelmente devido à incorporação da mucuna nesse tratamento. No entanto, as diferenças nos teores de matéria orgârica e fósforo entre os sistemas nao foram significativas.

Foi significativa também, a interação de sistemas de produção e profundidade de amostragem para os teores de fósforo no solo (Tabela 7). Na profundidade de $\theta$ a $28 \mathrm{~cm}$, o teor de fósforo foi superior no tratamento Mi$\mathrm{Aa} / \mathrm{Mu}$, apenas em relação ao milho continuo. Aqui também se 
aplicam as considerações sobre os maiores teores de matéria orgânica observados no tratamento que envolveu mucuna.

Na mesma profundidade, o teor de ferro foi maior no tratamento Mi-Aa/As (Tabela 8). Nas demais profundidades nao houve diferenças entre os sistemas.

Tabela 6 . Efeito de sistemas de produção e niveis de calcário, sobre o teor de fósforo no solo (ug/ $\mathrm{cm}^{3}$ ), independente da profundidade de amostratem.

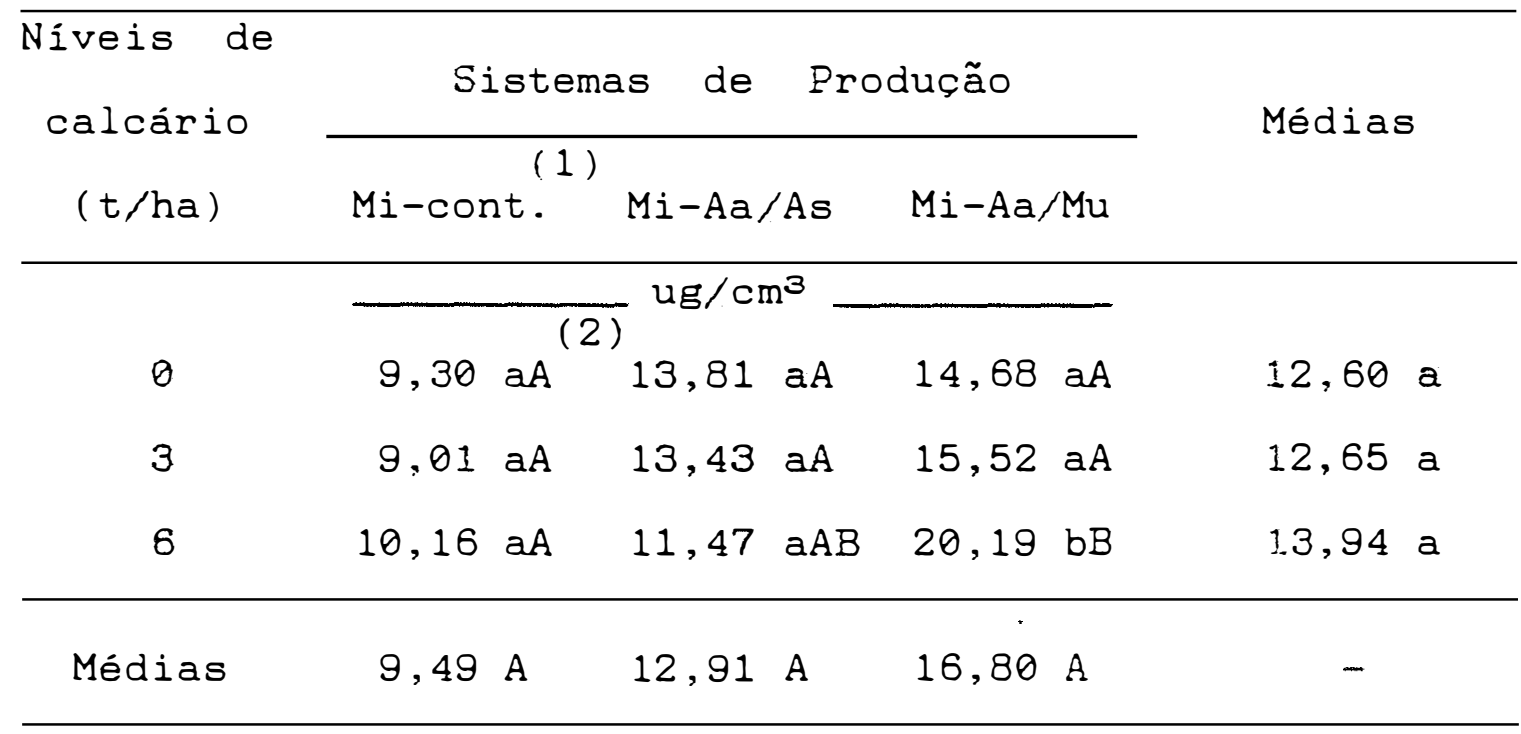

(1) Mi-milho; Aa-amendoim "das águas"; As-amendoim "da seca" e Mu-mucuna-preta.

(2) Médias seguidas da mesma letra nao diferem estatísticamente pelo Teste de Tukey a 5\% de probabilidade. Letras maiúsculas expressam o comportamento entre os sistemas de produção e letras minúsculas entre os niveis de calcário.

Uma interação tripla ocorreu entre sistemas de produção, niveis de calagem e profundidade de amostragem sobre os teores de magnésio no solo (Tabela 9). 
Na dose de calagem 6 t/ha e na profundidade de 20 a $40 \mathrm{~cm}$, o tratamento $\mathrm{Mi}-\mathrm{Aa} / \mathrm{As}$ foi o que apresentou menor teor de magnésio, enquanto os outros sistemas de produção não diferiram entre si, sendo que somente no tratamento $\mathrm{Mi}-\mathrm{Aa} / \mathrm{Mu}$ o teor de magnésio foi superior ao tratamento $\mathrm{Mi}-\mathrm{Aa} / \mathrm{As}$.

No efeito isolado de sistemas de produção (Tabela 5), o tratamento Mi-Aa,As já se mostrou inferior

Tabela 7,. Efeito de sistemas de produç̃o e profundidade de amostragem, sobre o teor de fósforo no solo $\left(\mathrm{ug} / \mathrm{cm}^{3}\right)$, independente da dose de calagem.

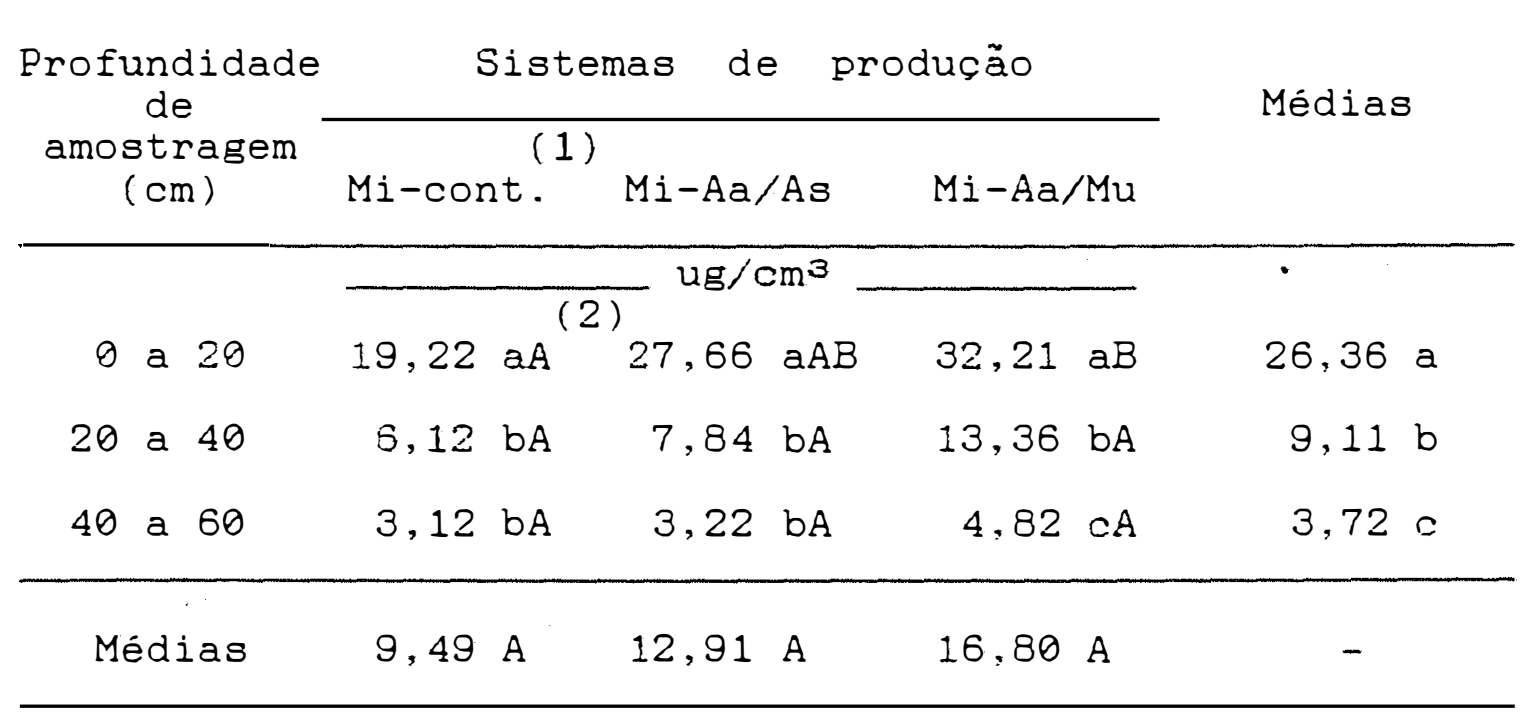

(1) Mi-milho; Aa-amendoim "das águas"; As-amendoim "da seca" e Mu-mucuna-preta.

(2) Médias seguidas da mesma letra nao diferem estatisticamente pelo Teste de Tukey a 5\% de probabilidade. Letras maiúsculas expressam o comportamento entre os sistemas de produção e letras minúsculas entre as profundidades. 
aos demais, apesar de não significativo. No efeito isolado da calagem por sua vez, o teor de magnésio na dose $6 \mathrm{t} / \mathrm{ha}$ foi bastante superior quando relacionado aos outros niveis. O teor de magnésio no tocante à profundidade apresentou uma variabilidade muito grande nas diversas combinações entre sistemas de produção e níveis de calagem, de modo que a significância estatistica da interaçac tripla citada acima nao reflete o comportamento teórico esperado.

Tabela 8 . Efeito de sistemas de produção e profundidade de amostragem, sobre o teor de ferro no solo, (ppm), independente da dose de calagem.

\begin{tabular}{|c|c|c|c|c|}
\hline \multirow{2}{*}{$\begin{array}{c}\text { Profundidade } \\
\text { de } \\
\text { amostragem } \\
(\mathrm{cm})\end{array}$} & \multicolumn{3}{|c|}{ Sistemas de produção } & \multirow{2}{*}{ Médias } \\
\hline & Mi-cont. & $\mathrm{Mi}-\mathrm{Aa} / \mathrm{As}$ & $\mathrm{Mi}-\mathrm{Aa} / \mathrm{Mu}$ & \\
\hline & \multicolumn{3}{|c|}{ (2) } & \\
\hline 0 a 20 & $6,66 \mathrm{aAB}$ & 7,33 aA & $5,00 a B$ & $6,33 a$ \\
\hline 20 a 40 & $4,53 \mathrm{bA}$ & $4,66 \mathrm{bA}$ & 4,81 aA & $4,67 \mathrm{~b}$ \\
\hline 40 a 60 & $3,58 \mathrm{bA}$ & $3,16 \mathrm{cA}$ & $3,34 \mathrm{bA}$ & $3,36 c$ \\
\hline Médias & $4,92 A$ & $5,05 \mathrm{~A}$ & $4,38 \mathrm{~A}$ & - \\
\hline
\end{tabular}

(1) Mi-milho; Aa-amendoim "das águas"; As-amendoim "da seca"; Mu-mucuna-preta.

(2) Médias seguidas da mesma letra, nao diferem estatisticamente pelo Teste de Tukey a 5\% de probabilidade. Letras maiúsculas expressam o comportamento entre os sistemas de produção e letras minúsculas entre as profundidades. 
Sobre os sistemas de produção, mais especificamente sobre os beneficios esperados da rotação de culturas e da adubação verde, mais alguns comentários podem ser acrescentados.

Para BALDOCK et alii (1981), são muito antigas as citações dos benefícios do uso de leguminosas nas rotações, e pesquisas recentes têm mostrado que as leguminosas melhoram o solo, através da fixação simbiótica de nitrogênio. Em alguns casos, entretanto, tem sido observado, um efeito benéfico adicional da leguminosa sobre a cultura seguinte. As possiveis causas incluem: a reduzida infestação de doenças, a melhoria das propriedades físicas do solo, a eliminação de substâncias fitotóxicas do resíduo do milho e a adição de substâncias promotoras do crescimento em resíduo de leguminosas.

Mas parece estar bem estabelecido que são, - nitrogênio e alguns outros nutrientes supridos pela rotação ou adubação verde, os principais responsáveis pelos beneficios dessas práticas e desempenhos melhores das culturas, (TIESSEN, 1988; SUTHERLAND et alii, 1961; BALDOCK et alii, 1981).

FERRAZ et alii (1977), avaliaram o efeito da rotação entre mucuna, amendoim e duas variedades de algodão nos anos agrícolas de 1967/68 a 1972/73. Destacouse o efeito da mucuna seguida de amendoim. Depois do plantio consecutivo de algodoeiro durante três anos, 
praticamente cessaram os efeitos da rotação, c que sugere que os fatores envolvidos teriam ação temporárì, como é o caso do fornecimento de nutrientes.

Por esta razão, alguns trabalhos ressaltam que a maior possibilidade de êxito deve ocorrer em solos depauperados, e que menores efeitos devem ser observados nos solos em pousio (VASCONCELLOS \& PACHECO, 18B7; VIEGAS et alii, 1960).

SUTHERLAND et alii (1961), comentam que muitos dos estudos publicados, comparando milho continuo com milho crescendo em rotação incluindo leguminosas, foram conduzidos usando pouco ou nenhum fertilizante nitrogenado, e que nessas condições, a produção do milho continuo foi usualmente menor e mais rápida foi a redução da matéria orgânica.

No presente estudo portanto, a aplicação de fertilizantes quimicos anualmente, pode ter mascarado um possivel efeito benéfico das rotações sobre o milho, quando comparadas com o plantio de milho contínuo.

\subsubsection{Efeito da calagem}

O uso da calagem, se considerarmos sua ação isolada, provocou variações significativas no valor do $\mathrm{pH}$, nos teores de cálcio ( $\mathrm{Ca}$ ), de magnésio ( $\mathrm{Mg}$ ), de hidrogênio 
+ aluminio $(H+A l)$, de aluminio trocável (Al troc.), na soma de bases (S), na saturação por bases (V\%), e nos tores de cobre $(\mathrm{Cu})$ e ferro ( $\mathrm{Fe}$ ), enquanto que não afetou os teores de fósforo (P), de matéria orgânica (M.O.), de potássio $(K)$, de manganês $\left(M_{n}\right)$, de zinco $(Z n)$ e nem o valor da capacidade de troca de cátions (CTC), como pode se perceber na Tabela 4.

Convém lembrar que as doses de calcário foram aplicadas em agosto de 1982 e reaplicadas em julho de

Tabela 9 . Efeito de sistemas de produção, na dose de calagem 6 t/ha e na profundidade de amostragem de 20 a $40 \mathrm{~cm}$, sobre o teor de magnésio no solo (meq/100 $\mathrm{cm}^{3}$ ).

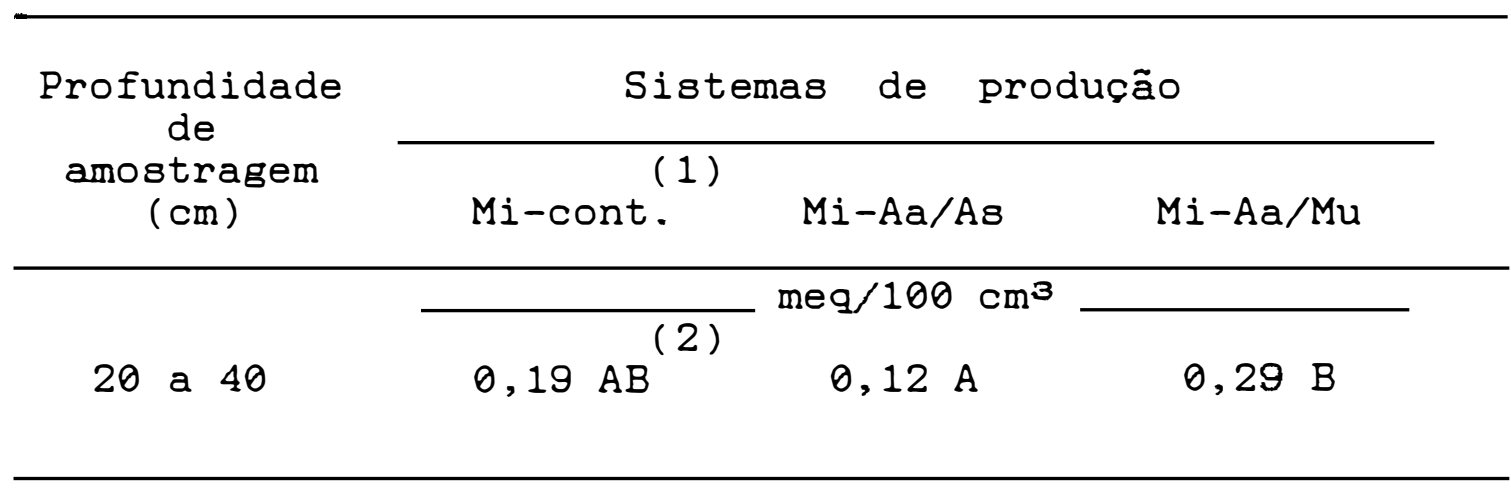

(1) Mi-milho; Aa-amendoim "das águas"; As-amendoim "da seca"; Mu-mucuna-preta.

(2) Médias seguidas da mesma letra, nao diferem estatisticamente pelo Teste de Tukey a 5\% de probabilidade.

1984. Portanto, os efeitos observados em fevereiro de 1989, época da amostragem do solo, são de aproximadamente quatro anos e meio após a última aplicação. Este fato demonstra o efeito residual do calcário, e por outro lado justifica 
algumas variações não muito expressivas, de algumas características químicas, em função da calagem.

\subsubsection{Fósforo}

O efeito isolado da calagem sobre o teor de fósforo no solo não foi significativo (Tabela 5), pela primeira vez desde o inicio do experimento, tomando-se por base as análises de solo realizadas nos anos anteriores (DECHEN, 1990). E que o efeito da calagem, o qual apresentou no ano agricola $85 / 86$ os seus resultados mais expressivos sobre as caracteristicas químicas do solo, tem decrescido paulatinamente. No pH atual, que está em torno de 4,0 , é de se esperar que parte do fósforo tenha se insolubilizado, na forma de fosfatos de ferro e alumínio.

Analisando-se a interação entre sistemas de produção e niveis de calagem (Figura 3 ) através da análise de regressão, no entanto, verifica-se que no sistema Mi$\mathrm{Aa} / \mathrm{As}$, houve um leve decréscimo no teor de fósforo, não significativo entretanto (Tabela 6), enquanto que no sistema $\mathrm{Mi}-\mathrm{Aa} / \mathrm{Mu}$ ocorreu um acréscimo mais acentuado e significativo em função do aumento das doses de calagem.

\subsubsection{Matéria organica}




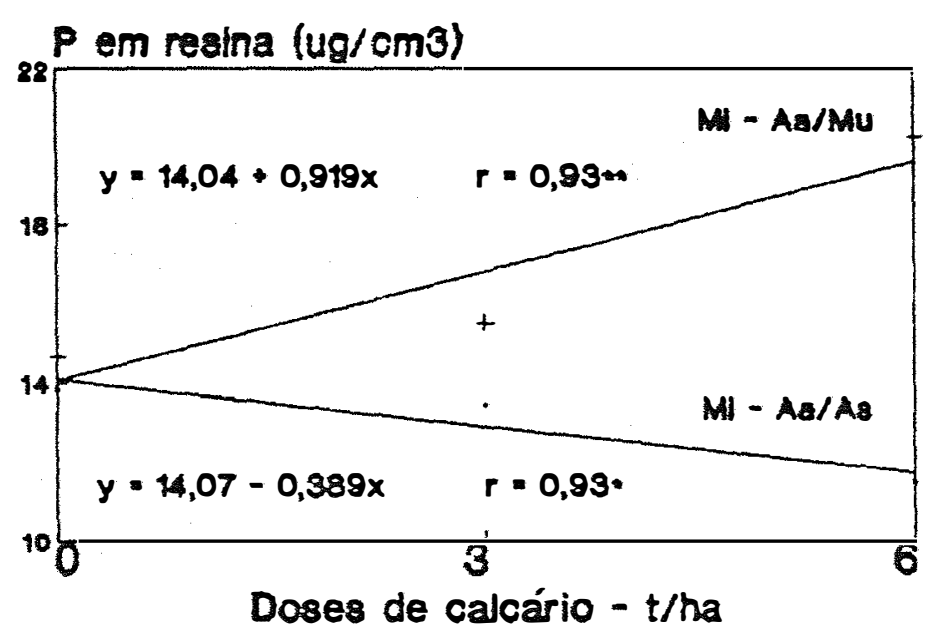

Eigura 3 . Equações de regressão que descrevem a interação de doses de calcário dentro de sistemas de produçäo sobre o teor de fósforo no solo (ug/ $\left.\mathrm{cm}^{3}\right)$.

A aplicação de calcário nao afetou significativamente os teores de matéria orgânica do solo. E possivel que as quantidades estudadas, e com apenas duas aplicações efetuadas, não foram suficientes para aumentar a produção de massa vegetal, a ponto de causar alguma alteração na quantidade de matéria orgânica acumulada nos oito anos de condução do experimento.

$$
4 \cdot 1 \cdot 2 \cdot 3 . \mathrm{pH}
$$

O efeito da calagem ainda se fez sentir no valor do pH do solo (Tabela 5), mesmo após quatro anos e 
meio da última aplicação. Somente na dose 6 t; ha, o valor do $\mathrm{pH}$ foi significativamente superior aos demais.

No entanto, o valor do $\mathrm{pH} 4,38$ para a dose 6 t/ha de calcário é baixo, o que reflete o deoréscimo da ação do efeito residual do calcário. Em conseguência, nas condições atuais já se observa a presença de alumínio trocável, apesar de ser em pequena quantidade. No ano agrícola 85/86, no mesmo nível de calagem, o phi era 6,3 (DECHEN, 1990).

Observa-se na Tabela 10, a qual analisa a interação entre níveis de calagem e a profundidade de amostragem, que o maior efeito foi verificado na profundidade $\theta$ a $20 \mathrm{~cm}$. Em geral, os efeitos da calagem se restringem a esta camada, devido à baixa solubilidade do calcário e às dificuldades práticas de incorporá-lo em profundidade. Por estas razões, recomenda-se que se faça uma distribuição uniforme e uma boa mistura com o solo (BARBER, 1967).

Mas os resultados mostram que o efeito da calagem, apesar de menor, também ocorreu nas profundidades 20 a $40 \mathrm{~cm}$ e 40 a $60 \mathrm{~cm}$, o que pode ser visualizado com mais clareza na Figura 4, através da análise de regressão, onde o valor do $\mathrm{pH}$ aumenta linearmente, que como será visto adiante, está associado ao deslocamento do cálcio e magnésio para essas camadas. QUAGGIO et alii (1982), também obtiveram resultados semelhantes após três anos da 
aplicação de quantidades crescentes de calcário, principalmente nas doses mais elevadas, em um Latossolo Roxo Distrófico.

Tabela 10 . Efeito da calagem e profundidade de amostragem, sobre o pH do solo, independente do sistema de produção.

\begin{tabular}{|c|c|c|c|c|}
\hline \multirow{2}{*}{$\begin{array}{l}\text { Profundidade } \\
\text { de } \\
\text { amostragem } \\
\text { (cm) }\end{array}$} & Doses de & \multicolumn{2}{|c|}{ calcário - t/ha } & \multirow[t]{2}{*}{ Médias } \\
\hline & 0 & 3 & 6 & \\
\hline & 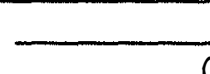 & $\mathrm{pH}$ & & \\
\hline 0 a 20 & 4,00 aA & 4,18 aA & $4,53 \mathrm{aB}$ & $4,24 a$ \\
\hline 20 a 40 & $3,94 \mathrm{aA}$ & $4,07 \cdot \mathrm{bA}$ & $4,42 b B$ & $4,14 b$ \\
\hline 40 a 60 & 3,98 aA & $4,04 \mathrm{bAB}$ & $4,19 \mathrm{cB}$ & $4,07 \mathrm{c}$ \\
\hline Médias & $3,98 \mathrm{~A}$ & $4,10 \mathrm{~A}$ & $4,38 \mathrm{~B}$ & - \\
\hline
\end{tabular}

(1) Médias seguidas da mesma letra, nao diferem estatisticamente pelo Teste de Tukey a 5\% de probabilidade. Letras maiúsculas expressam o comportamento entre as doses de calcário e letras minúsculas entre as profundidades.

\subsubsection{Potássio, cálcio e magnésio}

Os teores de potássio no solo nao sofreram nenhuma variação com a aplicação dos diversos níveis de calagem. Já o cálcio e o magnésio, como era de se esperar,tiveram seus teores aumentados (Tabela 5). Como aconteceu com o pH, essa variação ocorreu independente da 


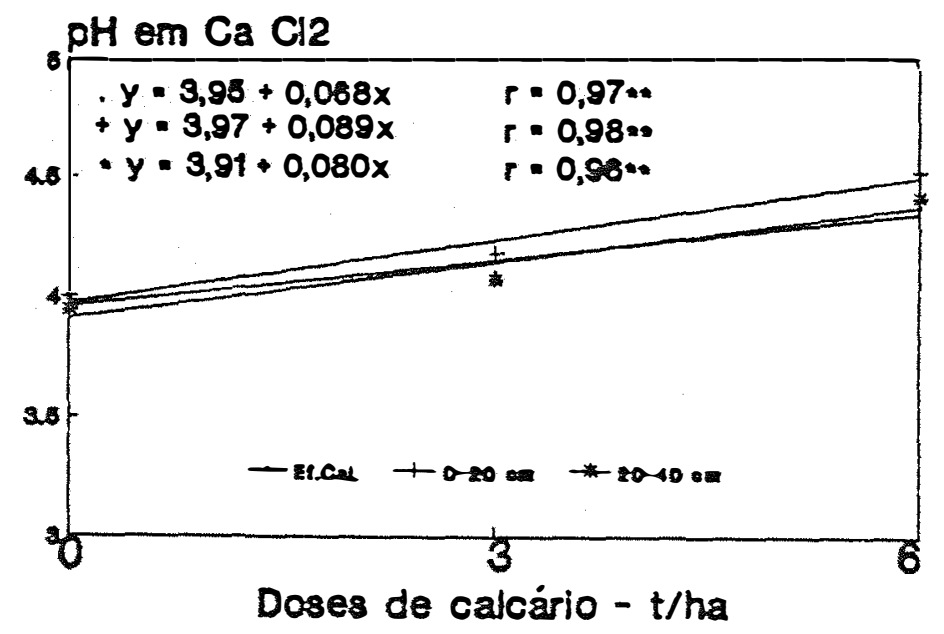

Figura 4. Equações de regressão que descrevem o efeito da calagem e a interaçao de dodoses de calcário dentro de profundidade de amostragem, sobre o valor do $\mathrm{pH}$ do solo.

profundidade, mas de forma mais acentuada na camada superficial, e somente a dose 6 t/ha é que proporcionou a elevação dos teores de forma significativa (Tabelas 11 e 12).

A análise de regressão, tanto para o cálcio quanto para o magnésio, evidencia esse efeito da dose 6 t/ha em relação às outras doses, comportamento esse que é descrito pelas equações de regressão quadráticas (Figuras 5 e 6).

Em razão do decréscimo do efeito da calagem com o tempo, praticamente nao existe mais diferença entre as doses $\theta$ e 3 t/ha. Os teores absolutos desses cátions no 
Tabela 11 . Efeito da calagem e profundidade de amostragem, sobre o teor de cálcio no solo (meq/ $100 \mathrm{~cm}^{3}$ ) independente do sistema de produção.

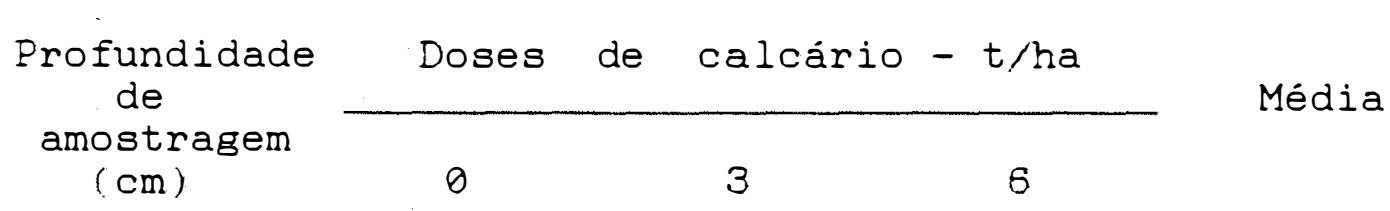

(1)

$\begin{array}{rllllll}0 \text { a } 20 & 0,57 \mathrm{aA} & 0,57 \mathrm{aA} & 1,42 \mathrm{aB} & 0,85 \mathrm{a} \\ 20 \mathrm{a} 40 & 0,40 \mathrm{abA} & 0,47 \mathrm{aA} & 0,83 \mathrm{bB} & 0,57 \mathrm{~b} \\ 40 \mathrm{a} 60 & 0,20 \mathrm{bA} & 0,48 \mathrm{aAB} & 0,57 \mathrm{bB} & 0,42 \mathrm{~b}\end{array}$

Média

$0,39 \mathrm{~A}$

$0,51 \mathrm{~A}$

$0,94 \mathrm{~B}$

$-$

(1) Médias seguidas da mesma letra, nao diferem estatisticamente pelo Teste de Tukey a 5\% de probabilidade. Letras maiúsculas expressam o comportamento entre as doses de calcário e letras minúsculas entre as profundidades.

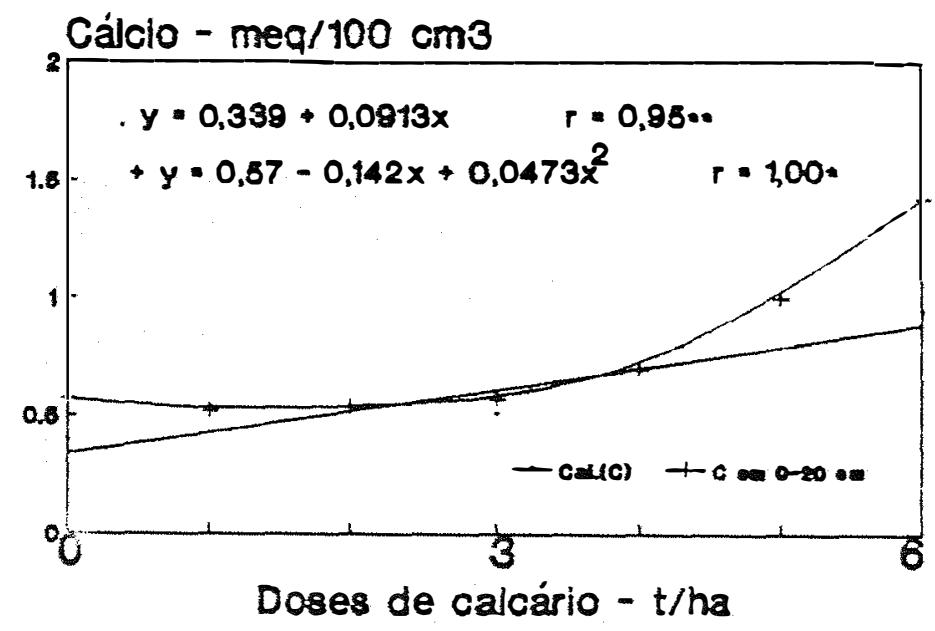

Figura 5 . Equações de regressão que descrevem o efeito da calagem e a interação de doses de calcário dentro da profundidade de $\theta$ a $20 \mathrm{~cm}$ sobre os teores de cálcio no solo (meq/100 $\mathrm{cm}^{3}$ ). 
Tabela 12 . Efeito da calagem e profundidade de amostragem, sobre o teor de magnésio no solo (meq/100 $\mathrm{cm}^{3}$ ), independente do sistsma de produção.

\begin{tabular}{ccccc}
\hline $\begin{array}{c}\text { Profundidade } \\
\text { de } \\
\begin{array}{c}\text { amostragem } \\
(\mathrm{cm})\end{array}\end{array}$ & Doses de calcário $-\mathrm{r} / \mathrm{ha}$ & Médias \\
\cline { 2 - 5 } & 0 & 3 & 6 & \\
0 a 20 & $0,09 \mathrm{aA}(1)$ & $0,13 \mathrm{aA}$ & $0,38 \mathrm{aB}$ & $6,20 \mathrm{a}$ \\
20 a 40 & $0,08 \mathrm{aA}$ & $0,09 \mathrm{aA}$ & $0,20 \mathrm{bB}$ & $0,12 \mathrm{~b}$ \\
40 a 60 & $0,08 \mathrm{aA}$ & $0,10 \mathrm{aAB}$ & $0,14 \mathrm{cB}$ & $0,11 \mathrm{~b}$ \\
\hline Médias & $0,08 \mathrm{~A}$ & $0,11 \mathrm{~A}$ & $0,24 \mathrm{~B}$ & - \\
\hline
\end{tabular}

(1) Médias seguidas da mesma letra, nao diferem estatisticamente pelo Teste de Tukey a 5\% de probabilidade. Letras maiúsculas expressam o comportamento entre as doses de calcário e letras minúsculas entre as profundidades.

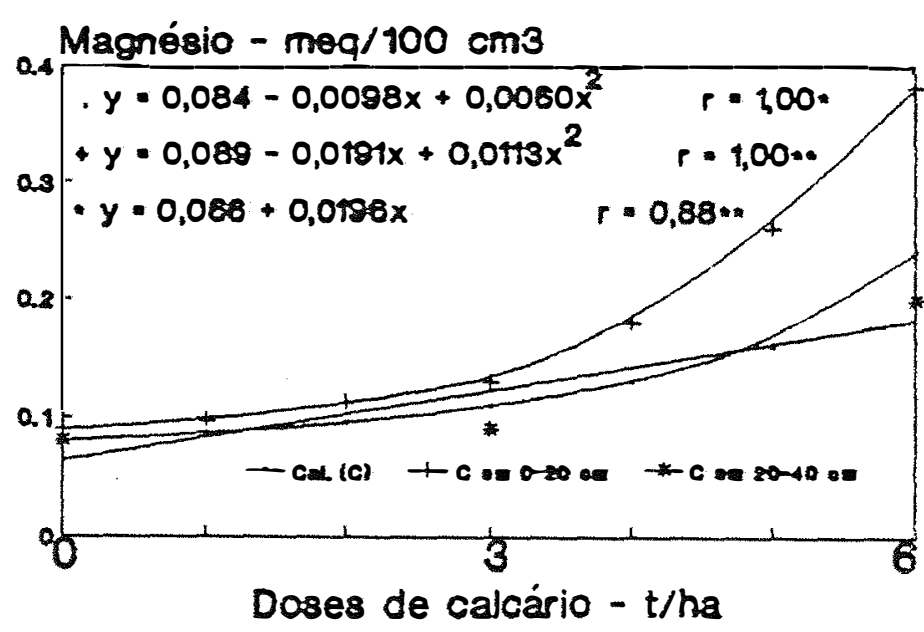

Figura 6 . Equações de regressão que descrevem o efeito da calagem e a interação de doses de calcário dentro de profundidade de amostragem, sobre o teor de magnésio no solo (meq/100 $\mathrm{cm}^{3}$ ). 


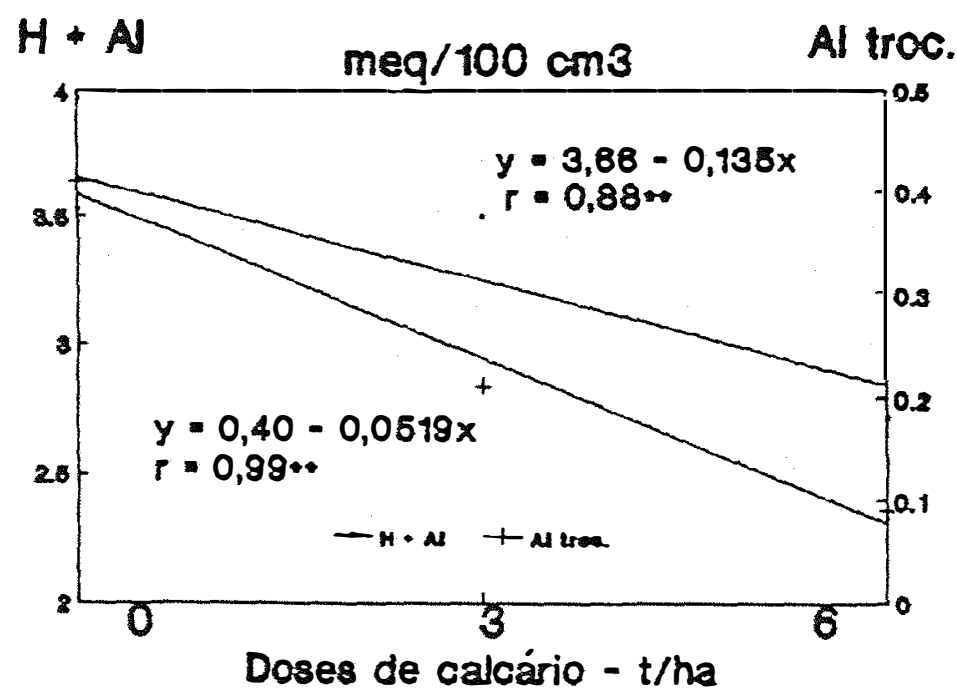

Figura 7 . Equações de regressão que descrevem o efeito da calagem sobre os teores de $\mathrm{H}+\mathrm{Al}$ e Al troc. no solo (meq/100 $\left(\mathrm{m}^{3}\right)$.

\section{1 .2 .6 .5$, CTC E V\%}

Em relação ao valor S (soma de bases), a interação entre níveis de calagem e profundidade de amostragem (Tabela 13), inostra que o efeito da dose $3 \mathrm{t} / \mathrm{ha}$ de calcário é muito pequeno em quaisquer das profundidades, mas a dose $6 \mathrm{t} / \mathrm{ha}$ na camada superficial ( 0 a $20 \mathrm{~cm}$ ) ainda está afetando significativamente os teores de cálcio e de magnésio, e como consequência, o valor da soma de bases, justificando assim a resposta quadrática. O comportamento foi idêntico ao do cálcio e ao do magnésio (Figura 8). 
Tabela 13 . Efeito da calagem e profundidade de amostragem, sobre o valor da soma de bases no solo (meq/100 $\mathrm{cm}^{3}$ ), independente do sistema de produção.

\begin{tabular}{|c|c|c|c|c|}
\hline \multirow{2}{*}{$\begin{array}{c}\text { Profundidade } \\
\text { de } \\
\text { amostragem } \\
\text { ( cm) }\end{array}$} & Doses & calcário & $-t / h a$ & \multirow[t]{2}{*}{ Médias } \\
\hline & 0 & 3 & 6 & \\
\hline & \multicolumn{3}{|c|}{$(1)^{\mathrm{meq} / 100 \mathrm{~cm}^{3}}$} & \\
\hline $0-20$ & $0,83 \mathrm{aA}$ & 0,89 aA & $1,86 \mathrm{aB}$ & 1,19 a \\
\hline 20 a 40 & $0,66 \mathrm{abA}$ & $0,72 \mathrm{aA}$ & $1,32 \mathrm{bE}$ & $0,90 \mathrm{~b}$ \\
\hline 40 a 60 & $0,44 \mathrm{bA}$ & $0,73 \mathrm{aAB}$ & $0,86 \mathrm{cB}$ & $0,68 \mathrm{c}$ \\
\hline Médias & $0,64 \mathrm{~A}$ & $0,78 \mathrm{~A}$ & $1,34 \mathrm{~B}$ & - \\
\hline
\end{tabular}

(1) Médias seguidas da mesma letra, nao diferem estatisticamente pelo Teste de Tukey a 5\% de probabilidade. Letras maiúsculas expressam o comportamento entre as doses de calcário e letras minúsculas entre as profundidades.

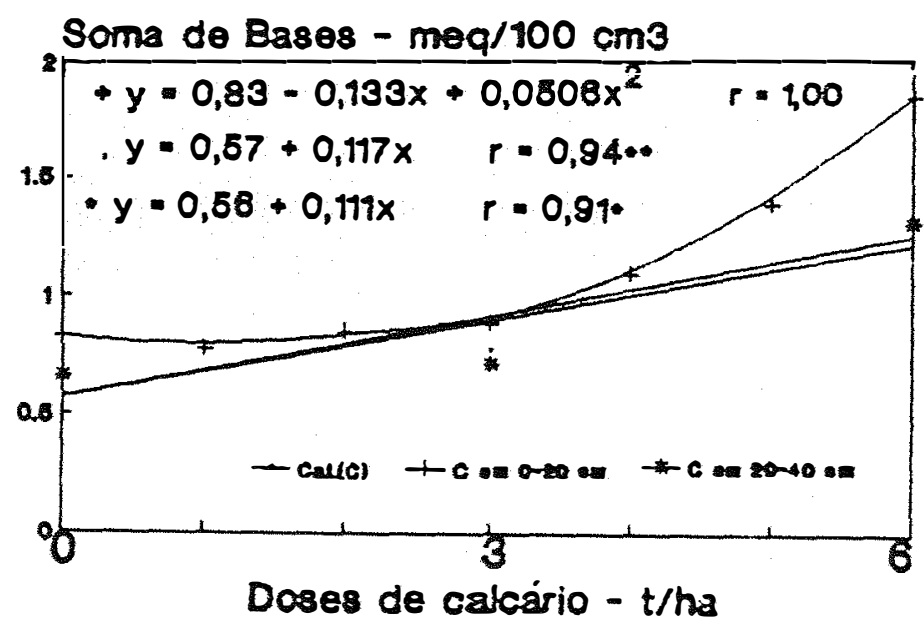

Figura 8 . Equações de regressão que descrevem o efeito da calagem e a interação de doses de calcário dentro de profundidade de amostragem, sobre o valor da soma de bases do solo (meq/100 $\mathrm{cm}^{3}$ ). 
A capacidade de troca de cátions, sendo determinada a $\mathrm{pH} 7,0$, não apresentou variação significativa em função da calagem (Tabela 5). Este baixo valor da CTC, em torno de 4,18, já era esperado para um Latossolo Vermelho-Escuro, com baixo teor de matéria orgânica.

Segundo KIEHL (1979), esse grande grupo de solo do Estado de São Paulo, apresentaria, em média, uma saturação por bases (V\%) de $33,6 \%$, com a seguinte distribuição porcentual média para os cátions: $\mathrm{Ca}=18,5$; $\mathrm{Mg}=10,6 ; \mathrm{K}=4,5 \mathrm{e} \mathrm{H}+\mathrm{Al}=66,4$. Na dose de $6 \mathrm{t} / \mathrm{ha}$ de calcário verificou-se, respectivamente, a seguinte distribuição: $V \%=32,5 ; \mathrm{Ca}=23,0 ; \mathrm{Mg}=5,9 ; \mathrm{K}=4,2 \mathrm{e} \mathrm{H}+$ $A 1=66,7$.

Com a calagem, a saturação por bases aumentou linearmente (Figura 9), mas, apesar dessa rèsposta linear observa-se, na Tabela 14, que nas profundidades de $\theta$ a 20 e de 20 a $40 \mathrm{~cm}$, as variações de $\mathrm{V} \%$ foram bem expressivas na dose 6 t/ha, quando relacionadas às outras doses.

4.1.2.7. Cobre, Ferro, Manganês e Zinco

Os micronutrientes estudados neste trabalho, todos cationicos, em geral diminuem sua disponibilidade com a elevação do pH, e portanto, com a aplicação da calagem (LINDSAY, 1972). Foi o que ocorreu com 


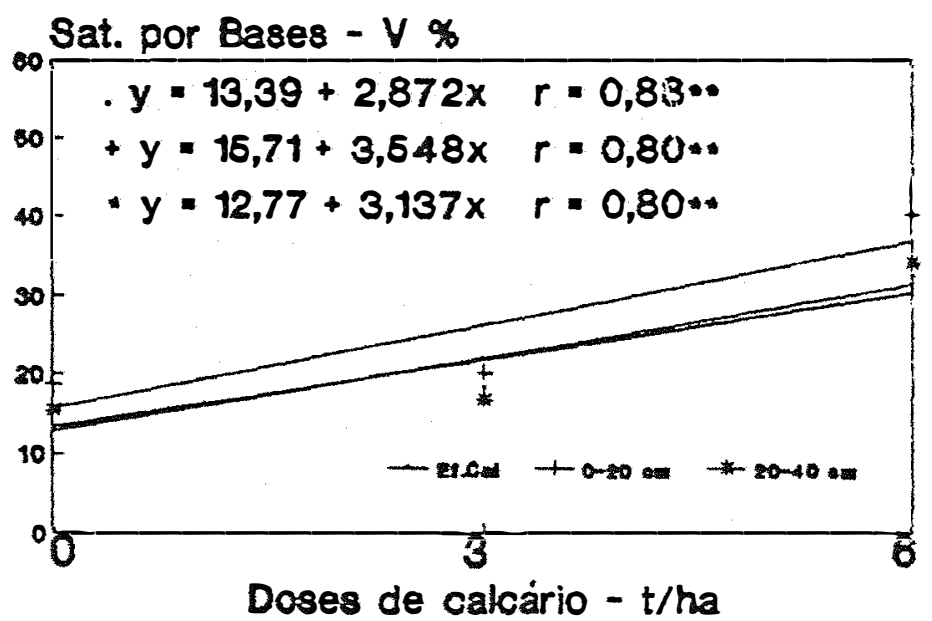

Figura 9 . Equações de regressão que descrevem o efeito da calagem e da interação de doses de calcário dentro de profundidade, sobre o valor da saturação por bases do solo (\%).

- cobre e o ferro de forma significativa, mas não com o manganês e o zinco (Tabela 5).

Mesmo para os micronutrientes que apresentaram decréscimo, isso apenas reflete o inicio do processo, pois se sabe que somente a partir de valores de $\mathrm{pH}$ bem mais elevados $(>6,0)$ é que a diminuição de disponibilidade pode se tornar critica.

No caso do cobre nao houve decréscimo significativo em função da calagem, dentro das profundidades, mas houve diferença no efeito isolado da calagem (Tabela 15). Na Figura 10 é apresentado seu comportamento linear em função da calagem. 
Tabela 14. Efeito da calagem e profundidade de amostragem, sobre o valor da saturação por bases do solo(\%), independente do sistema de produção.

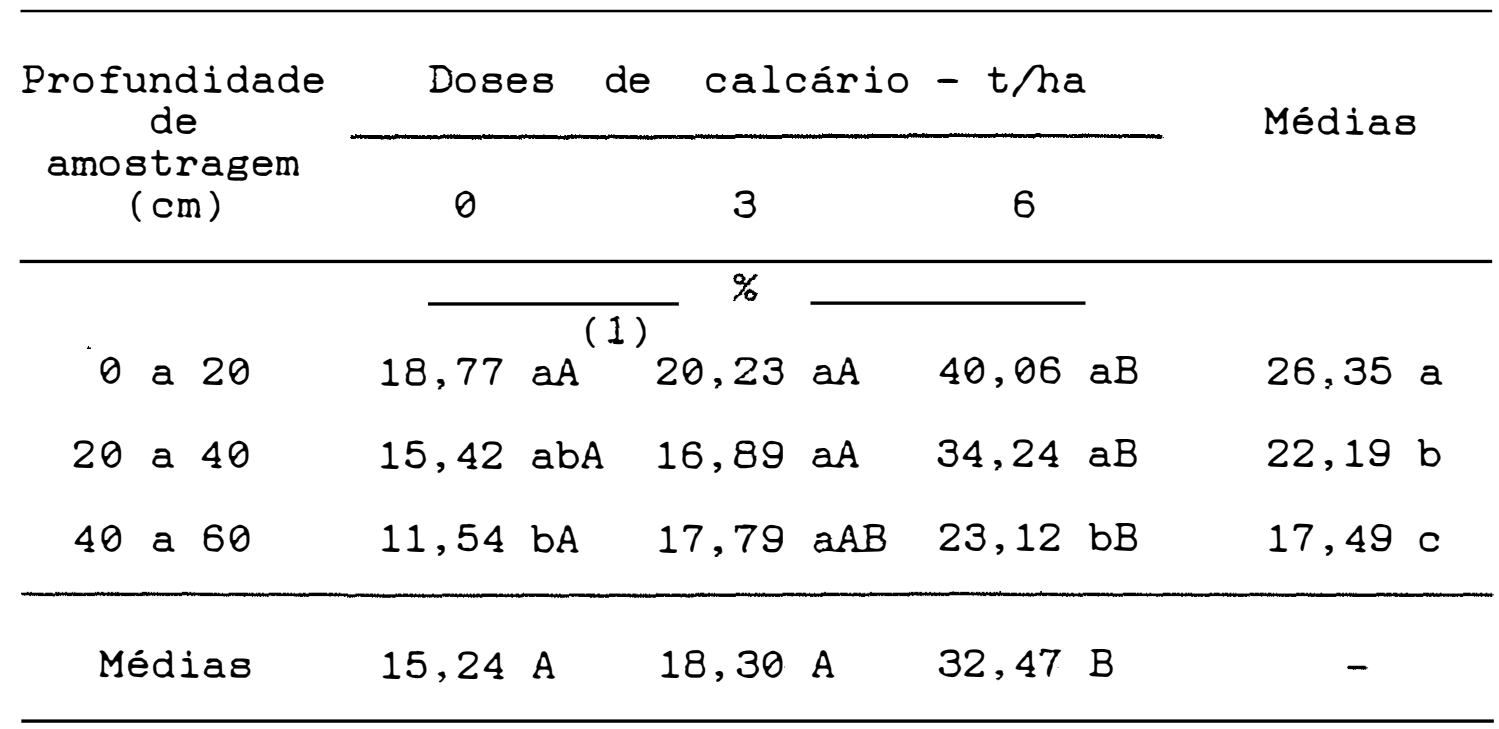

(1) Médias seguidas da mesma letra, nao diferem estatisticamente pelo Teste de Tukey a 5\% de probabilidade. Letras maiúsculas expressam o comportamento entre as doses de calcário e letras minúsculas entre as profundidades.

O manganês apresentou um comportamento meio discrepante entre as profundidades, em função da aplicação do calcário (Tabela 16), ocorrendo um inesperado acréscimo na camada superficial, enquanto tendeu a decrescer na profundidade de 20 a $40 \mathrm{~cm}$ e se firmou a tendência na de 40 a $60 \mathrm{~cm}$. Mais uma vez, o efeito da calagem se fez sentir em profundidade. O efeito isolado da calagem mostrou o decréscimo linear do teor de manganês (Figura 11). O decréscimo linear do teor de ferro, resultante da aplicação da calagem (Figura 12), foi mais acentuado na camada de 0 a $20 \mathrm{~cm}$ e tendeu a diminuir com a profundidade (Tabela 17). 
Tabela 15 . Efeito da calagem e profundidade de amostragem sobre o teor de cobre no solc ( $\mathrm{ppm}$ ), independente do sistema de produção.

\begin{tabular}{|c|c|c|c|c|}
\hline \multirow{2}{*}{$\begin{array}{c}\text { Profundidade } \\
\text { de } \\
\text { amostragem } \\
(\mathrm{cm})\end{array}$} & Doses de & \multicolumn{2}{|c|}{ calcário - t/ha } & \multirow{2}{*}{ Médias } \\
\hline & $\theta$ & 3 & 6 & \\
\hline \multicolumn{5}{|c|}{${ }_{-} \mathrm{PPm}$} \\
\hline 0 a 20 & 2,48 aA & 2,08 aA & $1,89 \mathrm{aA}$ & $2,15 \mathrm{ab}$ \\
\hline 20 a 40 & 2,30 abA & 2,26 aA & 2,10 aA & $2,22 a$ \\
\hline 40 a 60 & $2,22 \mathrm{bA}$ & 2,07 aA & $1,92 \mathrm{aA}$ & $2,07 \quad b$ \\
\hline Médias & $2,33 \mathrm{~A}$ & $2,14 \mathrm{AB}$ & $1,97 \mathrm{~B}$ & - \\
\hline
\end{tabular}

(1) Médias seguidas da mesma letra, nao diferem estatísticamente pelo Teste de Tukey a $5 \%$ de probabilidade. Letras maiúsculas expressam o comportamento entre as doses de calcário e letras minúsculas entre as profundidades.

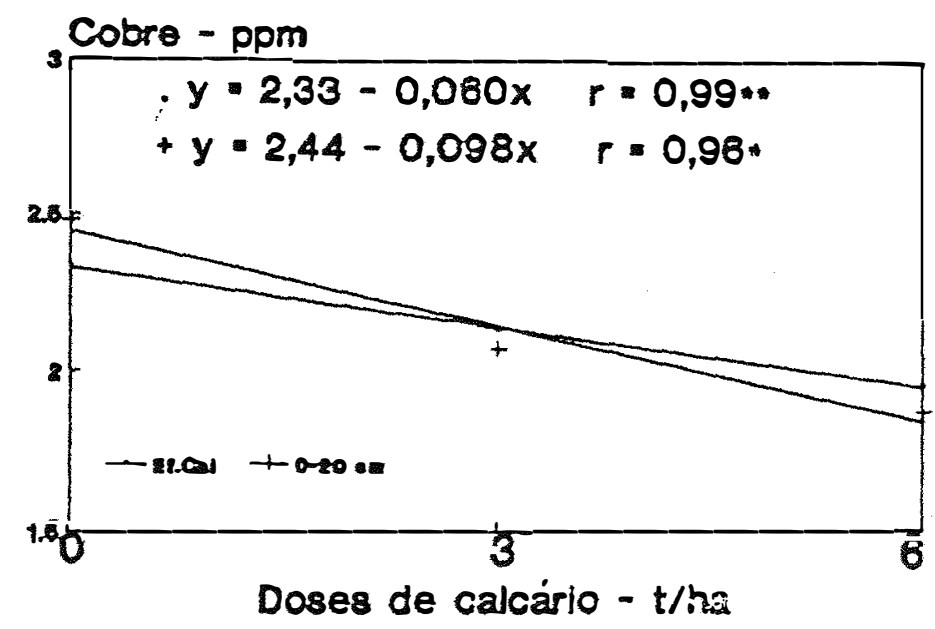

Figura 10 . Equações de regressão que descrevem 0 efeito da calagem e da interação de doses de calcário dentro da profundidade de amostragem $\theta$ a $20 \mathrm{~cm}$, sobre o teor de cobre no solo (ppm). 
Tabela 16 . Efeito da calagem e profundidade de amostragem, sobre o teor de manganês no solo, (ppm), independente do sistema de produção.

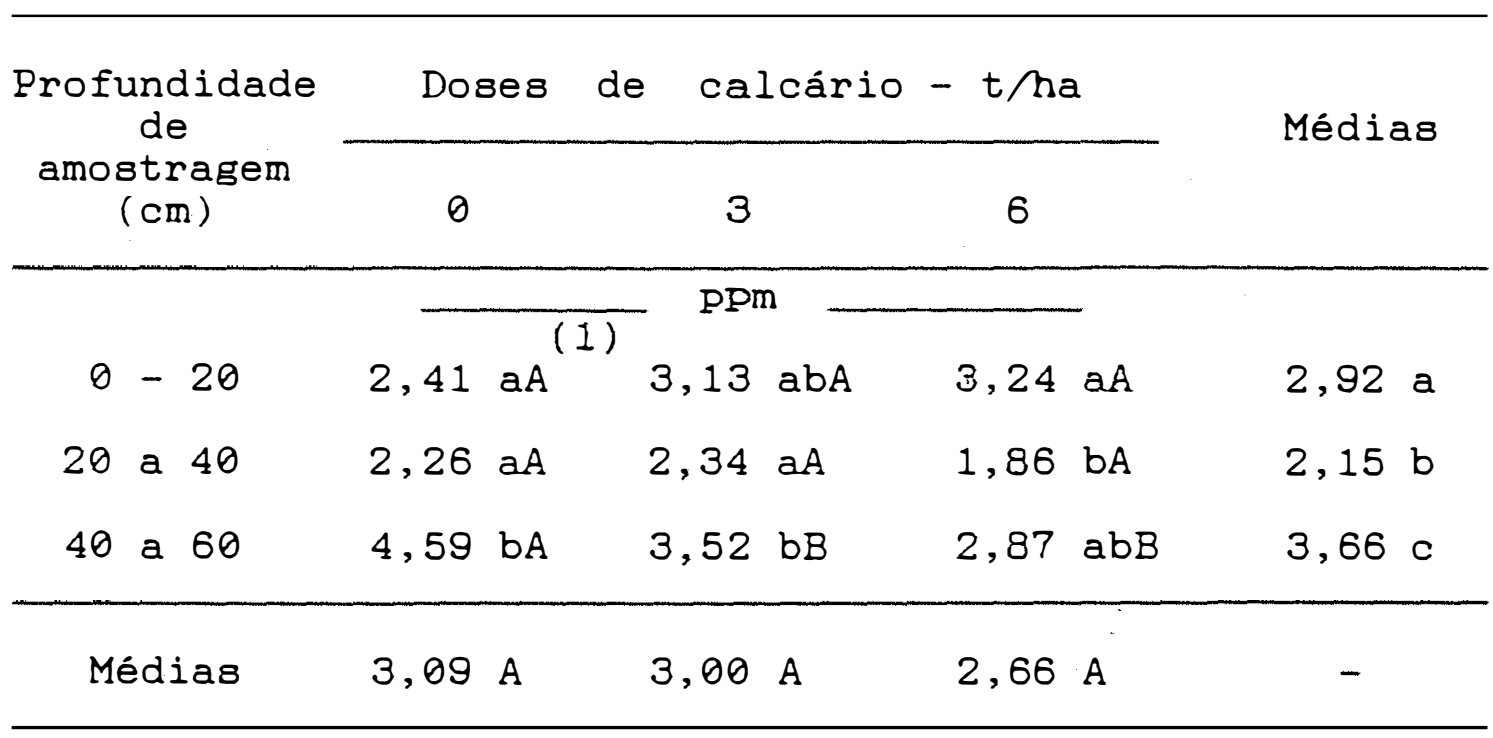

(1) Médias seguidas da mesma letra, nao diferem estatisticamente pelo Teste de Tukey a 5\% de probabilidade. Letras maiúsculas expressam o comportamento entre as doses de calcário e letras minúsculas entre as profundidades.

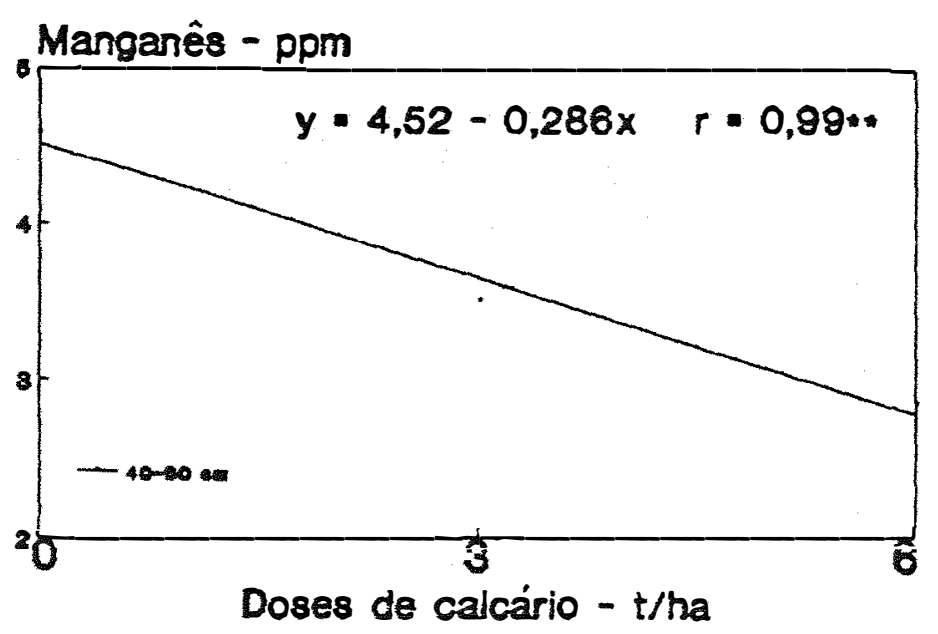

Figura 11 . Equação de regressão que descreve o efeito da interação de niveis de calcário dentro da profundidade 40 a $60 \mathrm{~cm}$, sobre 0 teor de manganês no solo ( $\mathrm{ppm}$ ). 
Tabela 17 . Efeito da calagem e profundidade de amostragem, sobre o teor de ferro no solo (ppm) independente do sistema de produção.

\begin{tabular}{|c|c|c|c|c|}
\hline $\begin{array}{c}\text { Profundidade } \\
\text { de }\end{array}$ & Doses & calcário & - t/Ma & \multirow[t]{2}{*}{ Médias } \\
\hline $\begin{array}{c}\text { amostragem } \\
(\mathrm{cm})\end{array}$ & $\theta$ & 3 & 6 & \\
\hline & $\overline{1}$ & $\mathrm{ppm}$ & 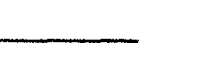 & \\
\hline$\theta-20$ & $9,37 \mathrm{aA}^{(1)}$ & $6,26 \mathrm{aB}$ & 3,37 ac & $6,33 \mathrm{a}$ \\
\hline 20 a 40 & $6,27 \mathrm{bA}$ & $4,91 \mathrm{abA}$ & $2,82 \mathrm{aB}$ & $4,67 \mathrm{~b}$ \\
\hline 40 a 60 & $4,01 \mathrm{cA}$ & $3,59 \mathrm{bA}$ & 2,48 aA & $3,36 \simeq$ \\
\hline Médias & $6,55 \mathrm{~A}$ & $4,92 B$ & $2,89 \mathrm{C}$ & - \\
\hline
\end{tabular}

(1) Médias seguidas da mesma letra, nao diferem estatisticamente pelo Teste de Tukey a 5\% de probabilidade. Letras maiúsculas expressan o comportamento entre as doses de calcário e letras minúsculas entre as profundidades.

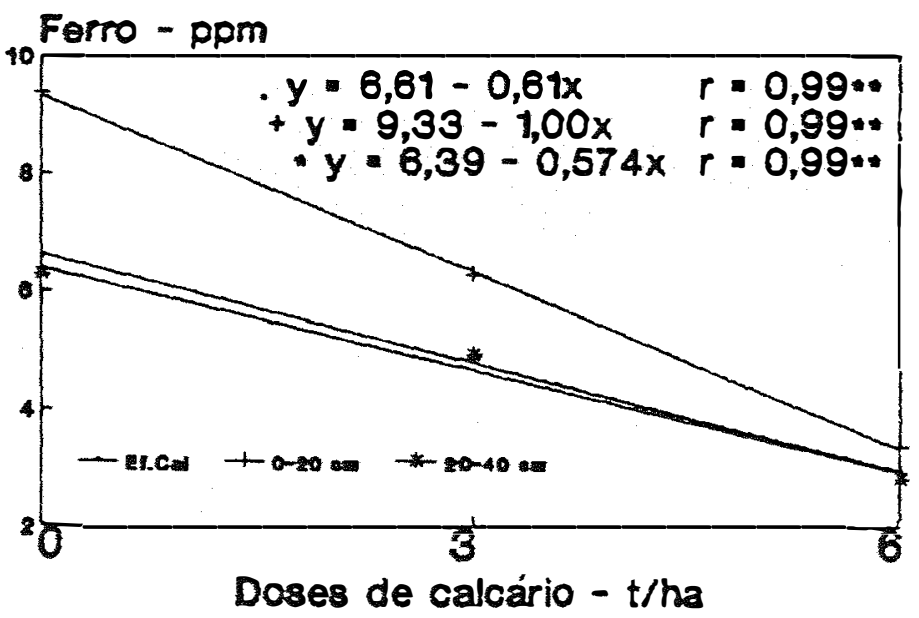

Figura 12 . Equações de regressão que descrevem 0 efeito da calagem e da interação de doses de calcário dentro das profundidades $\theta$ a 20 e 20 a $40 \mathrm{~cm}$, sobre o teor de ferro no solo ( $\mathrm{ppm}$ ). 


\subsubsection{Efeito da profundidade}

As caracteristicas físicas, químicas e biológicas do solo, em geral variam com a profundidade, o que é compreensivel, já que as camadas superficiais sofrem diretamente o impacto da ação dos diversos fatores do ambiente, o que não acontece com as camadas mais profundas, que são afetadas em menor intensidade e mais lentamente.

Da mesma forma, a ação do homem, através das práticas de manejo do solo visando a sua exploração, em geral atinge principalmente $\circ$ que se denomina de camada arável, sendo seu reflexo em profundidade menor, mas não menos importante.

O conhecimento desse efeito em profundidade permite avaliar sob quais condições uma boa parte do sistema radicular das plantas se desenvolve, e quando necessário, orienta a prevenção ou correção de possíveis limitações ao crescimento das raízes.

O teor de matéria orgânica decresceu em função da profundidade (Figura 13 A), já que é na superficie que são depositados os restos de plantas e animais, os quais, após decomposição constituem o húmus do solo.

Já o teor de alumínio trocável aumentou com a profundidade (Figura $13 \mathrm{~B}$ ), em razão da neutralização da acidez através da calagen, que atua mais na camada 
superficial, e só com o passar do tempo sua ação, já bem mais fraca, atinge as camadas inferiores, como os resultados bem 0 demonstram.

o valor da CTC diminuiu com o aumento da profundidade (Figura $13 \mathrm{C}$ ) porque na camada superficial ocorre maior quantidade de matéria orgânica e argila, como conseqüência da atuação mais intensa do intemperismo nessa camada.

A interação de sistemas de produção e profundidade de amostragem, em relação à teor de fósforo, ocorreu porque a diferença entre os sistemas só se verificou na profundidade $\theta$ a $20 \mathrm{~cm}$ (Tabela 7 ). 0 mesmo ocorreu no caso do ferro (Tabela 8). O teor de fósforo apresentou um decréscimo acentuado em função da profundidade (Figura 14 A), o que ocorreu, provavelmente, devido à pequena mobilidade deste nutriente no solo, tendendo portanto a se concentrar na superficie. O teor de ferro também decresceu com $\circ$ aumento da profundidade (Figura 14 B), pois na camada superficial há mais ferro disponivel, liberado pelo intemperismo.

Os valores de $\mathrm{pH}$, cálcio, magnésio, soma de bases, saturação por bases, cobre e ferro decresceram com o aumento da profundidade, mas ao mesmo tempo apresentaram algum tipo de interação com os niveis de calagem. De uma maneira geral, essas interações parecem estar relacionadas à ocorrência de um maior efeito da calagem na 


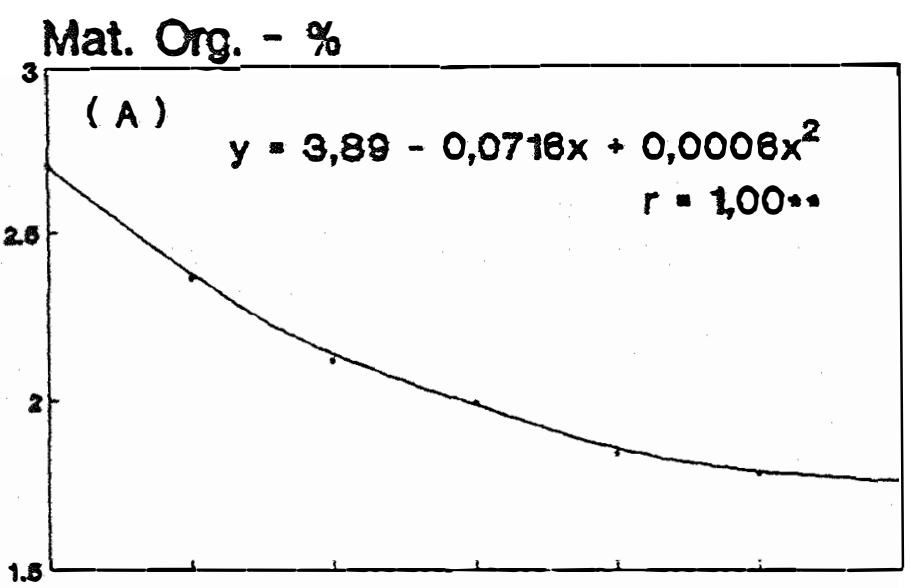

81
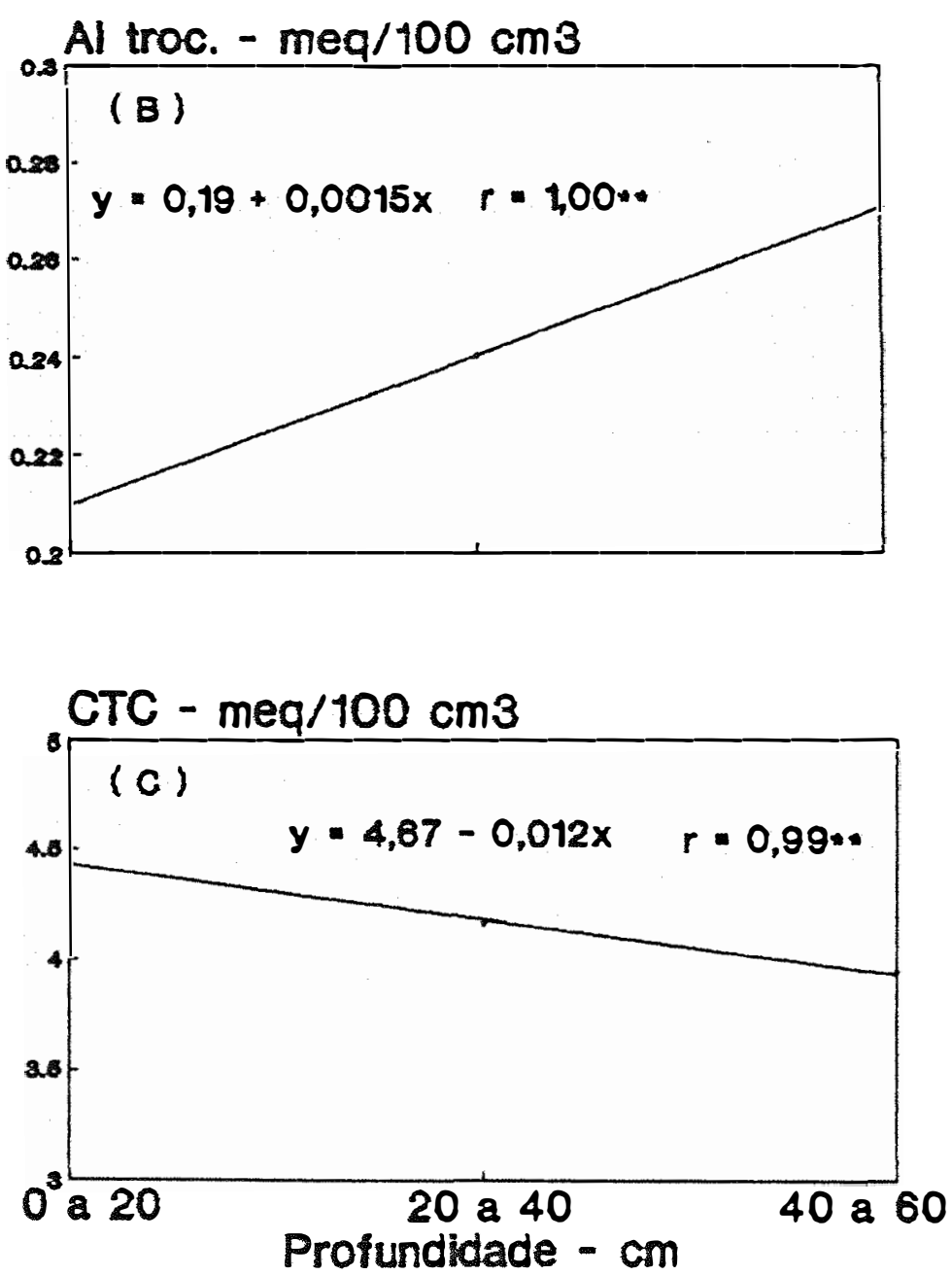

Figura 13. Equações de regressão que descrevem o comportamento dos teores de matéria orgânica (A)-\%, Al troc. (B)-meq/100 $\mathrm{cm}^{3}$ e o valor da CTC (C)-meq/ $100 \mathrm{~cm}^{3}$ (C), em função da profundidade. 
profundidade de $\theta$ a $2 \theta \mathrm{cm}$. Para ae diversas caracteristicas, nessa profundidade as diferengas entre os níveis de calagem são significativas, ao passo que nas demais profundidades o efeito da calagem é bem menos efetivo (Figuras 15 e 16).

O manganês (Figura 16 D) apresentou tendência de aumento, pela mesma razão que o aíliminio, só que a dose 3 t/ha de calcário parece não estar mais tendo efeito.

Dentre as características químicss do solo, somente o potássio, hidrogênio + alumínio e zinco, nao sofreram variação com a profundidade.
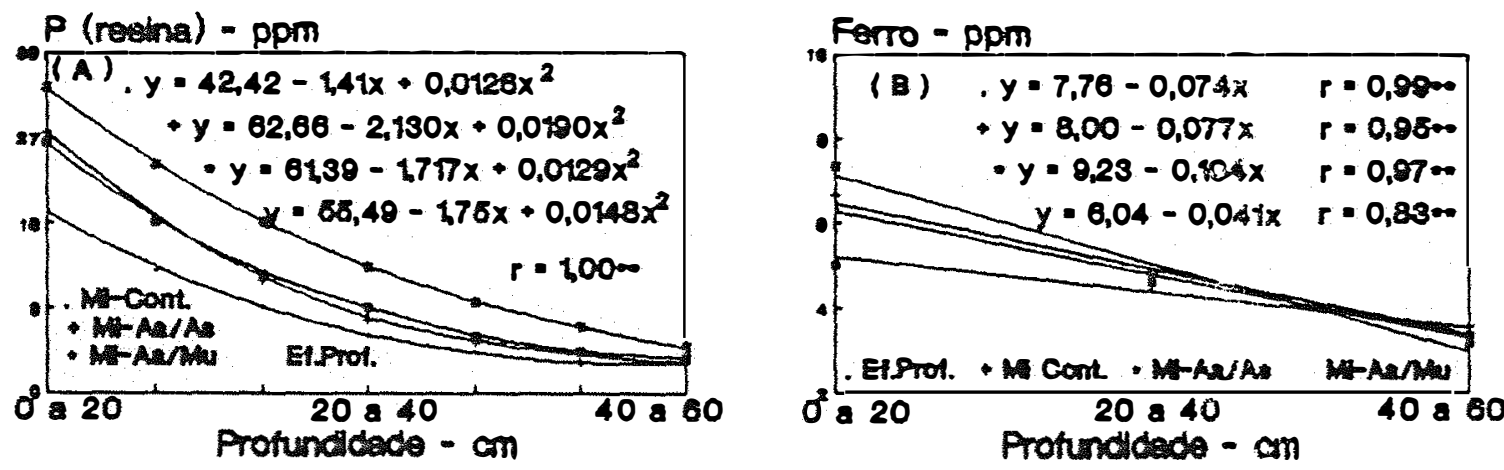

Figura 14. Equações de regressão que descrevem o comportamento dos teores de fósforo (A)-ug/ $\mathrm{cm}^{3}$ e ferro (B)-ppm, em função da profundidade e da interação profundidade dentro de sistemas de produção. 

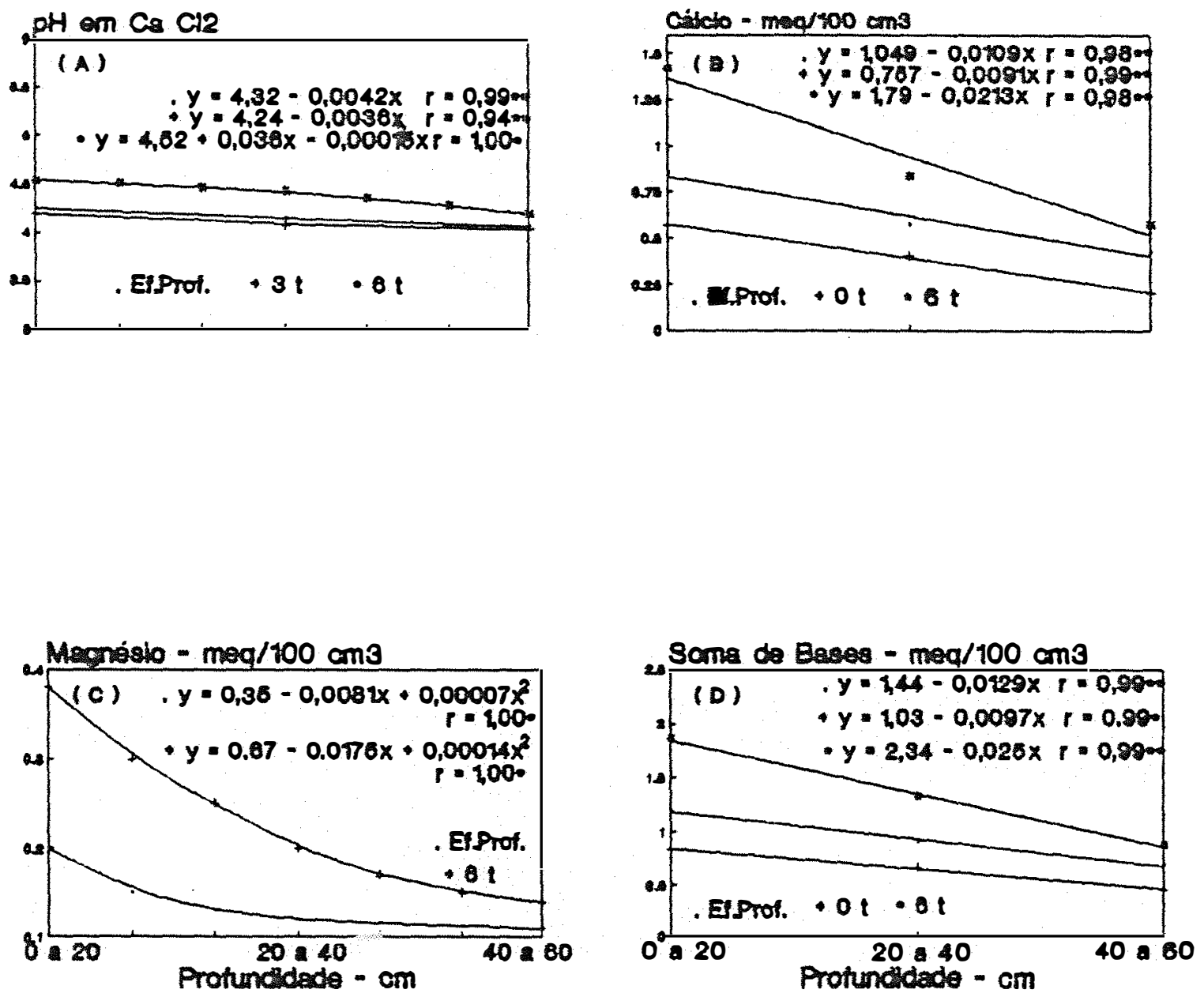

Eigura 15. Equações de regressão que descrevem o comportamento do valor do $\mathrm{pH}$ (A), dos teores de cálcio (B), magnésio (C) e valor da soma de bases (D) - meq/100 $\mathrm{cm}^{3}$, em função da profundidade e da interação profundidade dentro de calagem. 
Sat. por Bases $-V \approx$
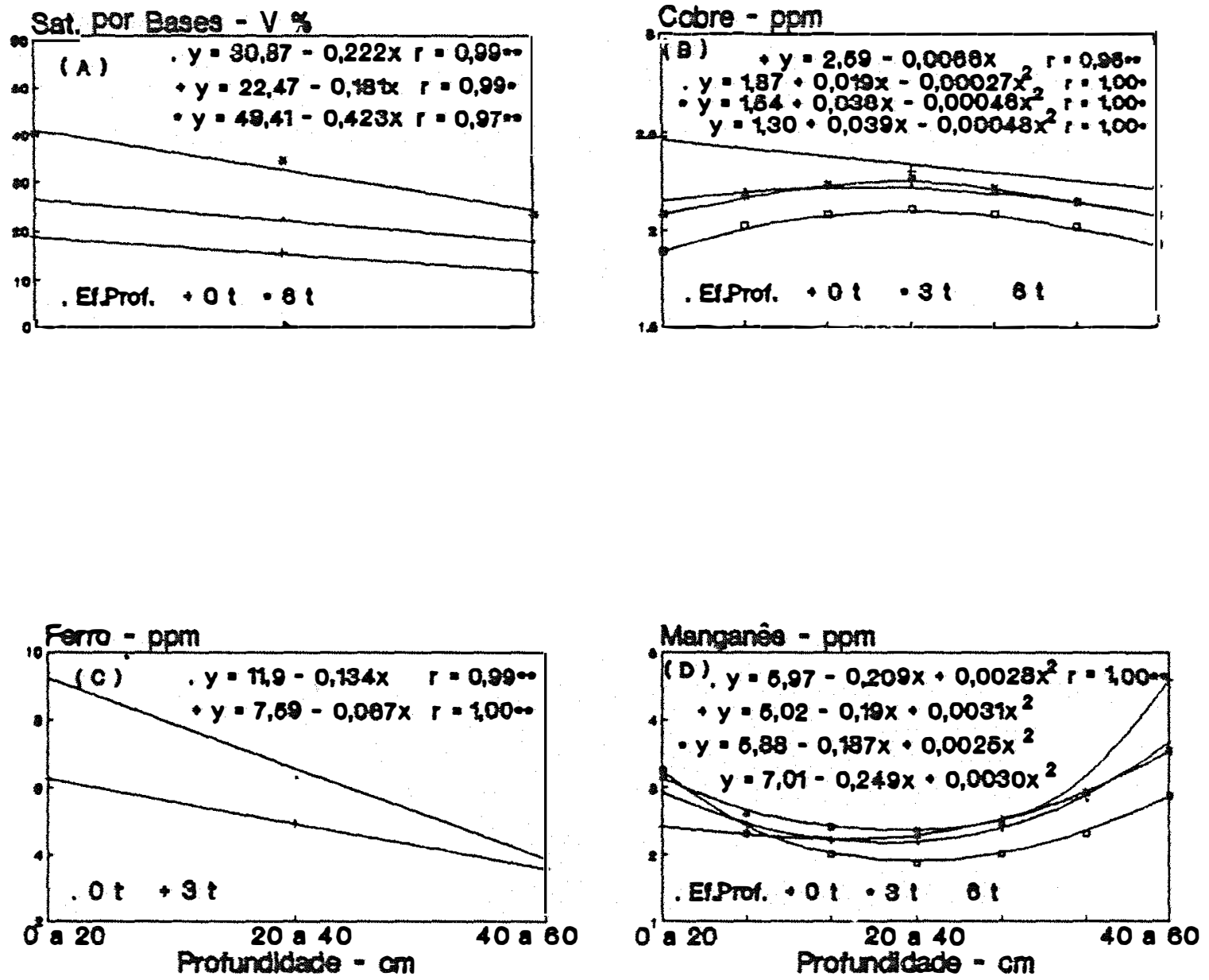

Figura 16. Equaçóes de regressão que descrevem o comportamento do valor da saturação por bases $(A)-\%$, dos teores de cobre ( $B$ ), ferro (C) e manganês (D) -ppm, em função da profundidade e da interação profundidade dentro de calagem. 


\subsection{Caracteristicas fisicas do solo}

A Tabela 18 apresenta um resumo da análise de variância (significância do Teste F), em relação ao efeito dos fatores, sistemas de produção, niveis de calagem e profundidade de amostragem, sobre as seguintes caracteristicas físicas do solo: porosidade total, macroporosidade e densidade aparente.

Pode-se verificar que nao houve efeito dos sistemas de produção e nem da calagem, sobre as citadas características físicas. Já em relação às profundidades de amostragem, todas as três caracteristicas apresentaram variação significativa.

Alguns trabalhos têm demonstrado que a rotação com culturas para a produção de grãos acarreta, além de aumentos de produtividade, beneficios físicoquímicos aos solos, similares àqueles obtidos pela incorporação de adubos verdes (MASCARENHAS et alii, 1978; GALLO et alii, 1981; CRUZ, 1982; VASCONCELLOS, 1984).

BOLTON et alii (1979a e 1979b, asseguram que os sistemas de rotação com milho, aveia e alfafa reduziram a compactação, o que se refletiu no aumento da porosidade total. Nesses mesmos trabalhos, eles verificaram que a calagem tendeu também a promover aumento na porosidade, mas outras pesquisas indicam que as 
caracteristicas fisicas nao foram afetadas por estas práticas (UCHIKAWA, 1989; MALTONI, 1988).

A porosidade e a densidacie estão intimamente relacionadas com a estrutura ou arranjo das particulas do solo. Um sistema radicular vigoroso e pivotante, como no caso do guandu, por exemplo, pode promover alteração na estrutura e, consequentemente, nessas caracteristicas físicas, com resultados favoráveis ao desenvolvimento das plantas (HURD \& SPRATT, 1982).

CINTRA \& MIELNICZUCK (1983), verificaram que colza-de-inverno e tremoço se mostraram mais promissores que cevada, soja e trigo, quando utilizados para recuperação de solos degradados, pois suas raizes pivotantes penetraram nos solos compactados com resistência à penetraçao de até $11 \mathrm{~kg} \cdot \mathrm{cm}^{2}$.

o efeito da incorporação de uma grande massa de adubo verde ao solo melhora a aeração devido ao aumento de volume do solo, havendo um aumento na porosidade, em favor da permeabilidade (JOFRE, 1955).

Pelos resultados, nao parece que o amendoim e ou mucuna-preta, assim como a prática da calagem, tenham tido condições de causar de alguma forma; mudanças sensiveis nas características físicas do solo.

Com relação à profundidade de amostragem, constata-se que a porosidade total (Tabela 19) e a macroporosidade (Tabela 20) sofreram um decréscimo significa- 
Tabela 18. Resumo da análise de variância (significância do Teste $F$ ), das características físicas do solo: porosidade total, macroporosidade $(0,06$ bar de tensão) e densidade aparente, em relação aos fatores: sistemas de produção, níveis de calagem, profundidade de amostragem e suas interações.

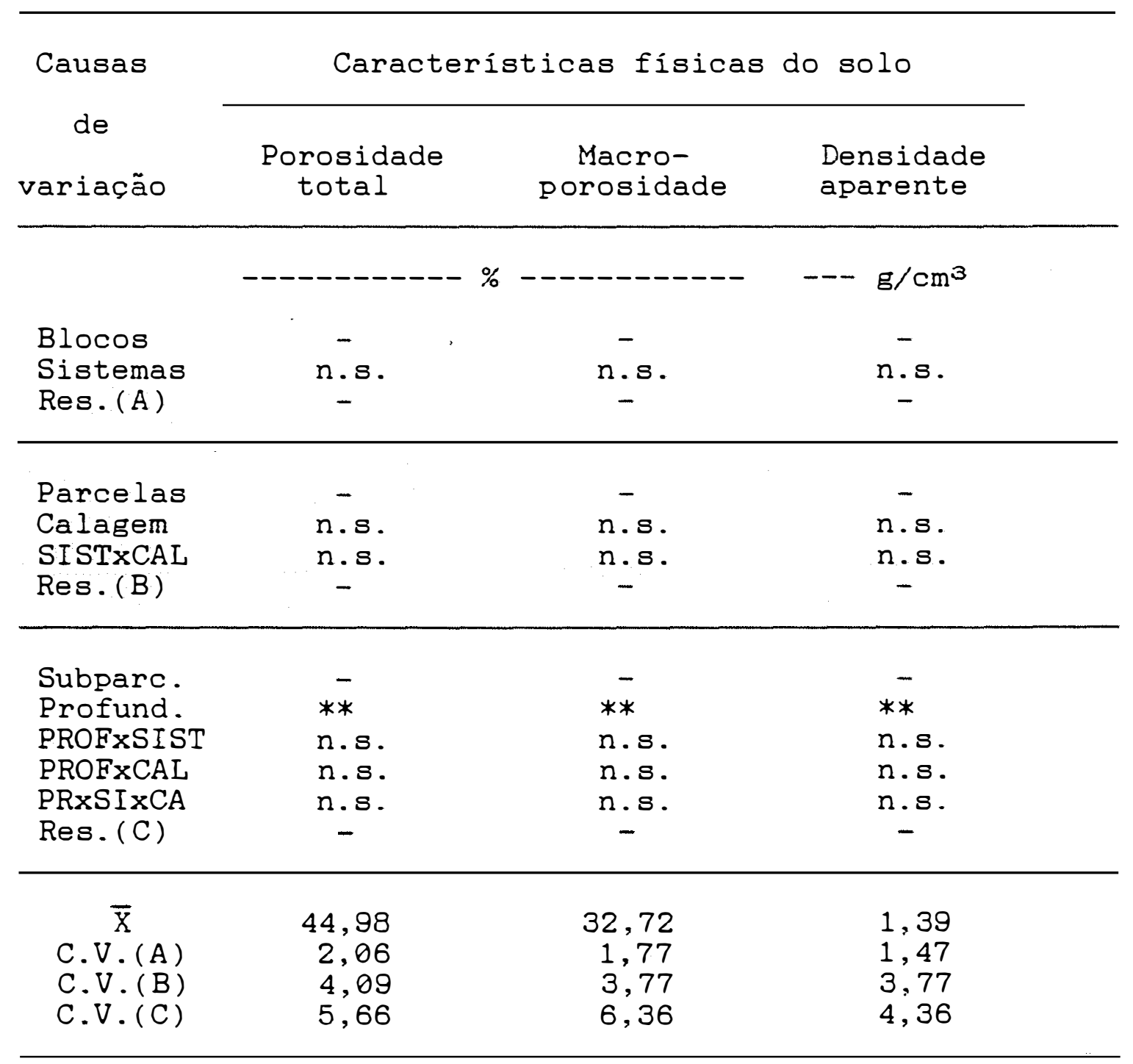

* e ** - Niveis de significância a $5 \%$ e $1 \%$ de probabilidade, respectivamente. 
tivo na camada de 20 a $40 \mathrm{~cm}$, enquanto a densidade aparente aumentou (Tabela 21). Resultados semelhantes foram obtidos no ano agrícola 85/86, quando se efetuou a avaliação de diversas características físicas no experimento (DECHEN et alii, 1990). Como nao ocorreu nenhuma interação entre profundidade e os outros fatores em estudo, admite-se que esses sintomas de compactação podem estar relacionados com as práticas gerais de manejo ou preparo do solo empregadas na área.

REICHARDT (1981), salienta que camadas compactadas dentro do perfil causam mais distúrbios ao crescimento de raízes, do que perfis homogêneos com maior densidade.

$\mathrm{Na}$ Figura 17 são apresentadas as curvas caracteristicas de umidade, de todas as combinações entre os fatores em estudo. Percebe-se que somente no nível 3 de calagem ( $6 \mathrm{t} / \mathrm{ha}$ ) e na profundidade de 20 a $40 \mathrm{~cm}$, surge uma pequena diferença de comportamento entre os sistemas de produção. Essa diferença faz supor que nas rotações, principalmente no tratamento com mucuna, para um mesmo teor de umidade, a água é retida a uma menor tensão, ou em outras palavras, está mais disponivel às plantas.

No ano agrícola 85/86, quando também se observou essa mesma diferenca para o efeito geral de sistemas, ela foi associada aos resultados de produção de grãos (DECHEN et alii, 1990). 
Tabela 19. Efeito de sistemas de produção, calagem e profundidade de amostragem, sobre a porosidade total do solo ( \%).

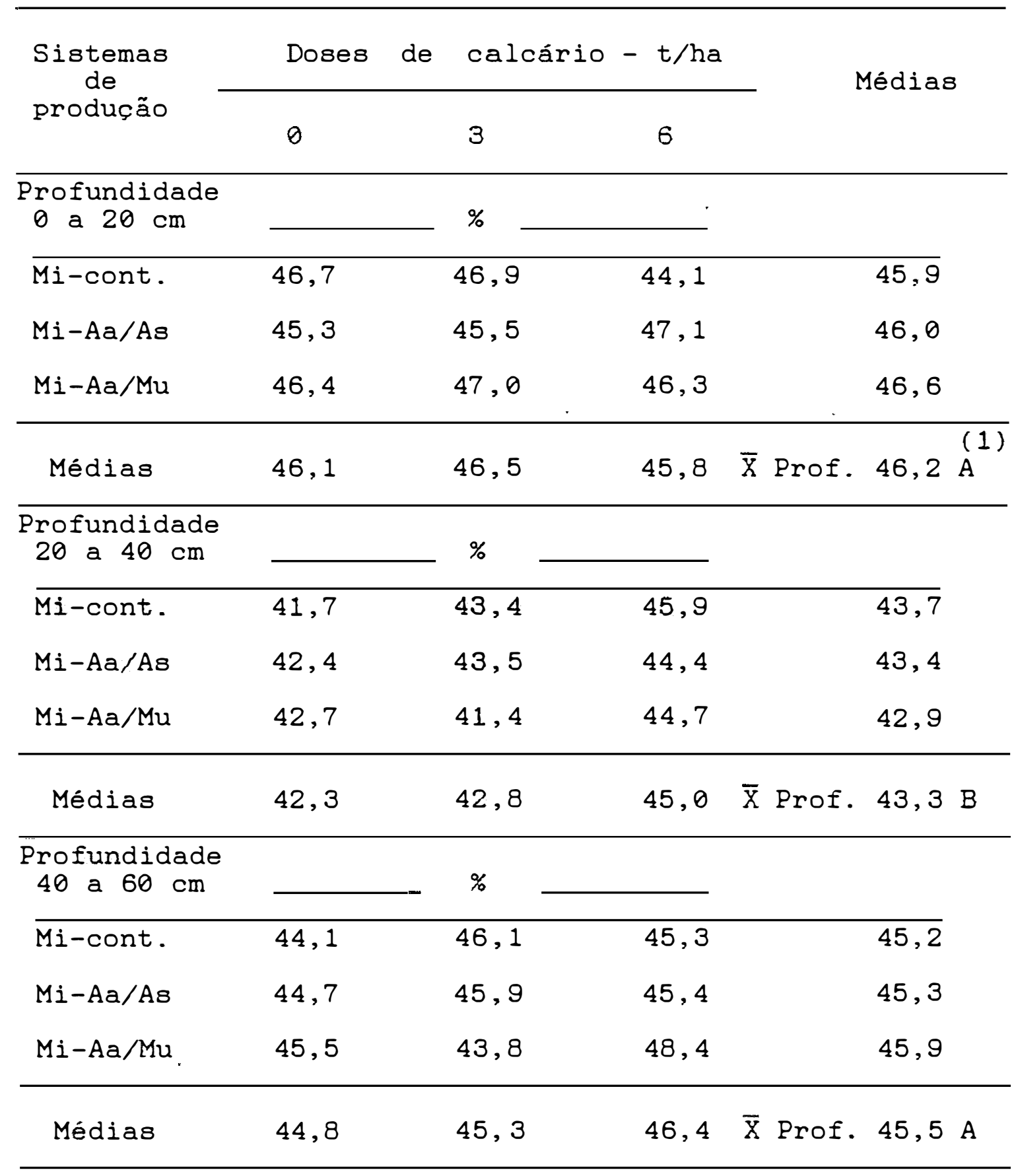

(1) Médias do fator profundidade de amostragem seguidas da mesma letra, nao diferem estatisticamente pelo Teste de Tukey a $5 \%$ de probabilidade. Os outros fatores não apresentaram diferença estatistica. 
Tabela 20. Efeito de sistemas de produção, cal fundidade de amostragem, sobre a macroporosidade do solo ( $\%$ ).

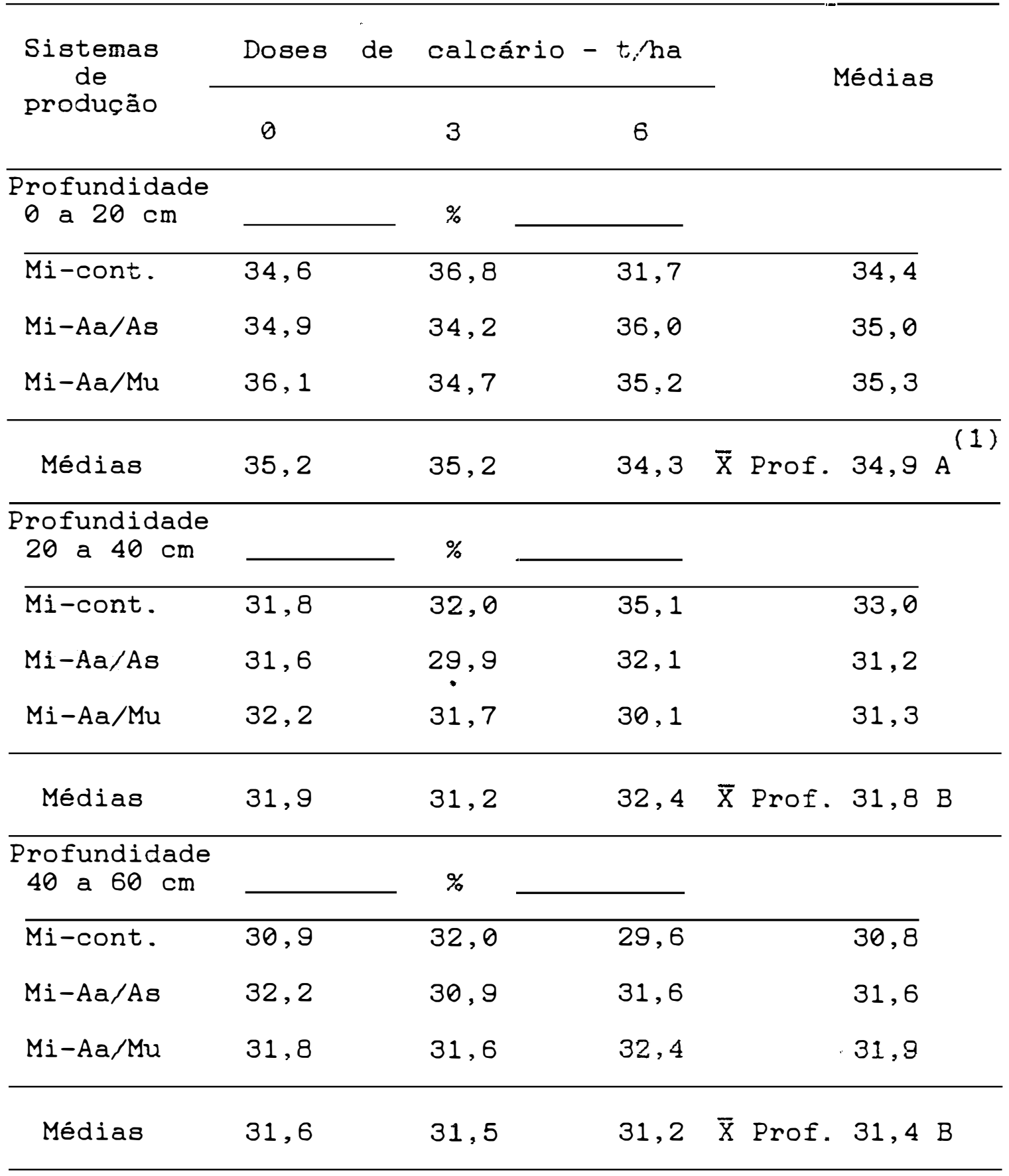

(1) Médias do fator profundidade de amostragem seguidas da mesma letra, nao diferem estatisticamente pelo Teste de Tukey a 5\% de probabilidade. Os outros fatores não apresentaram diferença estatistica. 
Tabela 21. Efeito de sistemas de produção, calagem e profundidade de amostragem, sobre a densidade aparente do solo $\left(\mathrm{g} / \mathrm{cm}^{3}\right)$.

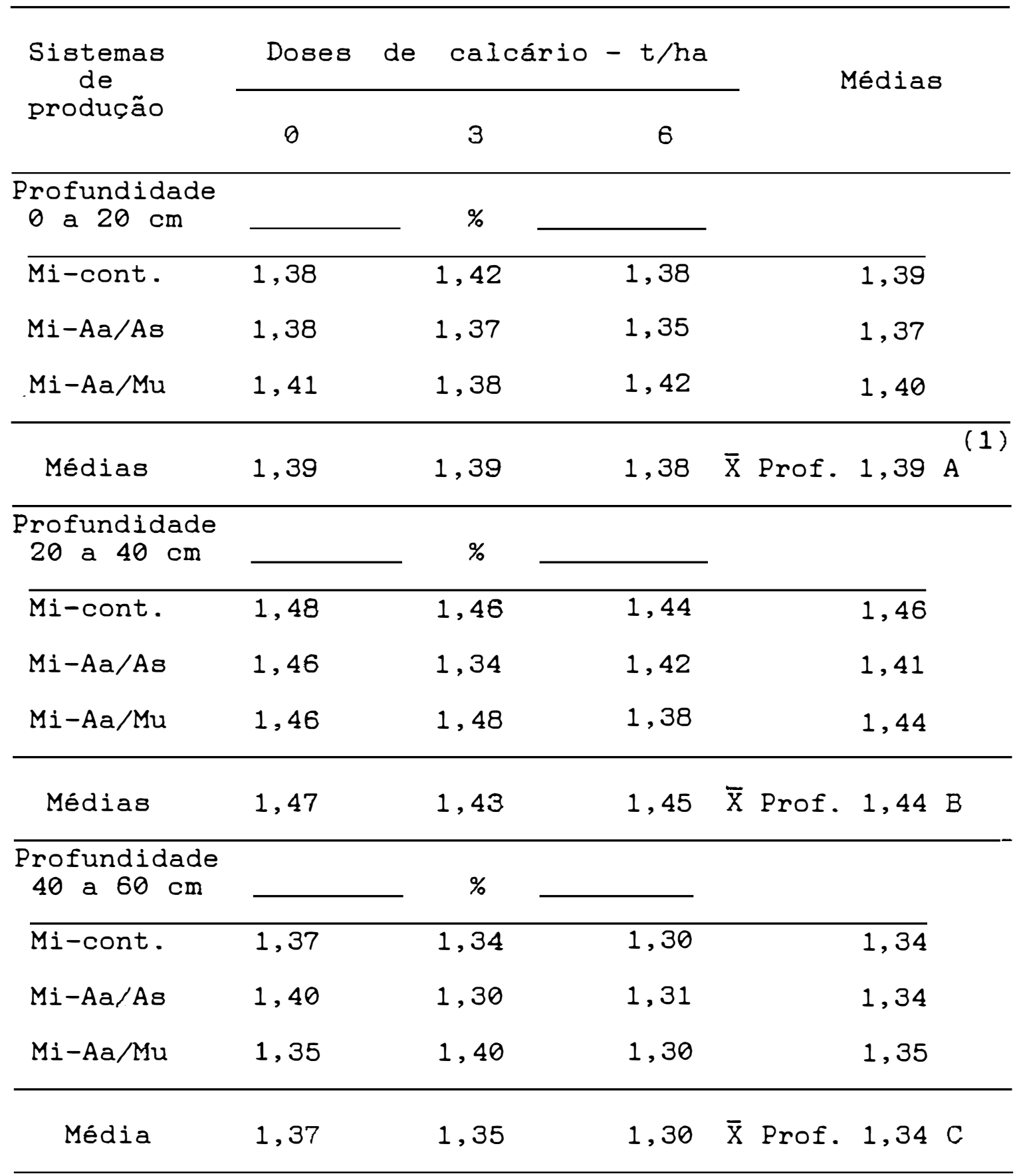

(1) Médias do fator profundidade de amostragem seguidas da mesma letra, nao diferem estatisticamente pelo Teste de Tukey a 5\% de probabilidade. Os outros fatores não apresentaram diferença estatistica. 


\section{CALAGEM 0}

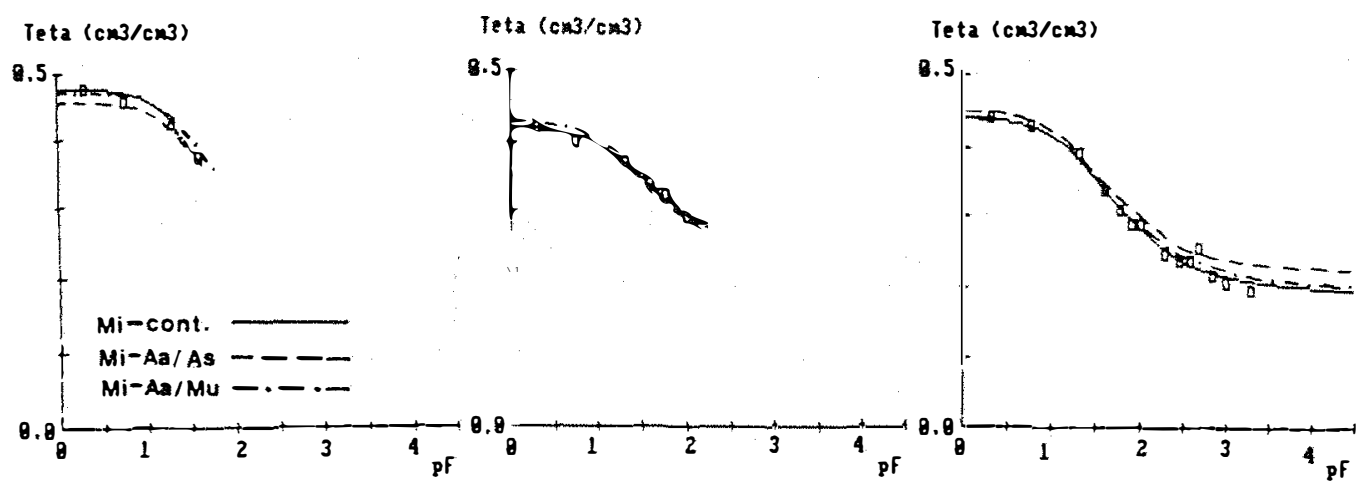

\section{CALAGEM 3}
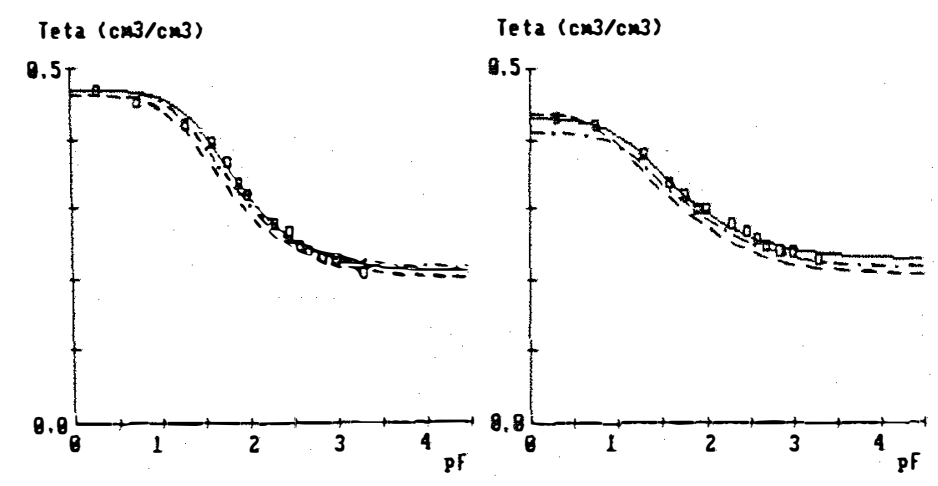

Teta $(c \times 3 / c \times 3)$
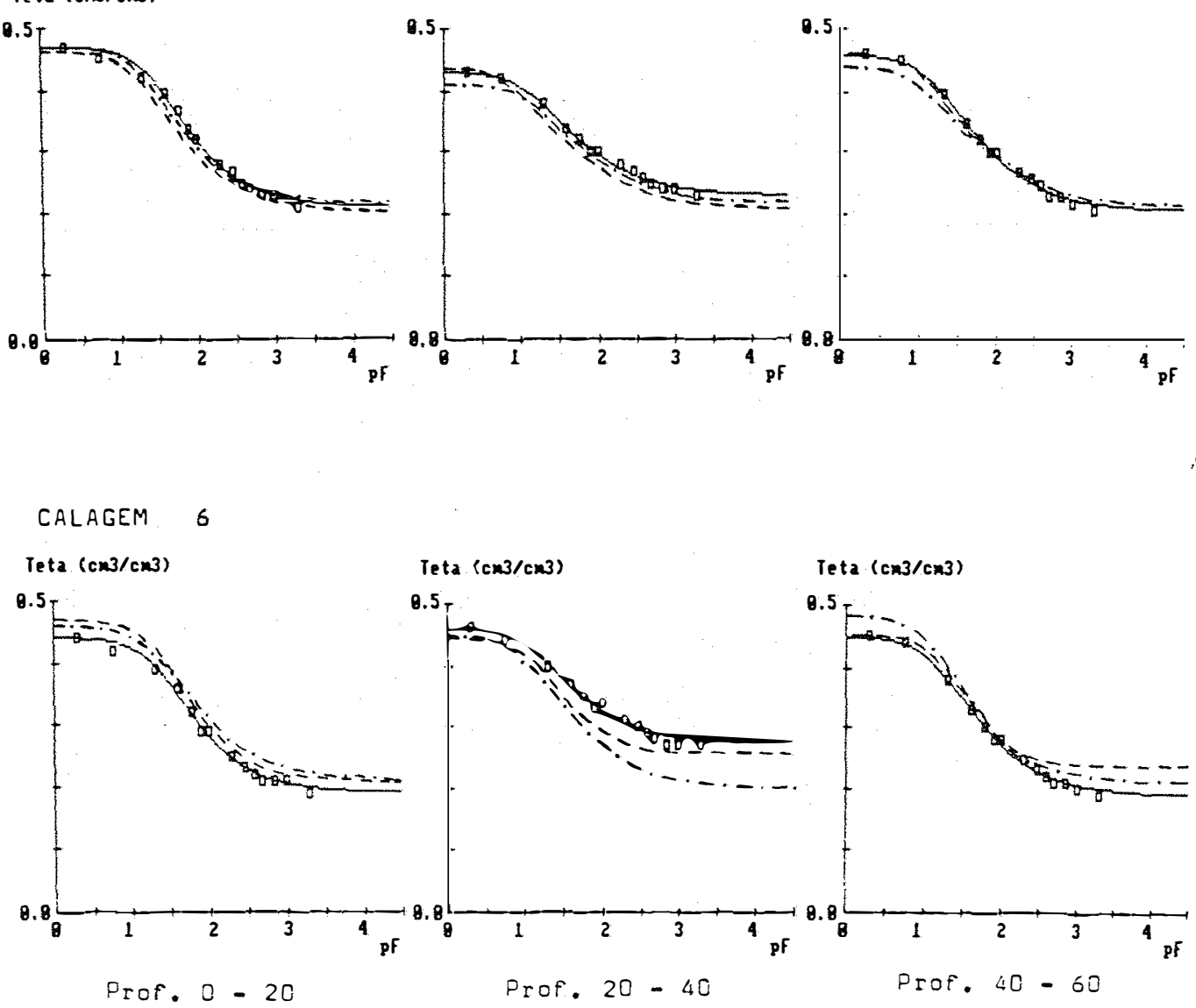

Teta $(c \times 3 / c \times 3)$

$0.5 \mathrm{~T}$

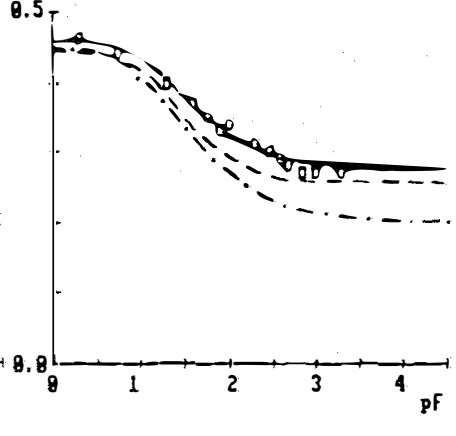

Prof. $20-40$
Teta $(c \times 3 / c \times 3)$

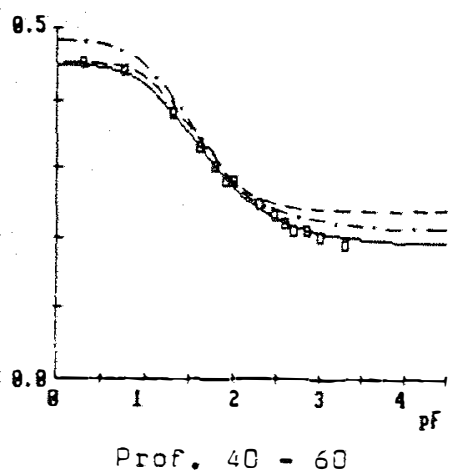

Figura 17. Curvas características de umidade para todas as combinações de sistemas de produção, doses de calcário e profundidade de amostragem. 


\subsection{Avaliação do sistema radicular}

\subsubsection{Método do trado}

As amostragens por subparcela, e nas diversas profundidades, foram feitas na linha e na entrelinha e após a separação das raizes do solo, determinou-se o peso de matéria seca.

A análise da variância é apresentada na Tabela 22. Verifica-se que, tanto na linha como na entrelinha não houve efeito de sistemas de produção sobre o peso de matéria seca de raizes (Tabela 23 e Figura 18), o que não deixa de ser um reflexo da inexistência de efeito dos sistemas sobre as caracteristicas quimicas e físicas do solo.

Vários trabalhos têm mostrado que guando as práticas de cultivo causam mudanças nas caracteristicas químicas e físicas do solo, estas se refiletem no crescimento das raizes (SCHUURMAN, 1965; BAREER, 1971; STYPA et alli, 1987; ALLMARAS \& NELSON, 1971; CRUZ, 1982).

Também nao foi significativo o efeito da calagem sobre o peso de matéria seca de raizes, tanto na linha como na entrelinha. No entanto, ocorreu uma interação entre sistemas de produção e doses de calcário, para peso de matéria seca de raizes na linha. 
Tabela 22. Resumo da análise de variância (significância do Teste F), do peso de matéria seca e quantidade de raizes, em função dos fatores: sistemas de produção, calagem e profundidade de amostragem e'suas interações.

\begin{tabular}{|c|c|c|c|}
\hline \multirow{3}{*}{$\begin{array}{c}\text { Causas } \\
\text { da } \\
\text { variação }\end{array}$} & \multirow{2}{*}{\multicolumn{3}{|c|}{ Peso de mat. seca e quantidade de raizes }} \\
\hline & & & \\
\hline & $\begin{array}{l}\text { Peso na } \\
\text { linha }\end{array}$ & $\begin{array}{c}\text { Peso na } \\
\text { entrelinha }\end{array}$ & Quantidade \\
\hline & -------- g/dm $\mathrm{d}^{3}$ & -------- & - Número - \\
\hline $\begin{array}{l}\text { Blocos } \\
\text { Sistemas } \\
\text { Res. (A) }\end{array}$ & ${ }_{-}^{-}$ & n. & n. \\
\hline $\begin{array}{l}\text { Parcelas } \\
\text { Calagem } \\
\text { SISTXCAL } \\
\text { Res.(B) }\end{array}$ & $\begin{array}{l}- \\
\text { n. } \\
-\end{array}$ & $\begin{array}{l}- \\
n \cdot 8 . \\
n \cdot 8 .\end{array}$ & $\begin{array}{c}- \\
\text { n. } \\
-\end{array}$ \\
\hline $\begin{array}{l}\text { Subparc. } \\
\text { Profund. } \\
\text { PROFxSIST } \\
\text { PROFxCAL } \\
\text { PRxSIxCA } \\
\text { Res. (C) }\end{array}$ & $\begin{array}{l}- \\
* * \\
\text { n. } 8 . \\
* * \\
* \\
-\end{array}$ & $\begin{array}{c}- \\
* * \\
n .8 . \\
* \\
\text { n. } 8 . \\
-\end{array}$ & $\begin{array}{l}- \\
* * \\
\text { n.s. } \\
\text { n.s. } \\
\text { n.s. } \\
-\end{array}$ \\
\hline $\begin{array}{l}\overline{\bar{X}} \\
\text { C.V. (A) } \\
\text { C.V. (B) } \\
\text { C.V. (C) }\end{array}$ & $\begin{array}{l}0,337 \\
29,77 \\
14,60 \\
36,50\end{array}$ & $\begin{array}{l}0,205 \\
15,74 \\
28,20 \\
34,27\end{array}$ & $\begin{array}{r}144,69 \\
10,12 \\
23,78 \\
32,59\end{array}$ \\
\hline
\end{tabular}

* e ** - Níveis de significância a $5 \%$ e $1 \%$ de probabilidade respectivamente. 
Tabela 23. Efeito de sistemas de produção, calagem e profundidade de amostragem sobre o peso de matéria seca na linha e na entrelinha e sobre a quantidade de raizes.

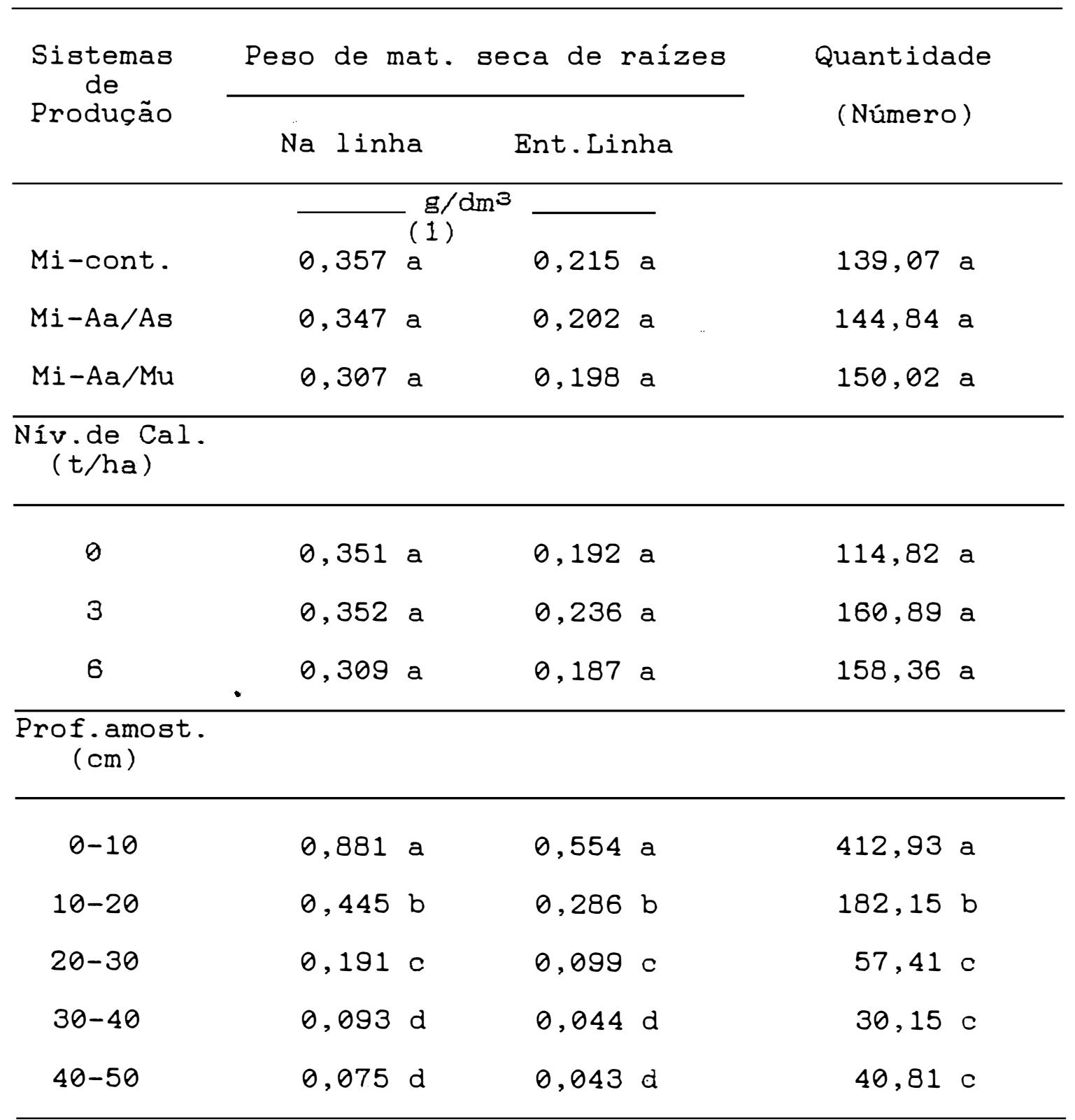

(1) Médias seguidas da mesma letra nao diferem pelo Teste de Tukey a $5 \%$ de probabilidade. 


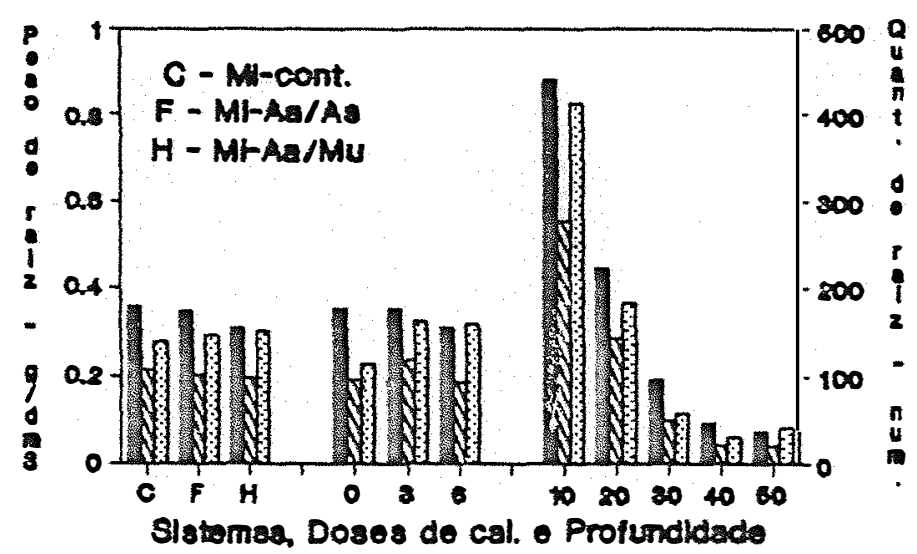

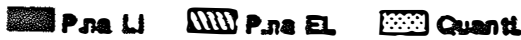

Figura 18. Efeitos isolados dos fatores: sistemas de produção, calagem e profundidade de amostragem, sobre - peso de matéria seca de raizes na linha e na entre linha e na quantidade de raizes.

Na Figura 19 verifica-se que no sistema de produção Mi-contínuo, com a aplicação de calagem, ocorreu um decréscimo do peso de matéria seca de raizes, em relacão ao tratamento que não recebeu a calagem, enquanto nos outros sistemas houve um aumento no peso, na dose de 3 t/ha e depois um decréscimo na de $6 \mathrm{t} / \mathrm{ha}$.

Analisando-se a Figura 20, que apresenta o peso de matéria seca de raizes na linha e na entrelinha, no sistema Mi-contínuo, nas diversas doses de calcário e profundidades, percebe-se que é na camada de $\theta$ a $10 \mathrm{~cm}$, que - peso de matéria seca de raizes na linha é bem maior, na dose $\theta$ t/ha de calcário, en rolação às outras doaøa. No aia- 


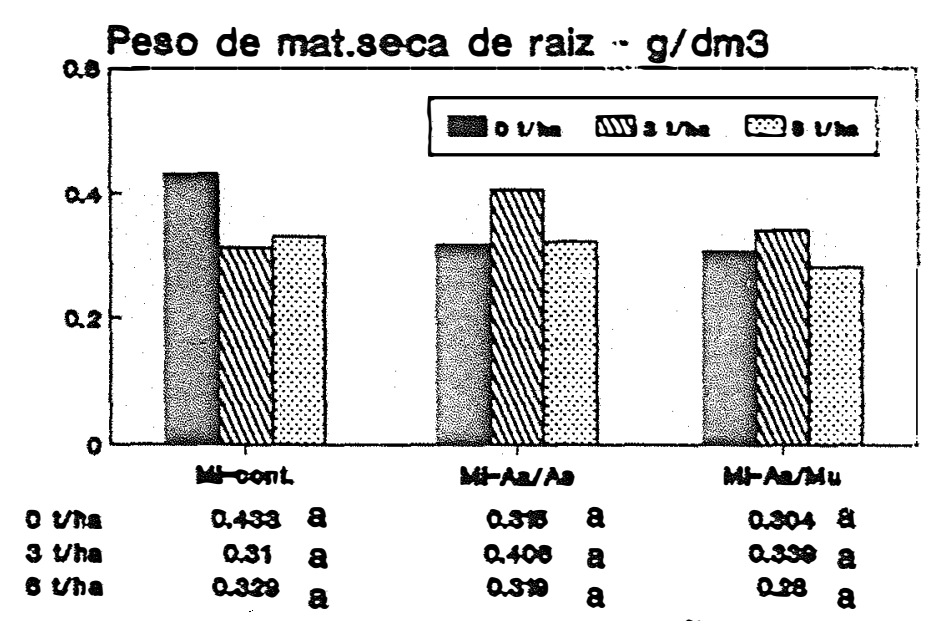

Sistemas de producão

Figura 19. Efeito da interação dos fatores sistemes de produção e calagem, sobre o peso de matéria seca de raiz na linha.

tema $\mathrm{Mi}-\mathrm{Aa} / \mathrm{As} \circ$ peso de matéria seca na mesma dose foi alto, mas não tanto (Figura 21), e no sistema Mi-Aa/Mu não houve diferença entre as doses $\theta$ e 3 t/ha, havendo um decréscimo na dose 6 t/ha (Figura 22).

A diferença entre os sistemas de produção é estatisticamente significativa, apenas na dose $\theta$ de calcário e na profundidade $\theta$ a $10 \mathrm{~cm}$, 0 que está bem caracterizado pela interação tripla entre sistemas, calagem e profundidade (Tabela 22) e ilustrada na Figura 23.

Desta forma constata-se que também foi significativa a interação entre calagem e profundidade, tanto na linha como na entrelinha. 


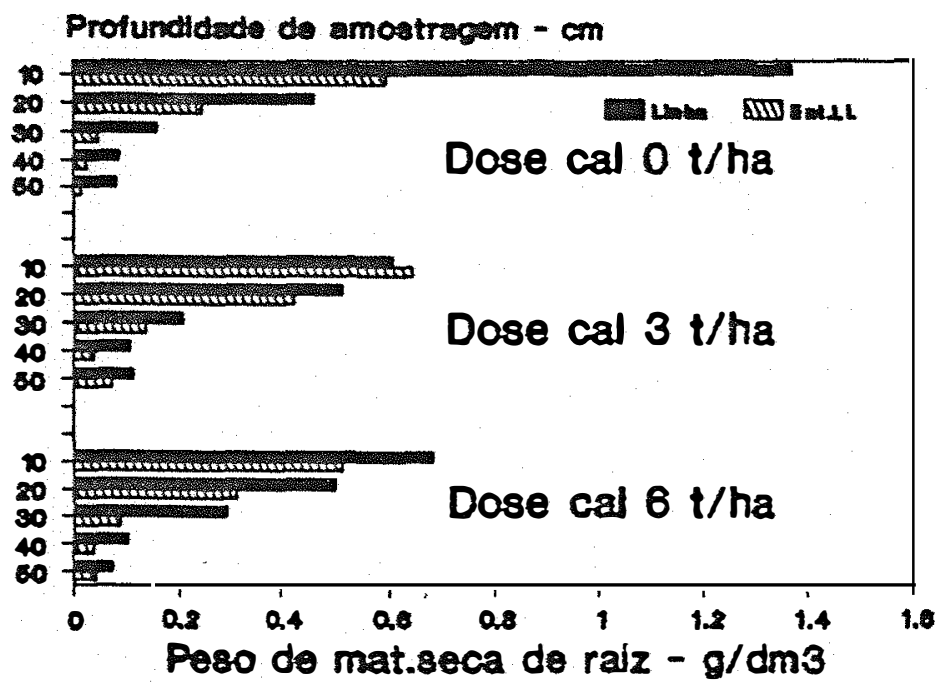

Figura 20. Peso de raizes na linha e entrelinha no sistema de produção Mi-contínuo, nos diversos níveis de calcário e profundidades de amostragem.

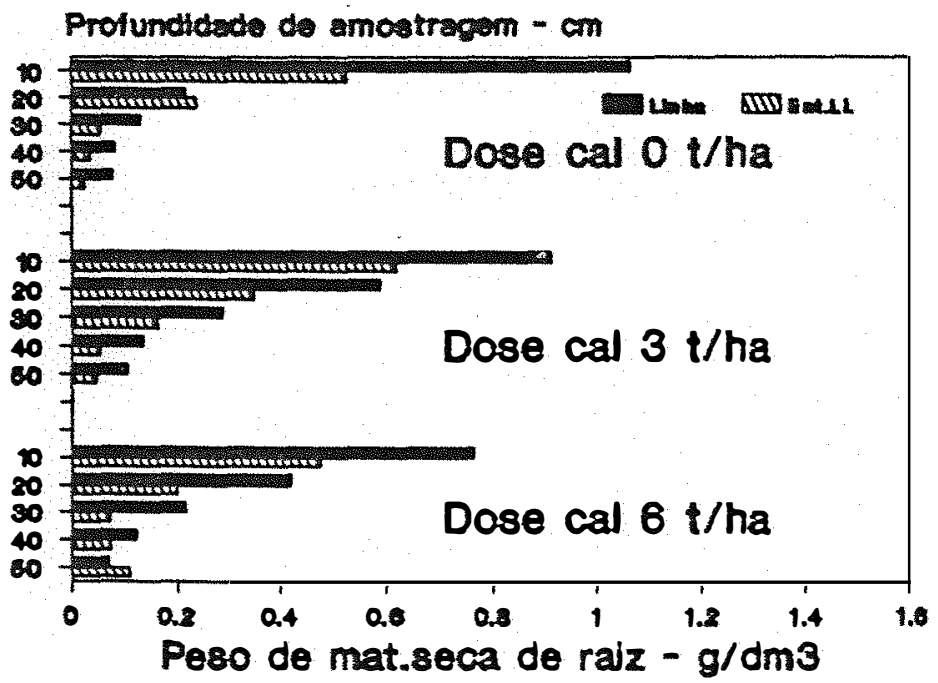

Figura 21. Peso de raizes na linha e entrelinha no sistema de produção $\mathrm{Mi}-\mathrm{Aa} / \mathrm{As}$, nos diversos niveis de calcário e profundidades de amostragem. 


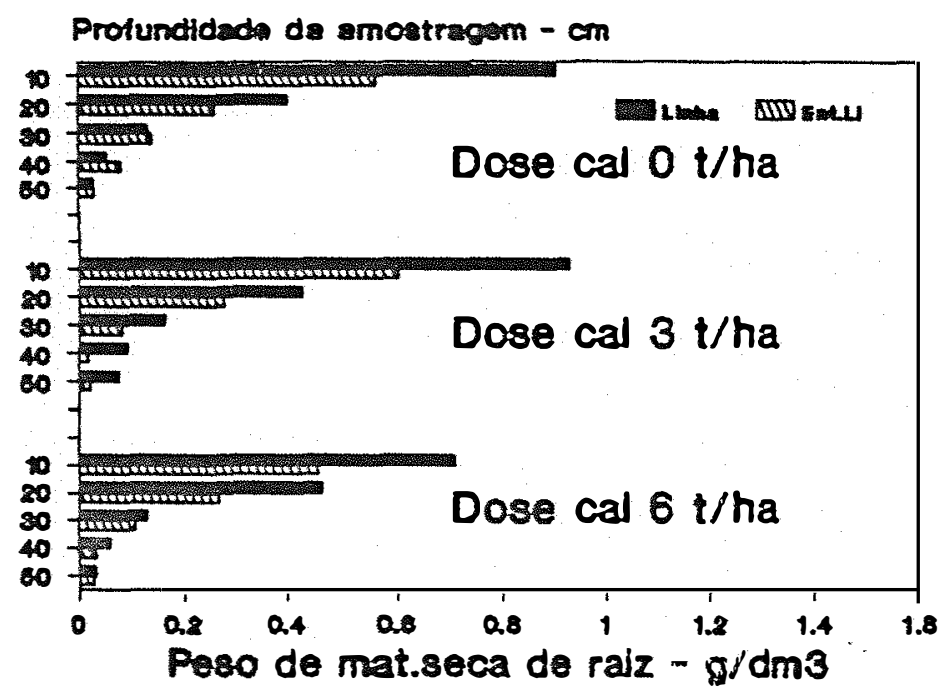

Figura 22. Peso de raizes na linha e entrelinha no sistema de produção $\mathrm{Mi}-\mathrm{Aa} / \mathrm{Mu}$, nos diversos niveis de calcário e profundidades de amostragem.

A Figura 24 indica que, independente do sistema de produção, na profundidade de de $\theta$ a $10 \mathrm{~cm}$, o uso da calagem diminui o peso seco de raizes, mas nas outras profundidades esse peso aumenta com a aplicação de 3 t/ha, decrescendo depois um pouco, na dose $6 \mathrm{t} / \mathrm{ha}$. Somente na camada de $\theta$ a $10 \mathrm{~cm}$ as diferenças são significativas.

Já para a amostragem feita na entrelinha (Figura 25), onde o peso de matéria seca de raizes, de uma maneira geral, foi aproximadamente a metade daqueles observados na linha, não se verificou o decréscimo do peso de matéria seca em função da calagem, em nenhuma profundidade. Ocorreu um aumento de peso na dose 3 t/ha e depois um decréscimo na dose 6 t/ha. Nas camadas de 30 a 40 


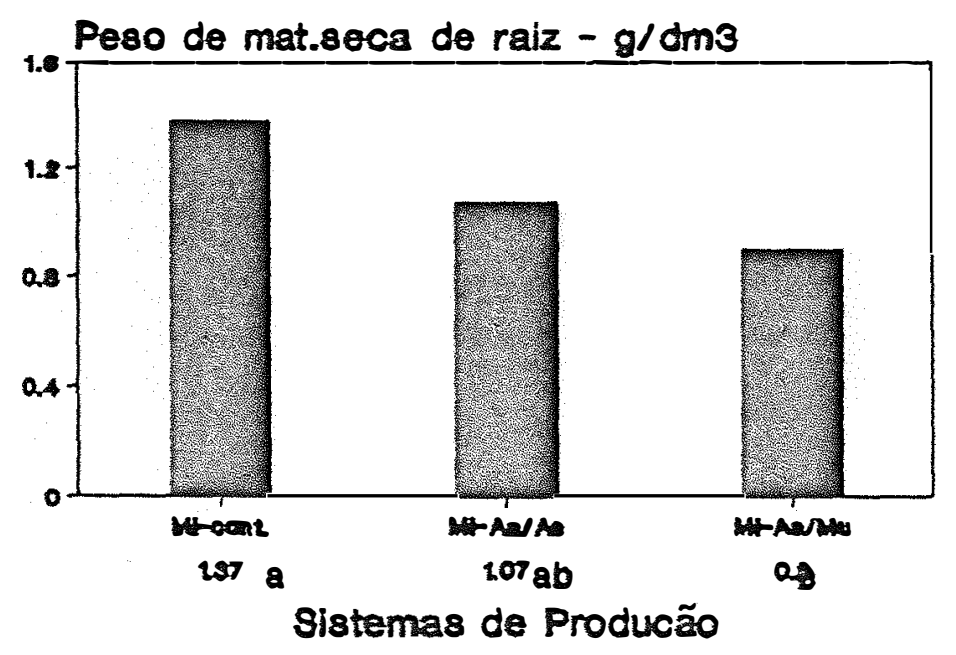

Figura 23. Efeito dos sistemas de produção no nível de calcário $\theta$ t/ha e profundidade de amostragem $\theta$ a $10 \mathrm{~cm}$, sobre o peso de matéria seca de raizes na linha.

$\mathrm{cm}$ e 40 a $50 \mathrm{~cm}$ o comportamento foi diferente, o que justifica a ocorrência da interação.

Através do método do trado verificou-se que as raízes se concentram mais nas camadas superficiais do solo, decrescendo com a profundidade. Em geral isso ocorre, segundo RUSSELL (1981), devido à estrutura de desenvolvimento dos sistemas radiculares. As ramificações laterais que se desenvolvem a partir das raizes principais crescem por um período em sentido horizontal, embora posteriormente também cresçam para baixo. Essa concentração maior na superficie, ocorre mesmo quando os fatores do solo nao restringem a sua extensão.

Também se associa à maior concentração de raizes na superficie, o fato de ocorrer nessa camada maior 


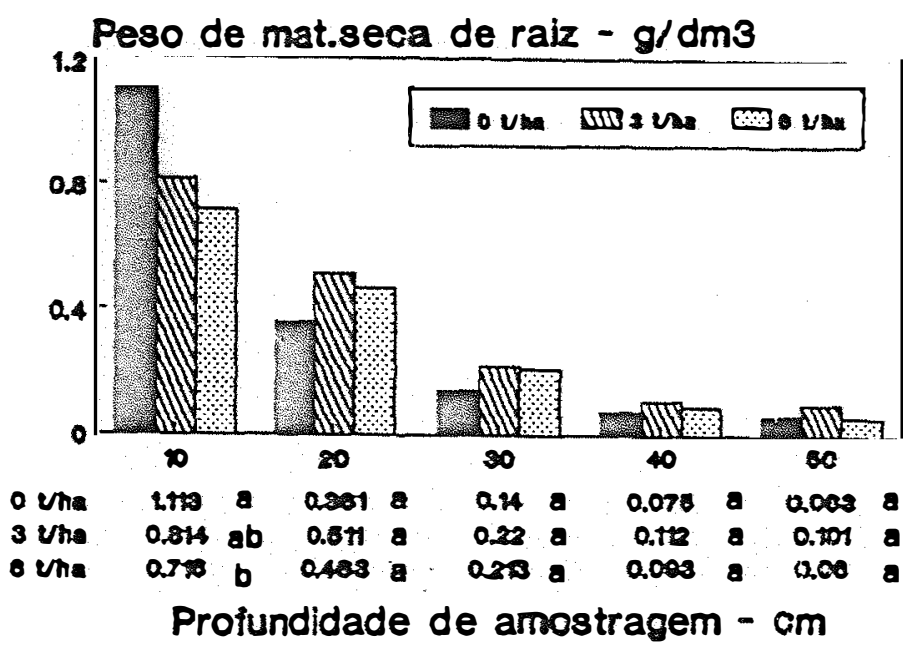

Figura 24. Efeito da interação dos fatores calagem e profundidade de amostragem, sobre o peso de matéria seca de raizes na linha.

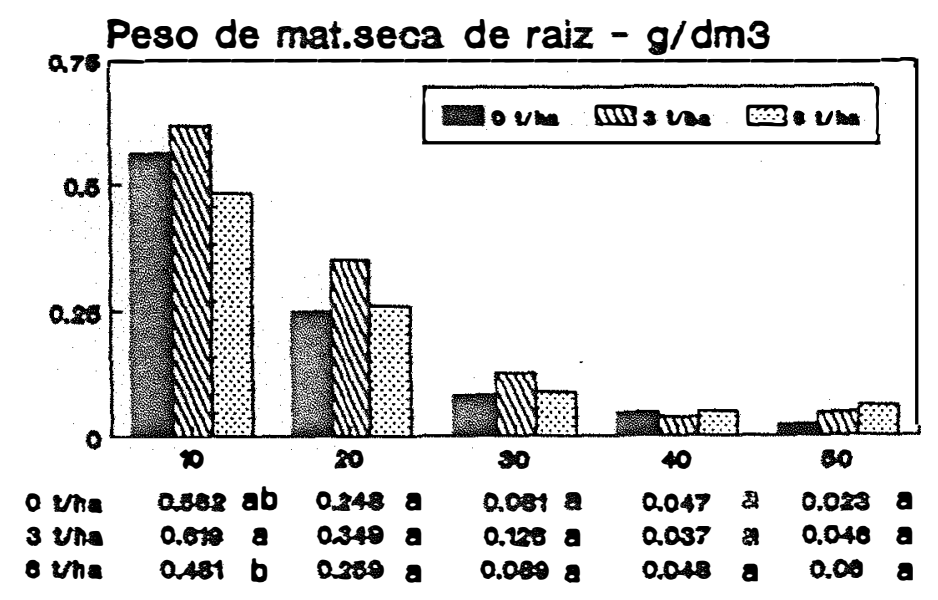

Profundidade de amostragem - $\mathrm{cm}$

Figura 25. Efeito da interação dos fatores calagem e profundidade de amostragem, sobre o peso de matéria seca de raizes na entrelinha. 
disponibilidade de nutrientes (Tabela 5), embora as variações no suprimento de água possam causar alguma modificação, tanto na distribuição das raizes, como na própria absorção de nutrientes (MARSCHNER, 1986).

Com a aplicação de calcário houve um decréscimo do peso de raizes na linha, na profundidade de 0 a $10 \mathrm{~cm}$, acompanhado de um certo aumento no peso de raizes em profundidade. O efeito da calagem, apesar de estar decrescendo, após quatro anos e meio da última aplicação, ainda mantém alguns beneficios, como a neutralização de aluminio trocável e aumento nos teores de cálcio e de magnésio, o que também se refletiu em profundidade, como já foi visto.

Assim, as raizes tendem a se desenvolver mais em profundidade, diminuindo sua concentração na superficie (Figuras 20, 21 e 22).

Por outro lado, segundo NYE \& TINKER (1977), citados por MARSCHNER (1986), a relação entre densidade de raízes e taxa de absorção de nutrientes não é linear. Quando a densidade de raizes é alta, a taxa de absorção não acompanha, o que é causado por superposição de raizes nas zonas de absorção das raizes individuais.

NYE, P.H. \& TINKER, P.B. "Solute movements in the root-soil system". Blackwell, Oxford, 1977. 
Mas, deve-se levar em conta também que o decréscimo no peso de raizes em função da callsgem pode estar relacionado à diminuição da espessura das raízes, como resultado da diminuição do alumínio trocável no meio. Como se sabe, dentre outros efeitos, o engrossamento ou inchação das raízes, é um dos sintomas mais característicos da fitotoxidez desse elemento (FOY, 1984).

Como a concentração de raízes na camada superficial é grande, o efeito da diminuição da espessura, causando o decréscimo de peso, encobre o provável aumento no número de raizes que ocorre com o uso da calagem, como será visto adiante quando da abordagem do método do perfil.

A ocorrência de uma maior concentração de raízes em peso, no tratamento sem calagem, na camada $\theta$ a 10 cm, foi registrada no sistema de produção Mi-contínuo.No sistema Mi-Aa/As essa diferença foi bem menor e no sistema $\mathrm{Mi}-\mathrm{Aa} / \mathrm{Mu}$ praticamente nao existiu. A presença de leguminosa na rotação, e no caso deste último tratamento, a incorporação da mucuna, pode ter alguma relação com esses resultados.

\subsubsection{Método do pertil}

Neste método de avaliação do sistema radicular determinou-se a quantidade de raizes visiveis em um perfil perpendicular à linha de plantio. 
Ele não fornece a estimativa da densidade de raizes por volume, o que, dependendo das circunstâncias, pode ser uma limitação, mas permite uma avaliação comparativa entre os tratamentos.

$\mathrm{Na}$ Tabela 22 verifica-se que os sistemas de produção não afetaram a quantidade de raízes, ao contrário do que ocorreu com as doses de calcário e nas diversas profundidades de amostragem, nas quais houve significância estatística pelo Teste F. No entanto, pelo Teste de Tukey a 5\% de probabilidade, não se registraram diferenças entre os níveis de calagem (Tabela 23).

Estatisticamente, $\quad$ Teste $F$ é mais consistente, e na realidade, a diferença na quantidade de raízes de 114 para 160, da dose 0 para a dose 3 t/ha é relativamente alta.

A análise de regressão foi significativa para a forma linear, o que é demonstrado na Figura 26.

Como não ocorreu nenhuma interação entre os fatores de estudo, admite-se que, independente dos sistemas de produção e das profundidades, o uso da calagem promoveu aumento da quantidade de raízes.

Assim sendo, pode-se interpretar o decréscimo no peso seco em função da calagem, como resultante da diminuição da espessura das raizes, já que sua quantidade aumentou. 


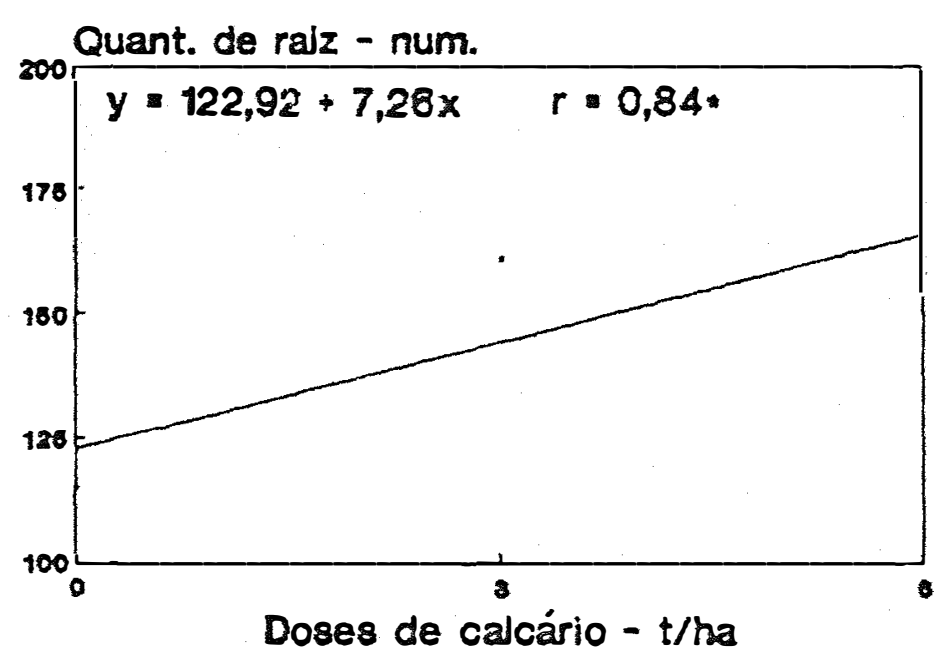

Figura 26. Equação de regressão que descreve o comportamento da quantidade de raizes em função dos niveis de calcário.

Com o aumento do número de raizes, e se supoe que de raizes mais finas, haveria portanto um acréscimo na ârea absorvente, o que seria benéfico para a cultura, e estaria de alguma forma associado aos beneficios que o efeito residual da calagem ainda vem proporcionando. Sabe-se que o crescimento das raizes de culturas está intimamente relacionado com o nivel de cálcio disponivel no solo (LUND, 1970; HAYNES \& LUDECKE, 1981; GOEDERT et alii, 1985; RITCHEY et alii, 1983).

Aa Figuras 27 a 35 apresentam, para todas as combinações de sistemas de produção e níveis de calagem, a representação grâfica da distribuição espacial das raizes no perfil, além de informações sobre a delimitação dos horizontes do solo, a profundidade, e o número de raizes em 
camadas de $5 \mathrm{~cm}$ e sua porcentagem em camadas de $10 \mathrm{~cm}$ de solo, além do número total de raizes encontrado na subparcela.

Percebe-se, de uma forma mais nitida, que houve aumento da quantidade de raizes em todos os sistemas de produção, quando comparamos o tratamento sem calagem, e - tratamento que recebeu 3 t/ha de calcário. 0 uso de 6 t/ha, entretanto, não promoveu mais aumento na quantidade de raízes. Como o peso de raizes nesse nível de calagem tendeu a diminuir, conforme foi descrito anteriormente no método do trado, é possível que as raizes tenham se tornado ainda mais finas.

A distribuicão espacial das raízes nas citadas figuras permite uma melhor visualização da ocorrência de um quase constante decréscimo, nos diversos subtratamentos, do número de raízes na profundidade de 30 a $40 \mathrm{~cm}$, e por outro lado, de um certo aumento após esta camada. Este fato pode estar associado ao aumento da densidade ou diminuição da porosidade, o que foi constatado e já relatado (Tabelas 19,20 e 21 ).

Segundo SCHUURMAN (1965), é opinião geral que o crescimento das raizes é impedido pelo aumento da densidade do solo. Entretanto, existe uma considerável variabilidade nos dados em relação à intensidade com que o crescimento de raízes é impedido, e sobre a densidade do solo na qual o crescimento é totalmente impedido. Esse 
autor estima como densidade critica, $1,65 \mathrm{~g} / \mathrm{m}^{3}$ em solos arenosos, e $1,50 \mathrm{~g} / \mathrm{cm}^{3}$ em solos de textura média. VEIHMEYER \& HENDRICKSON (1948), estabeleceram como limites $1,75 \mathrm{~g} / \mathrm{cm}^{3}$ para solos arenosos, e de 1,46 a $1,63 \mathrm{~g} / \mathrm{cm}^{2}$ para solos argilosos, para raizes de girassol.

Entretanto, deve-se reconinecer que alterações na forma do sistema radicular podem ser conseqüência de diferentes fatores, agindo separadamente ou em conjunto. A resistência mecânica, por exemplo, é um dos fatores que, freqüentemente, não é considerado como responsável pela penetração de raízes, e portanto uma das dificuldades em se avaliar esse fator é a estreita similaridade entre os efeitos da densidade do solo, do excesso de umidade e da aeração deficiente (WIERSUM, 1957). A faixa de compactação observada no experimento ocorreu no horizonte $A з$, O qual, pela descrição pedológica (Tabela 24) não deveria apresentar quaisquer restrições de ordem física. A densidade aparente inclusive, era originalmente até menur.

A concentração de raízes de, em média 78\% na profundidade de 0 a $20 \mathrm{~cm}$, é alta, o que pode, de alguma forma, estar relacionada com a ocorrência desta camada subsuperficial mais densa. 


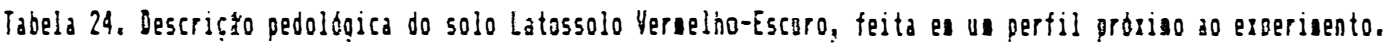
(OLIVEIRA, s.d.)

- Caracteristicas da drea: Relevo - suave ondulado. Erosăn - Ad̆o evidente. Yegetaçăo - cerrada Pedras - näo existeate

- Descrifodos horizontes:

\begin{tabular}{|c|c|c|c|c|c|c|c|c|c|}
\hline \multirow[t]{2}{*}{ Cabada } & \multirow[t]{2}{*}{ Horizonte } & \multirow{2}{*}{$\begin{array}{c}\text { Profundidade } \\
\text { (CI) }\end{array}$} & \multirow{2}{*}{$\begin{array}{c}\text { Espessura } \\
\text { (ca) }\end{array}$} & \multirow[t]{2}{*}{ Transiçăo } & \multirow[t]{2}{*}{ Cor } & \multirow[t]{2}{*}{ Textura } & \multirow{2}{*}{$\begin{array}{l}\text { Estrutura e } \\
\text { cerosidade }\end{array}$} & \multicolumn{2}{|c|}{ Consistêbcia } \\
\hline & & & & & & & & $\forall$ & n \\
\hline 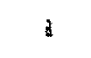 & dip & $8-19$ & 14 & grad. pl. & $2,5 Y 8 \quad 3 / 3,5$ & arọ. & gran.peq.aod. & ir. & al.peo. \\
\hline$b$ & $\dot{n}_{3}$ & $19-48$ & 26. & dif.pl. & $2,5 Y R 3 / 4$ & $x$ & subang.ad.fr. & $i r$ & ' \\
\hline 8 & $\hat{x}_{21}$ & $48-188$ & 68 & ; & $2,5 Y R \cdot 3,516$ & : & acişa porosa & e.tr. & ' \\
\hline 6 & 822 & $188-168$ & 68 & arbitr. & ' & : & ' & $\cdot$ & : \\
\hline e & $R_{23}$ & 168- -288 & 48 & - & . & : & * & ' & ' \\
\hline
\end{tabular}

- Caracteristicas físicas:

\begin{tabular}{|c|c|c|c|c|c|c|c|c|c|}
\hline \multirow[b]{2}{*}{ Conada. } & \multicolumn{4}{|c|}{ Cosp. ọranulosétrica } & \multirow{2}{*}{$\begin{array}{l}\text { Argodisp. } \\
\text { es dguda. }\end{array}$} & \multirow{2}{*}{$\begin{array}{l}\text { Grau de } \\
\text { flocul. }\end{array}$} & \multirow{2}{*}{$\begin{array}{l}\text { Siltel } \\
\text { srọ. }\end{array}$} & \multirow{2}{*}{$\begin{array}{l}\text { Densigade } \\
\text { Ap. feal }\end{array}$} & \multirow{2}{*}{$\begin{array}{c}\text { Poros. } \\
?\end{array}$} \\
\hline & Ar.ọr. & Ar.fi. & Si. & Arọ. & & & & & \\
\hline 3 & 29 & 28 & 89 & 34 & 25 & 26 & 8,26 & $1,292,53$ & 49 \\
\hline$b$ & 22 & 31 & 89 & 38 & 29 & 24 & 8,24 & - & - \\
\hline 5 & 26 & 25 & 87 & 42 & 82 & 95 & 8.17 & $1,162,65$ & 35 \\
\hline$d$ & 30 & 25 & $B 8$ & 41 & 86 & 85 & 8,28 & - & - \\
\hline e & 21 & 24 & 11 & 44 & 88 & 188 & 8,25 & - & - \\
\hline
\end{tabular}

- Caracteristicas pquicicas:

\begin{tabular}{|c|c|c|c|c|c|c|c|c|c|c|c|c|c|c|}
\hline & obt & & Bases tr & ocdvei & & Yalor & Acetroc. & & & & Sat. & & & \\
\hline Cacada & dọua KCI & $1 p H$ & $\mathrm{C}_{a^{2+}} \mathrm{H}_{9}{ }^{2+}$ & $x+h$ & & $\mathfrak{s}$ & AI & $\mathrm{H}^{*}$ & CTC & $y z$ & A] & Corg. & 船 & Cis \\
\hline a & $4,3 \quad 4,8$ & $-8,3$ & $8,3 \quad 8,2$ & 8,13 & - & 8,63 & 8,7 & 3,3 & 4,63 & 19 & 53 & 1,1 & 8,11 & 19,8 \\
\hline$b$ & $4,4 \quad 4,1$ & $-8,3$ & $8,1 \quad 8,1$ & 8,87 & - & 8,27 & 8,6 & 3,7 & 3.57 & 8 & 69 & 8,8 & 8,88 & 19,8 \\
\hline $\mathrm{c}$ & $4,8 \quad 4,7$ & $-8,1$ & $8,1 \quad 8,1$ & 8,82 & - & 8.22 & 8,1 & 2,4 & 2,72 & 8 & 33 & 8,7 & 8,86 & $11, ?$ \\
\hline$d$ & $4,9 \quad 5,1$ & $+8,2$ & $8,2 \quad 8,8$ & 8,82 & - & 8,22 & 8,8 & 1,9 & 2,12 & 18 & 8 & 8,3 & $\cdot$ & - \\
\hline 8 & $4,9 \quad 5,6$ & $+8,7$ & $8,1 \quad 8,8$ & 8,82 & - & 8,12 & 8,8 & 1,3 & 1,42 & 8 & B & 8,3 & - & - \\
\hline
\end{tabular}




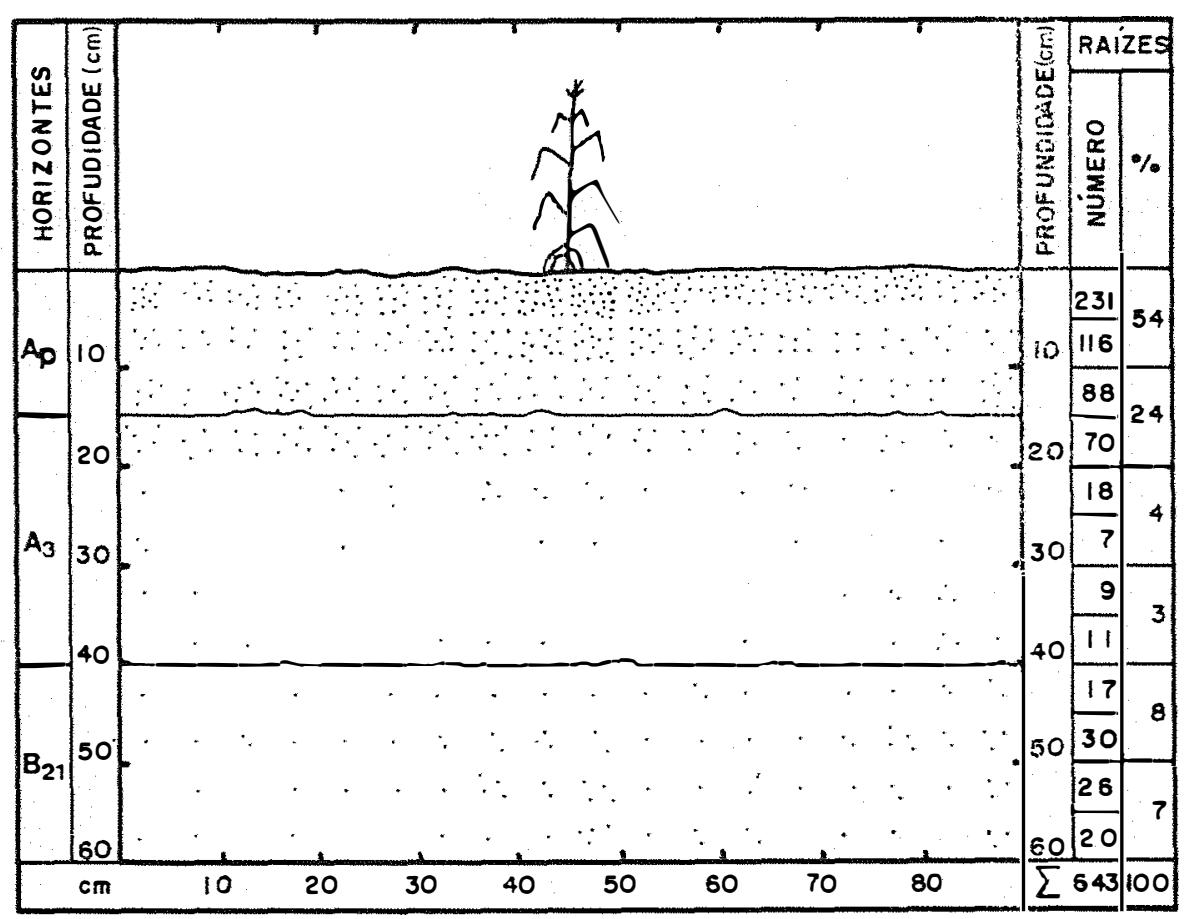

Figura 27 (A). Distribuição espacial das raízes no perfil, para o sistema de produção Mi-contínuo e na dose de calcário $\theta$ t/ha.

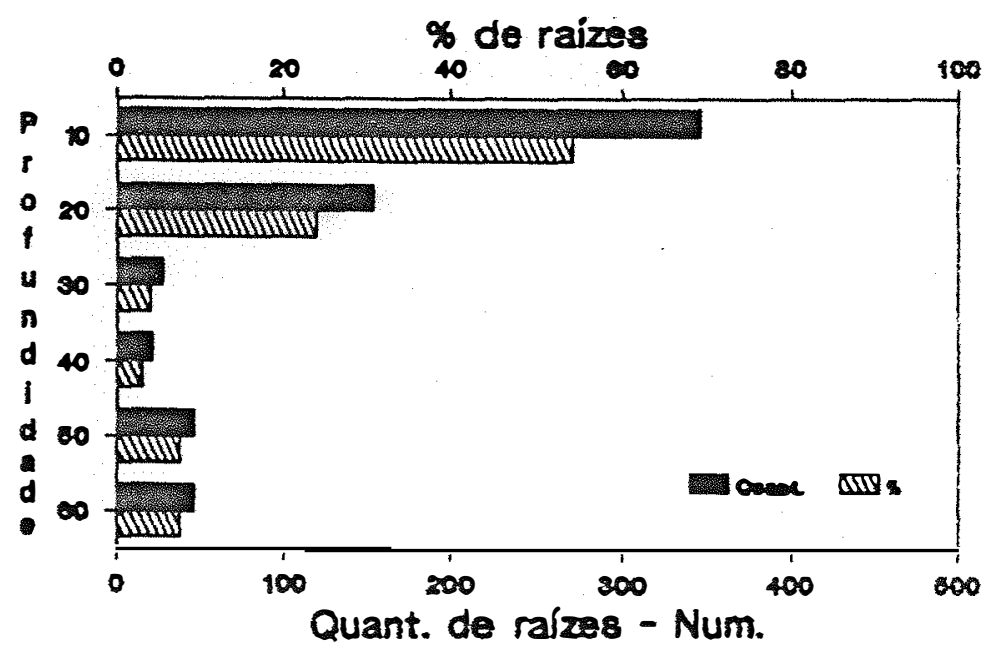

Figura 27 (B). Quantidade e valor percentual de raizes em função da profundidade, no sistema de produção Mi-continuo e na dose de calcário $\theta$ t/ha. 


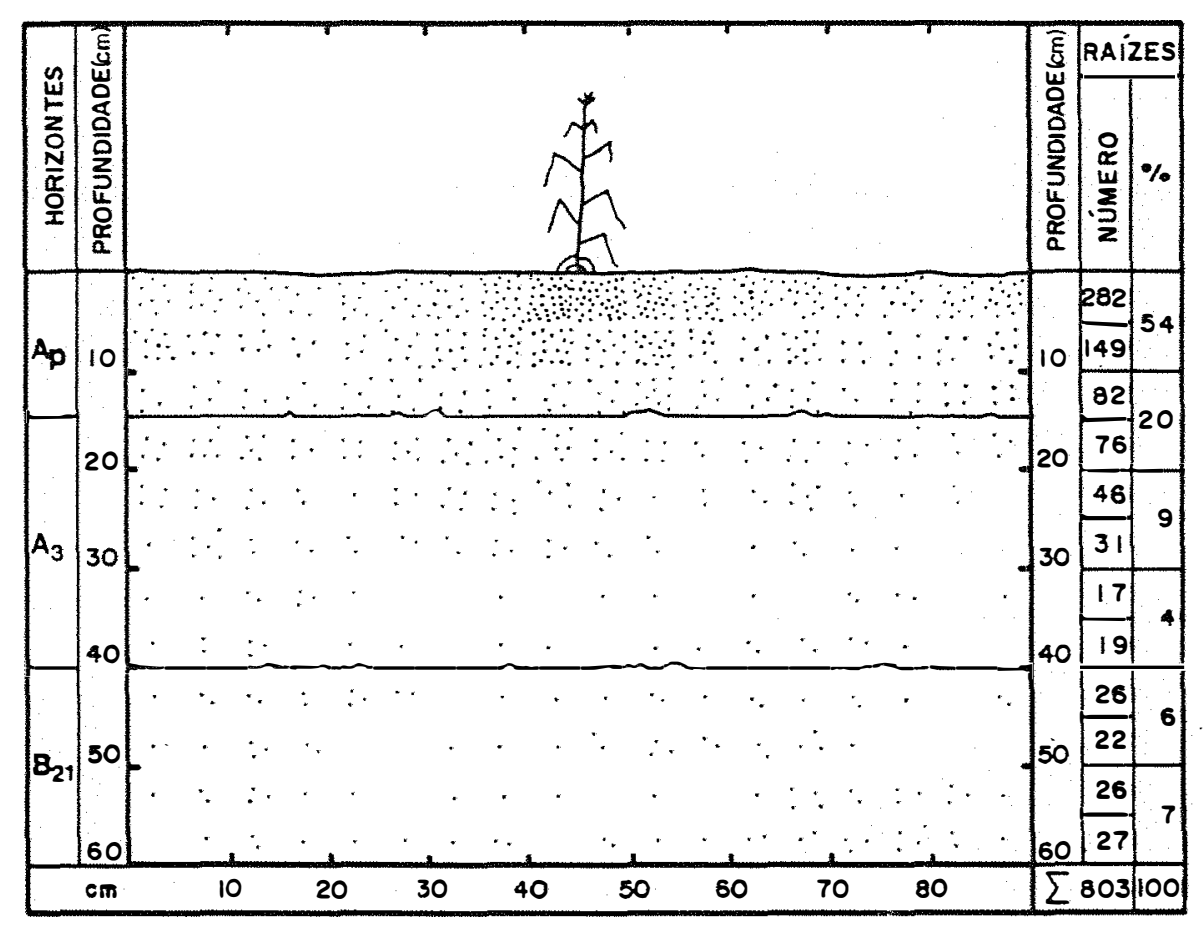

Figura 28 (A). Distribuição espacial das raíes no perfil, para o sistema de produção Mi-contínuo e na dose de calcário $3 \mathrm{t} / \mathrm{ha}$.

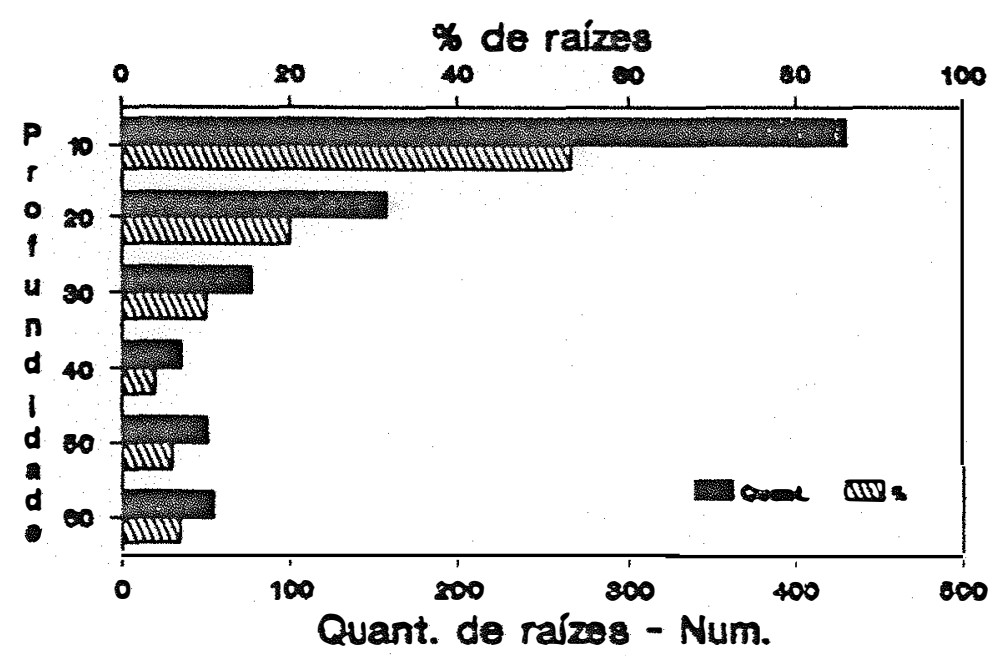

Figura 28 (B). Quantidade e valor percentual de raizes em função da profundidade, no sistema de produção Mi-continuo e na dose de calcário 3 t/ha. 


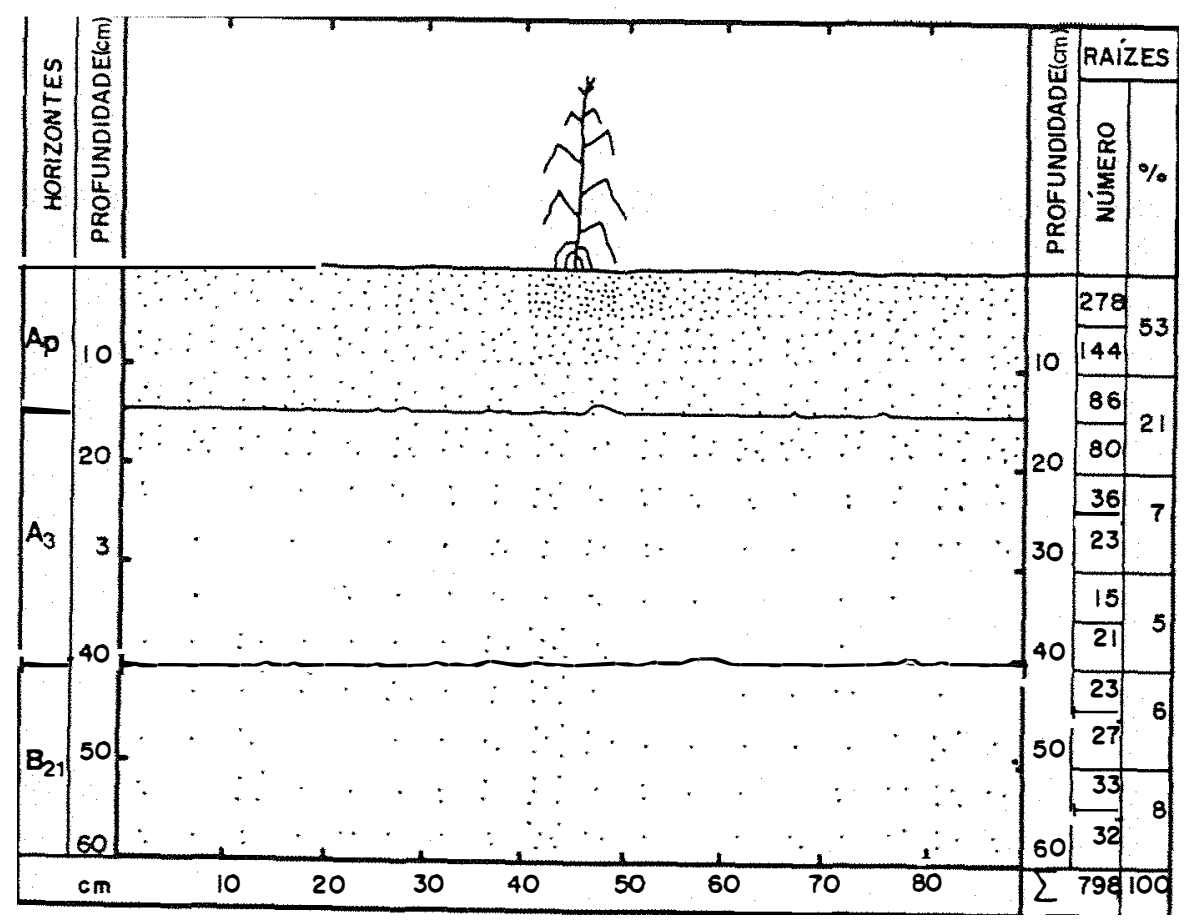

Figura 29 (A). Distribuição espacial das raizes no perfil, para o sistema de produção Mi-contínuo e na dose de calcário $6 \mathrm{t} / \mathrm{ha}$.

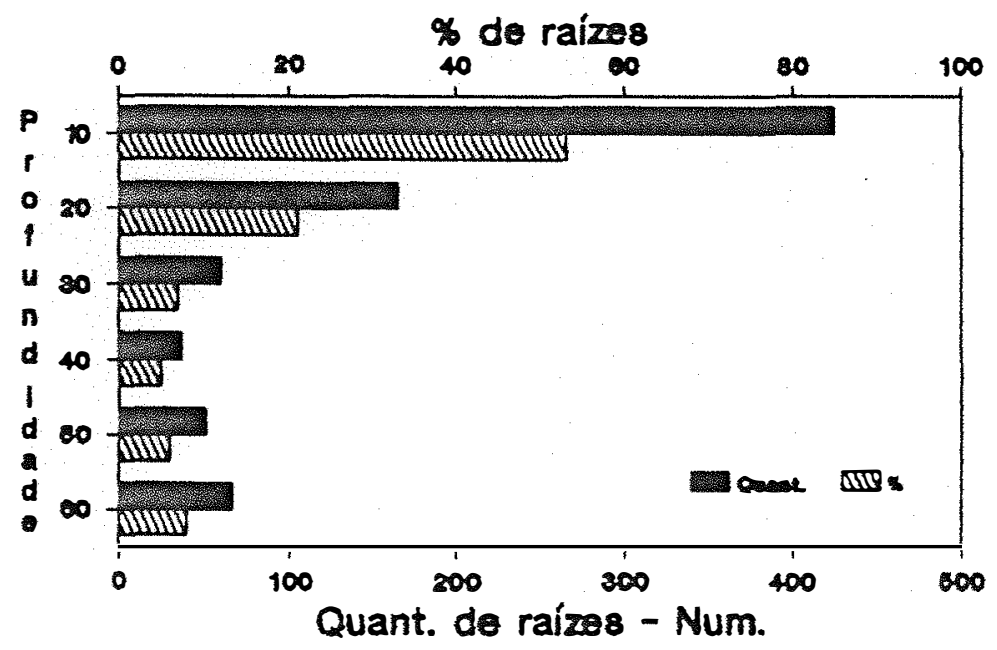

Figura 29 (B). Quantidade e valor percentual de raizes em função da profundidade, no sistema de produção Mi-contínuo e na dose de calcário 6 t/ha. 


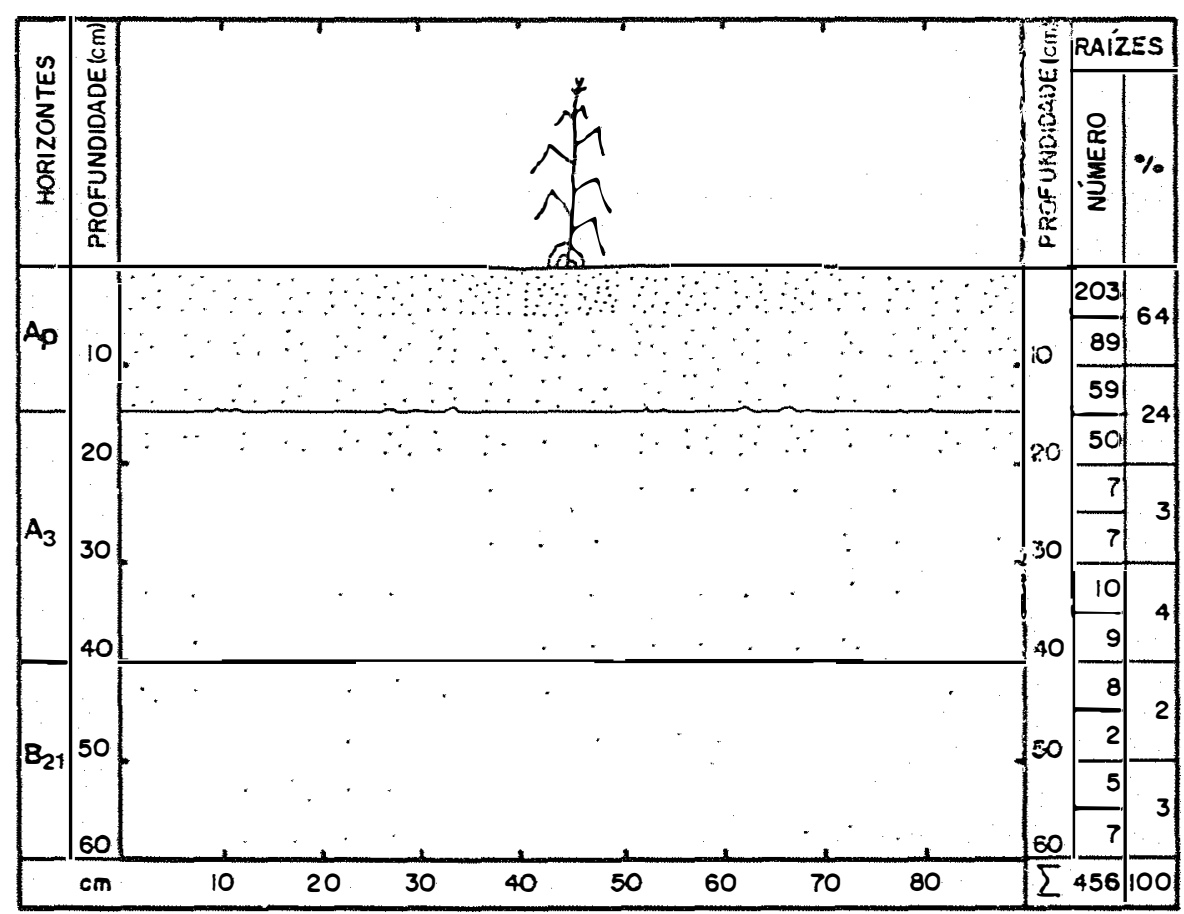

Figura 30 (A). Distribuição espacial das raizes no perfil, para o sistema de produção $\mathrm{Mi}-\mathrm{Aa} / \mathrm{As}$ e na dose de calcário $\theta \mathrm{t} / \mathrm{ha}$.

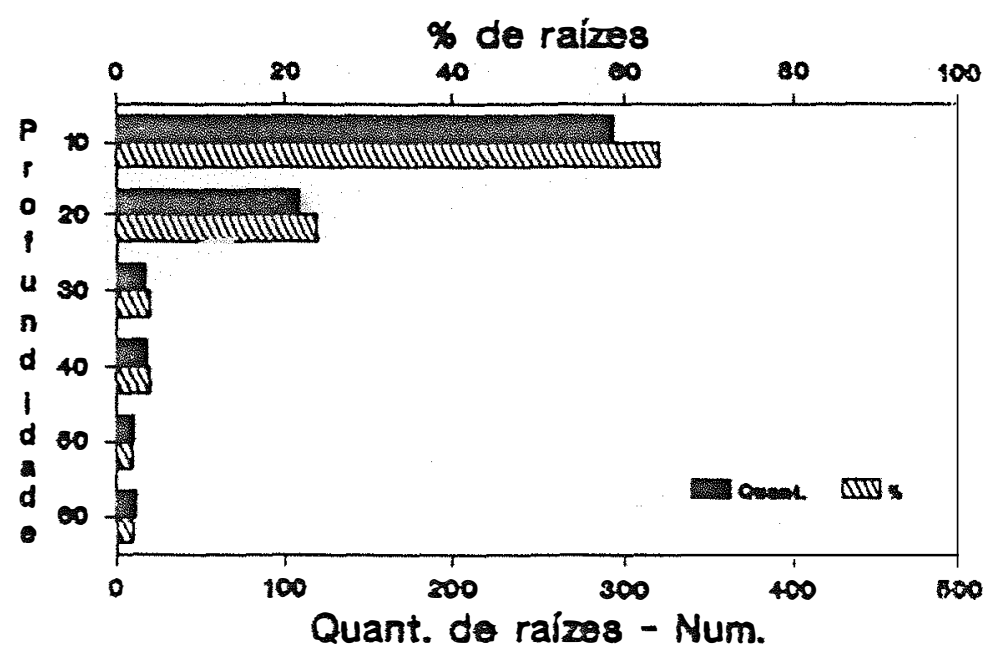

Figura 30 (B). Quantidade e valor percentual de raizes em função da profundidade, no sistema de produção Mi-Aa/As e na dose de calcário $\theta \mathrm{t} / \mathrm{ha}$. 


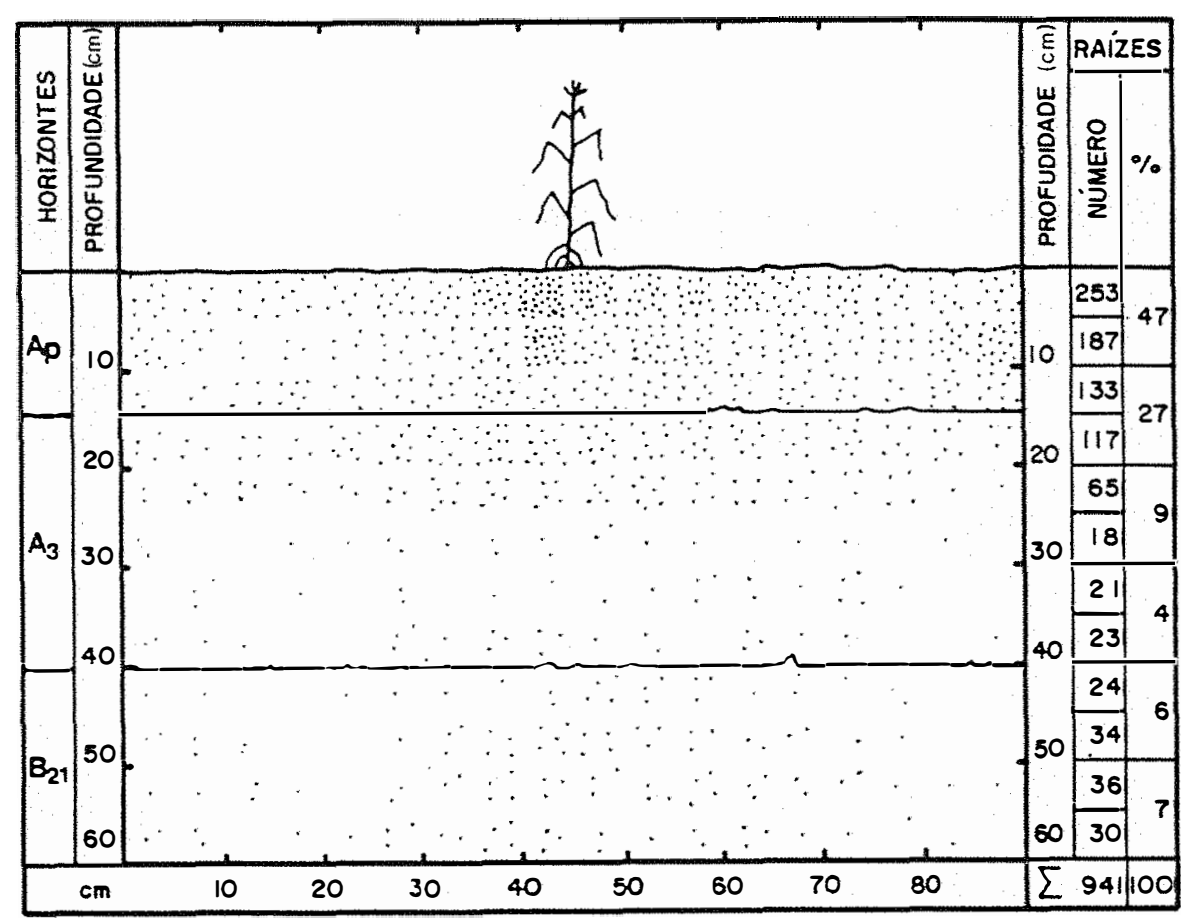

Figura 31 (A). Distribuição espacial das raizes no perfil, para o sistema de produção Mi-Aa/As e na dose de calcário 3 t/ha.

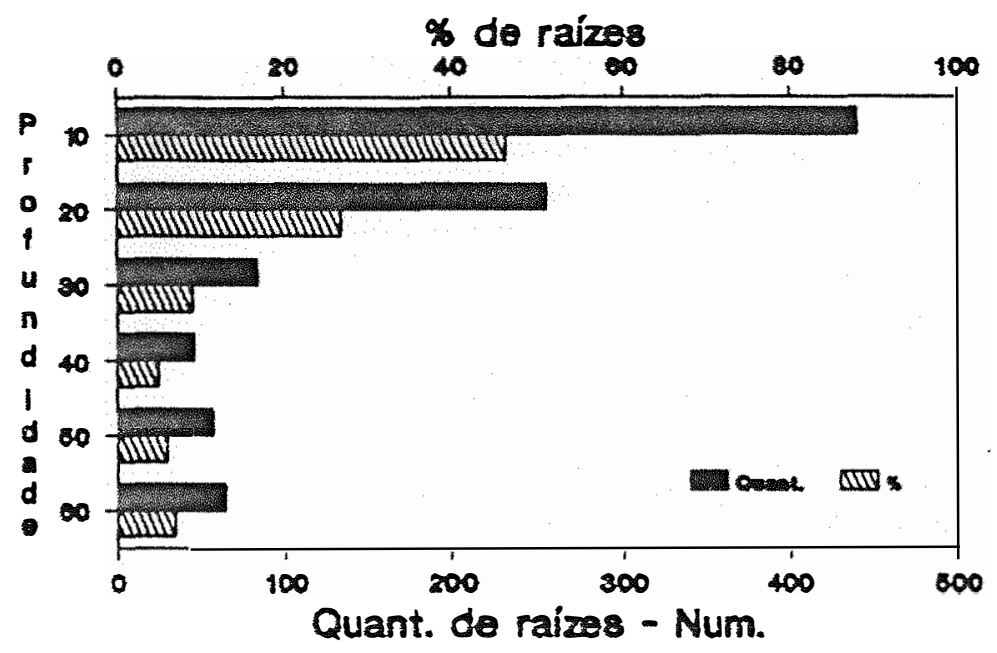

Figura 31 (B). Quantidade e valor percentual de raizes em função da profundidade, no sistema de produção $\mathrm{Mi}-\mathrm{Aa} / \mathrm{As}$ e na dose de calcário 3 t/ha. 


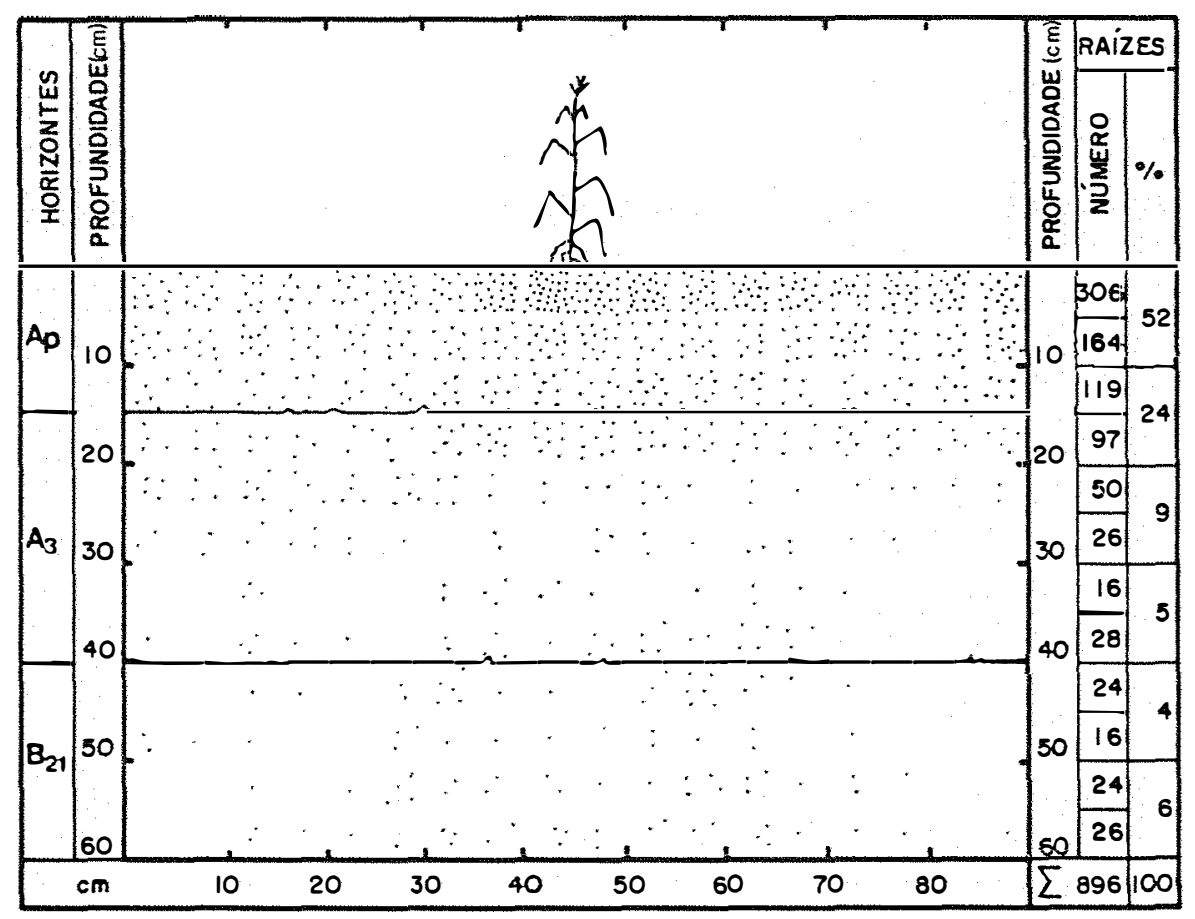

Figura 32 (A). Distribuição espacial das raizes no perfil, para o sistema de produção $\mathrm{Mi}-\mathrm{Aa} / \mathrm{As}$ e na dose de calcário 6 t/ha.

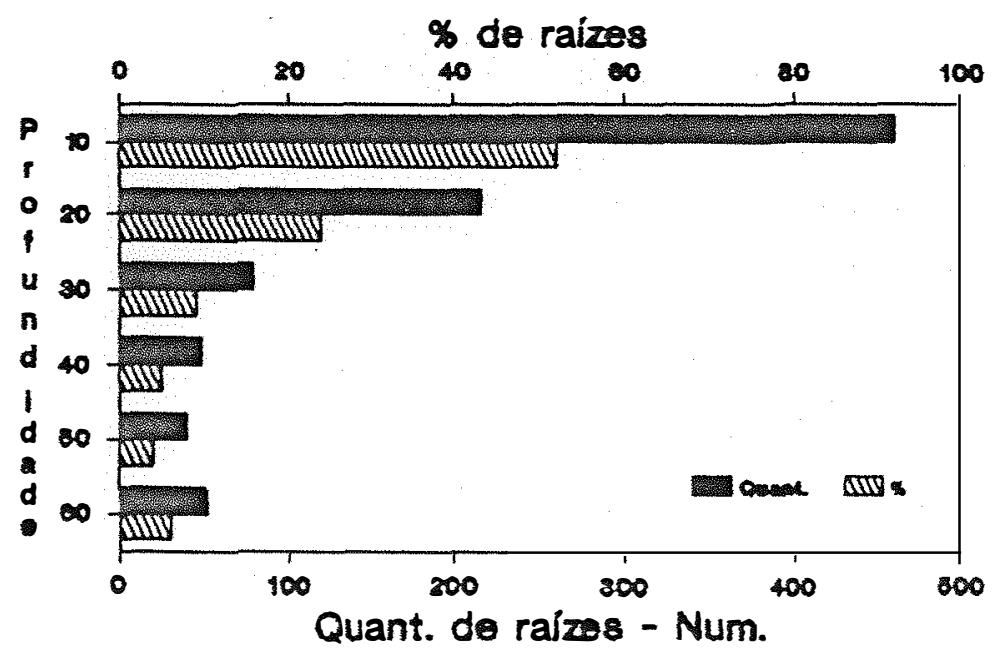

Figura 32 (B). Quantidade e valor percentual de raizes em função da profundidade, no sistema de produção Mi-Aa/As e na dose de calcário 6 $t / h a$. 


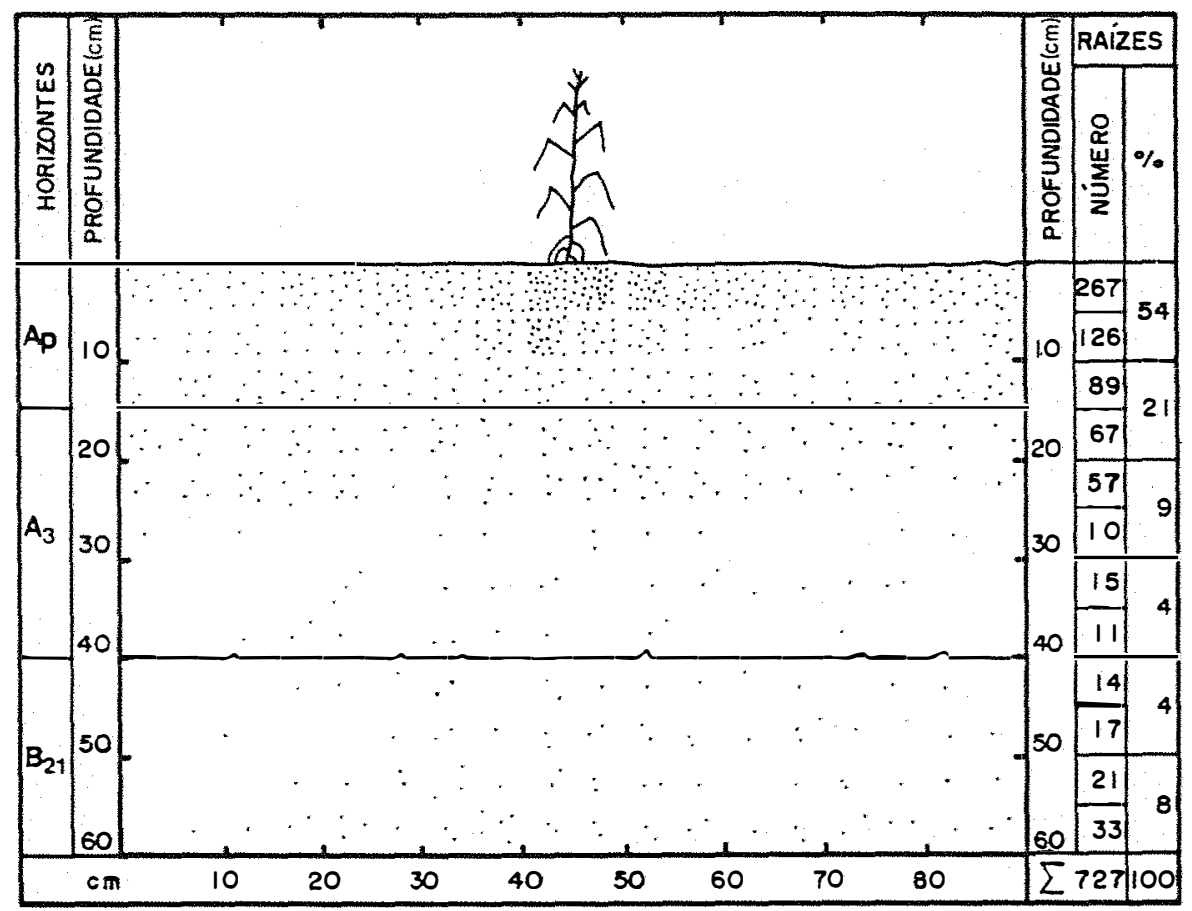

Figura 33 (A). Distribuição espacial das raízes no perfil. para o sistema de produção $\mathrm{Mi}-\mathrm{Aa} / \mathrm{Mu}$ e na dose de calcário 0 t/ha.

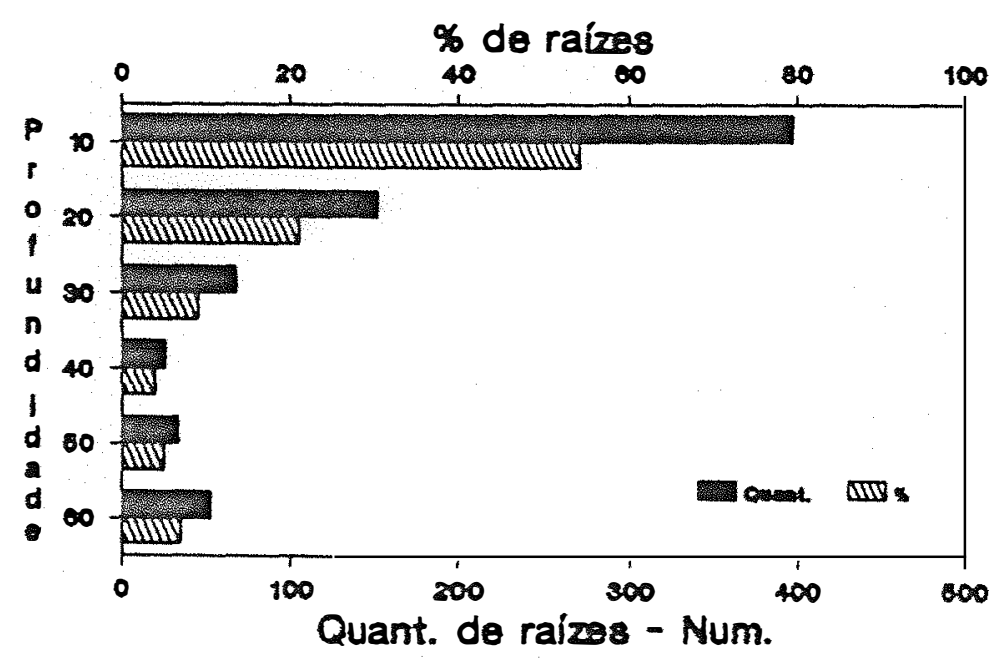

Figura 33 (B). Quantidade e valor percentual de raizes em função da profundidade, no sistema de produção $\mathrm{Mi}-\mathrm{Aa} / \mathrm{Mu}$ e na dose de calcário $\theta$ t/ha. 


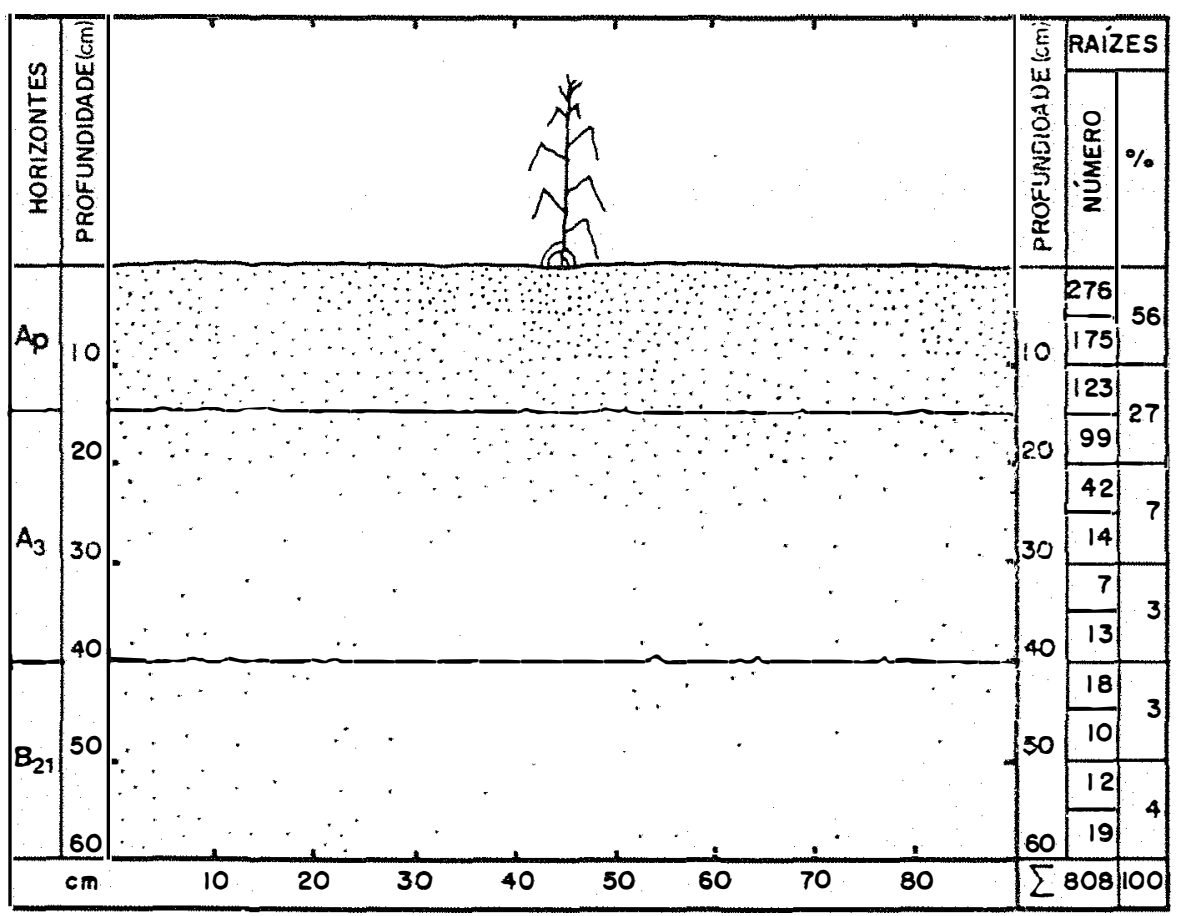

Figura 34 (A). Distribuição espacial das raizes no perfil, para o sistema de produção Mi-Aa/Mu e na dose de calcário 3 t/ha.

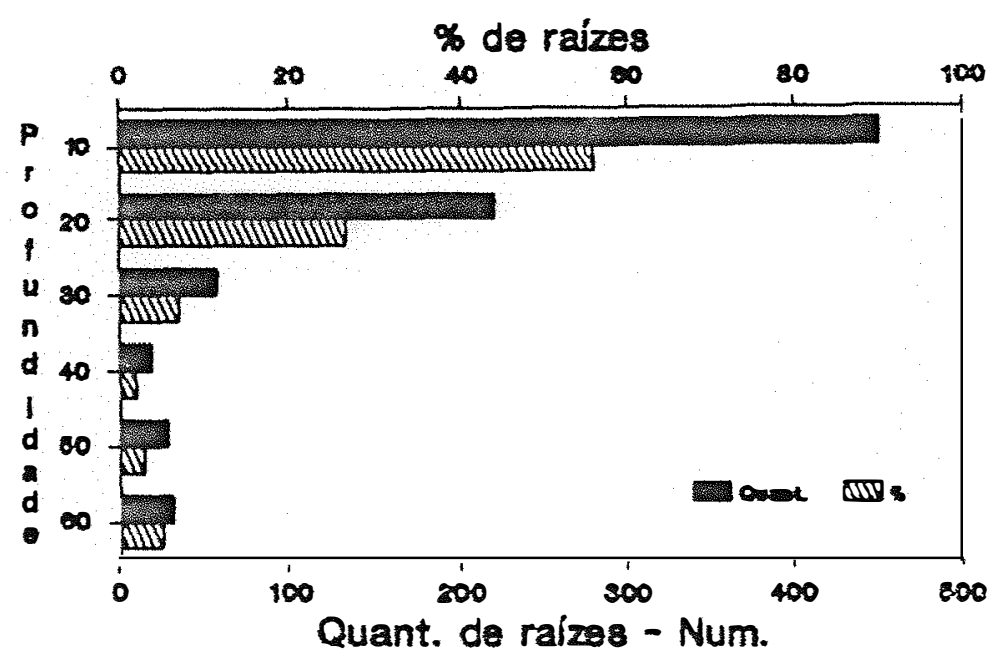

Figura 34 (B). Quantidade e valor percentual de raizes em função da profundidade, no sistema de produção $\mathrm{Mi}-\mathrm{Aa} / \mathrm{Mu}$ e na dose de calcário 3 t/ha. 


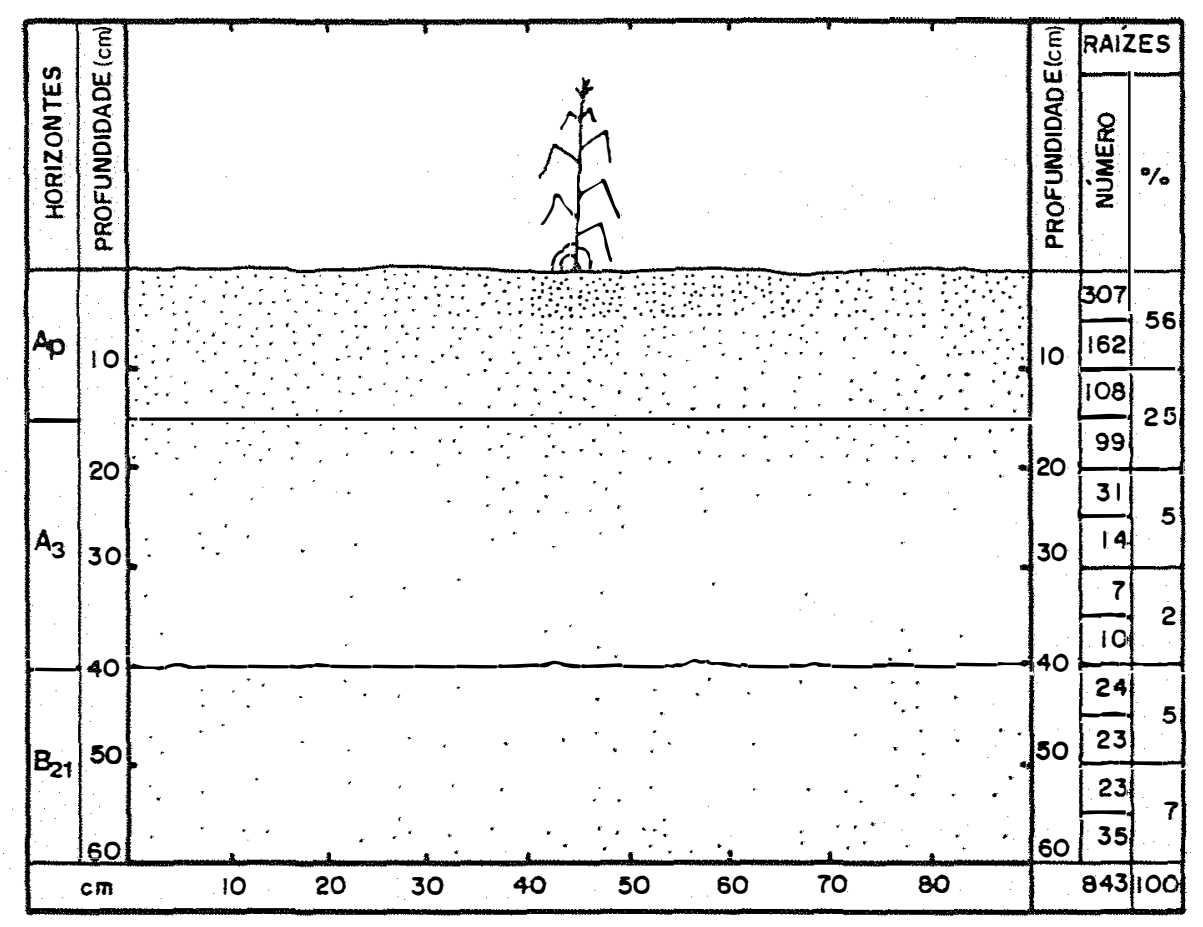

Figura 35 (A). Distribuição espacial das raízes no perfil, para o sistema de produção $\mathrm{Mi}-\mathrm{Aa} / \mathrm{Mu}$ e na dose de calcário $6 \mathrm{t} / \mathrm{ha}$.

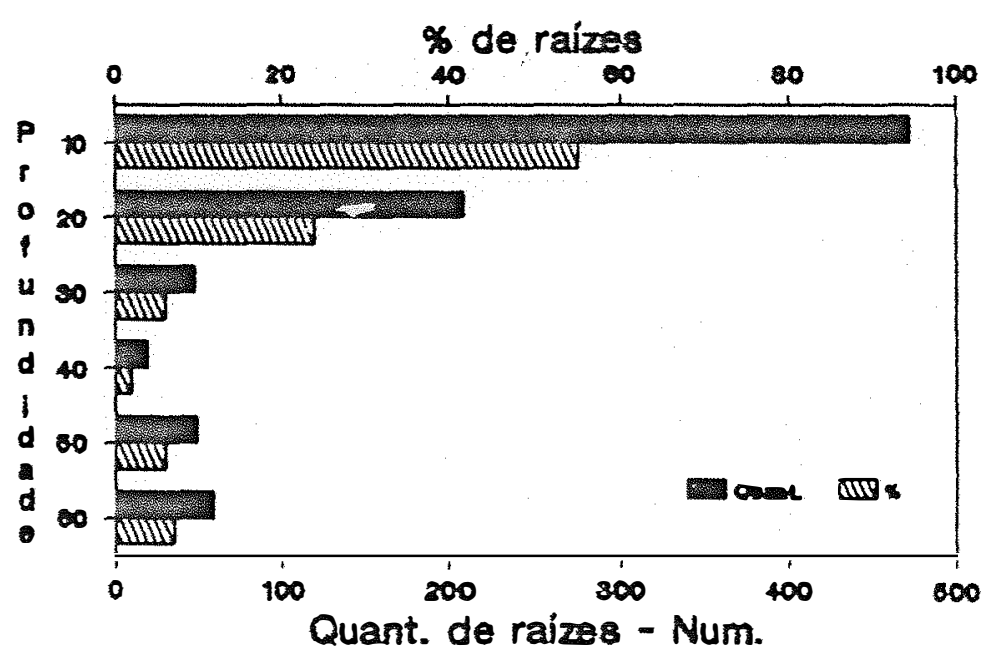

Figura 35 (B). Quantidade e valor percentual de raizes em função da profundidade, no sistema de produção $\mathrm{Mi}-\mathrm{Aa} / \mathrm{Mu}$ e na dose de calcário 6 t/ha. 


\subsection{Nutrientes absorvidos}

Como pode-se ver na Tabela 25 , o efeito dos sistemas de produção foi significativo para os teores de nitrogênio e de fósforo nas folhas de milho.

Para o nitrogênio observa-se que os sistemas Mi-continuo e Mi-Aa/As apresentaram teores estatisticamente iguais, e que somente no sistema Mi-Aa/As, o teor foi superior ao do sistema $\mathrm{Mi}-\mathrm{Aa} / \mathrm{Mu}$.

Em relação ao fósforo, apesar da diferença muito pequena, no sistema Mi-continuo o teor foi superior aos outros dois sistemas, os quais nao diferiram entre si (Tabela 26).

Considerando-se que os sistemas de produção não causaram variações significativas nas caracteristicas químicas do solo, fica dificil associar essas diferenças à alguma razão especifica.

TIESSEN (1988), avaliando para rotações e consórcios entre sorgo, milho e amendoim, o efeito destes sobre o conteúdo de nitrogênio orgânico no solo, verificou que niveis significantemente maiores desse nutriente foram observados nas rotações que incluiram amendoim.

o efeito da calagem piruvocou aumento nos teores de cálcio e magnésio das folhas, e de forma previsivel, diminuiu significativamente o teor de potássio. Sabe-se que, na solução do solo, o potássio depende dos 


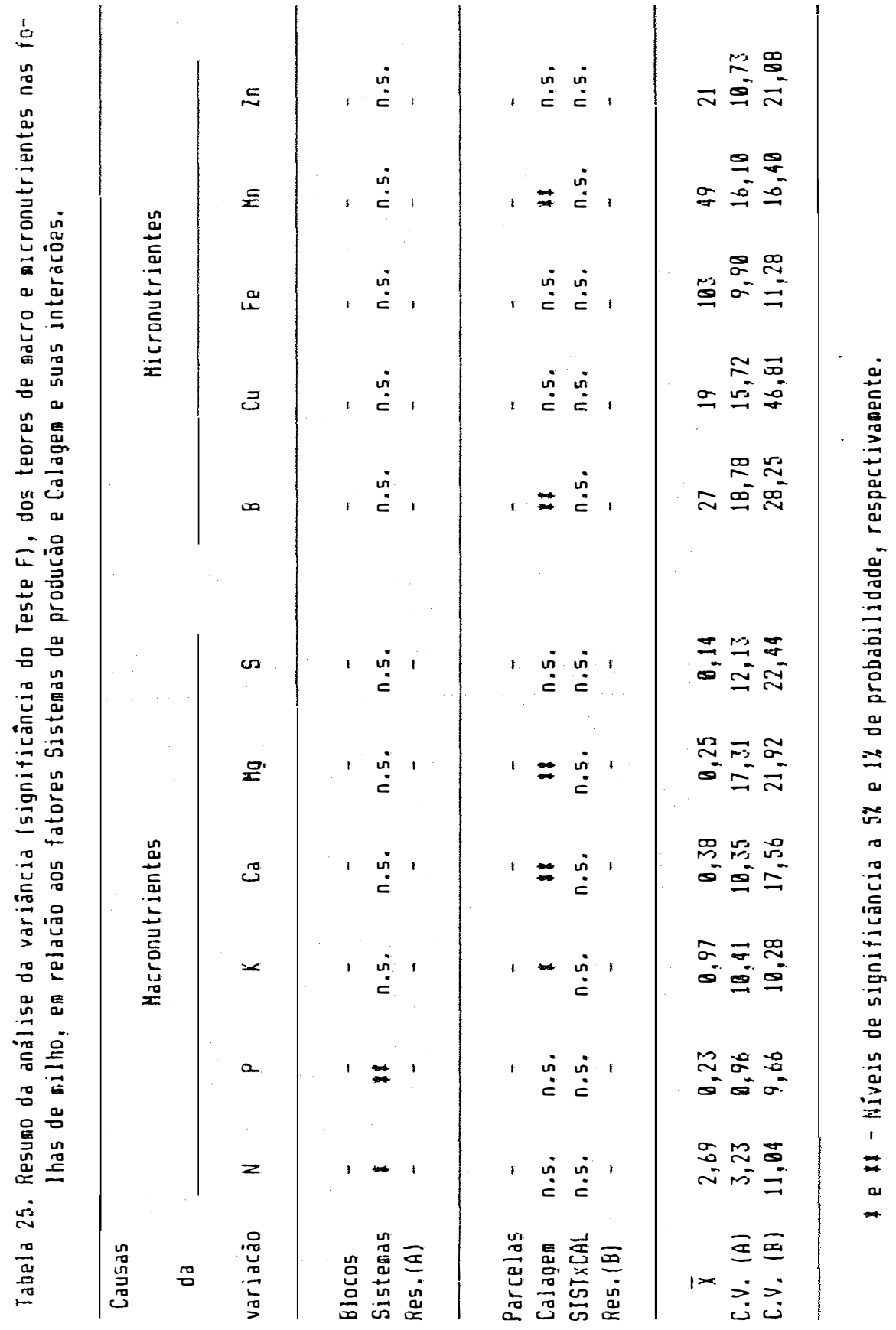




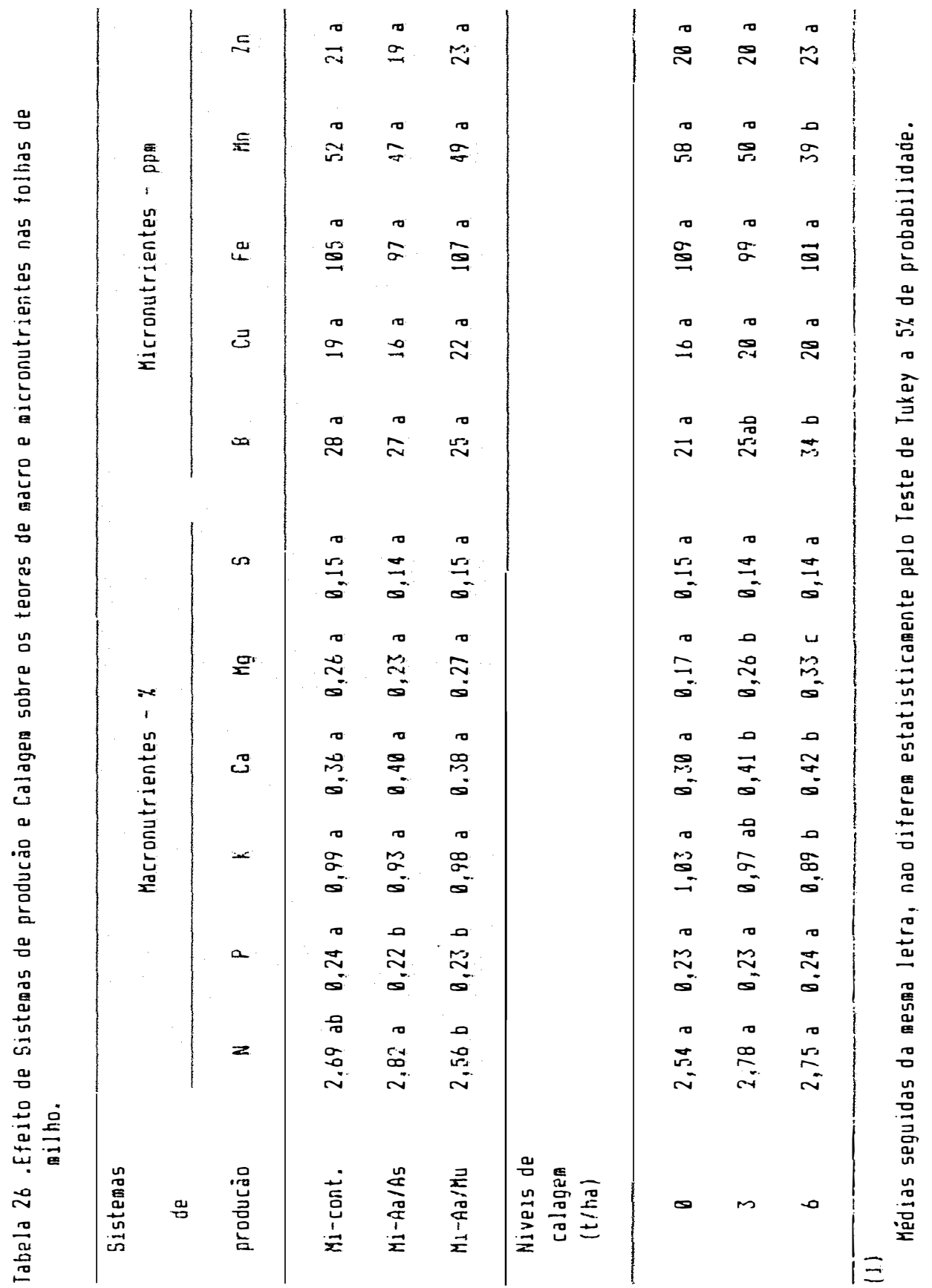


depende dos teores de cálcio e magnésio, e que para um mesmo teor de $K$ trocável, seu teor na solução, e portanto a disponibilidade de potássio, será menor se maiores forem os teores daqueles cátions (MIELNICZUK, 1984; RAIJ, 1983). Apesar da adubação anual com potássio, seu teor na planta, encontra-se abaixo da faixa considerada adequada para o milho na época da amostragem.

Outro efeito da calagem foi o aumento no teor de boro, já que sua disponibilidade costuma aumentar com a elevação do pH até aproximadamente 6,5 , sofrendo decréscimo somente a valores mais altos. O decréscimo do teor de manganês era também previsto, como consequiência de sua neutralização no solo devido à calagem.

\subsection{Produção de girãos}

Além dos resultados referentes ao ano agricola 88/89, que foi o periodo da realização deste estudo, também são mostrados, com o intuito de enfatizar a tendência da resposta ao longo do tempo, os resultados dos anos agricolas 82/83, 84/85 e 86/87, apresentados por DECHEN (1990), nos quais os mesmos tratamentos foram instalados nas mesmas parcelas.

O efeito de sistemas de produção nao foi significativo, inclusive em nenhum dos anos considerados, ao contrário do efeito da calagem, que apresentou signifi- 
Tabela 27. Resumo da análise de variância (significância do Teste F), para a produção de grãos de milho em alguns anos agricolas, em relação aos fatores: sistemas de produção e calagem.

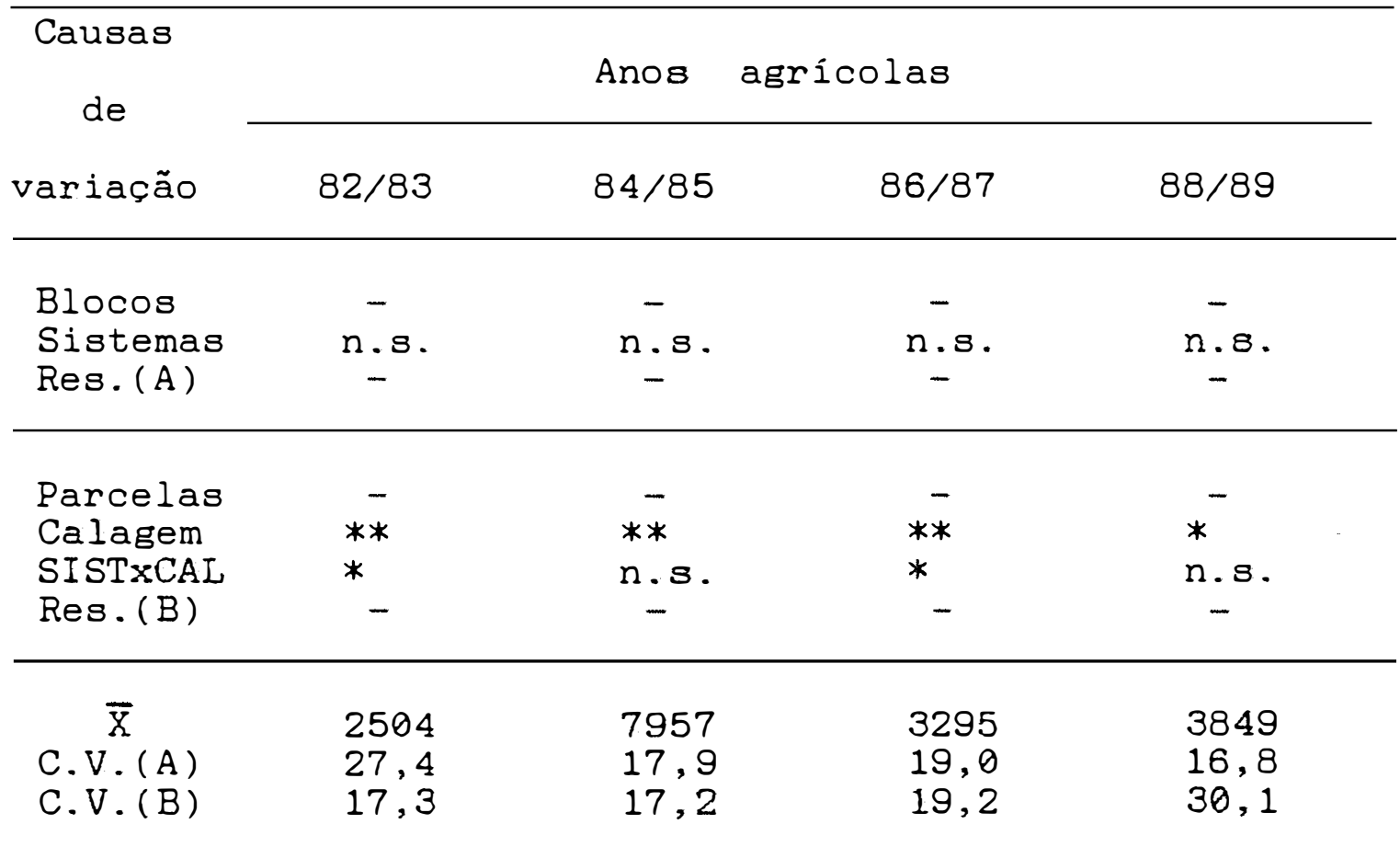

* e ** - Niveis de significância a 5\% e 1\% de probabilidade, respectivamente.

cância estatistica em todos os anos (Tabela 27).

Os sistemas em rotação e ou sucessão não foram capazes de modificar as caracteristicas físicas e químicas do solo e nem de alterar o desenvolvimento do sistema radicular do milho, quando comparados com o sistema Mi-contínuo. Portanto, como consequência, em termos de produção de milho os sistemas nao diferiram entre sí.

As variações das características químicas promovidas pela calagem, refletiram-se no desenvolvimento 
do sistema radicular, nos teores de alguns nutrientes nas folhas, e finalmente, também na produção de grãos.

Com relação à avaliação das raízes, NAVAS, em 1969, citado por CRUZ (1982), tambèm encontrou resultados que mostraram haver uma correlação positiva entre a quantidade de raizes e o crescimento vegetativo e também a produção de milho. No entanto, isto nem sempre se verifica, como constatou BACCHI (1976), ao observar que, em função do teor satisfório de umidade do solo, não houve relação entre produção de cana-de-açucar e crescimento de raizes.

\subsection{Métodos de avaliacão do sistema radicular}

A escolha do método mais apropriado para o estudo das raízes depende de fatores de ordem técnica, mas também de fatores de ordem prática.

Segundo BOHM et alii (1977), existem, infelizmente, poucos estudos comparando dois ou mais métodos, em relação ao tempo requerido, à necessidade de equipamentos, à necessidade de pessoal treinado, à aplicabilidade do método ao tipo de solo e à validade dos

NAVAS, J. The effects of several tillage systems on some soil physical properties and on corn growth. M.S. Thesis, Purdue University, W. Lafayette, IN., 1969. 
Tabela 28. Efeito de sistemas de produção e caläem sobre a produção de grãos de milho, nos anos agrícolas de $82 / 83,84 / 85,86 / 87$ e 86,89.

\begin{tabular}{|c|c|c|c|c|c|}
\hline \multirow{2}{*}{$\begin{array}{c}\text { Sistemas } \\
\text { de } \\
\text { Produção }\end{array}$} & \multicolumn{5}{|c|}{ Anos agrícolas } \\
\hline & $82 / 83$ & $84 / 85$ & $86 / 87$ & $88 / 8$ & \\
\hline & \multicolumn{5}{|c|}{$\mathrm{kg} / \mathrm{ha}$} \\
\hline Mi-cont. & 2732 a & 8836 a & 3062 a & 4054 & a \\
\hline $\mathrm{Mi}-\mathrm{Aa} / \mathrm{As}$ & 2557 a & 7028 a & 3050 a & 3928 & a \\
\hline $\mathrm{Mi}-\mathrm{Aa} / \mathrm{Mu}$ & 2224 a & 8008 a & 3771 a & 3567 & a \\
\hline $\begin{array}{c}\text { Níveis de } \\
\text { calcârio } \\
\text { (t/ha) }\end{array}$ & & . & & & \\
\hline$\theta$ & $1961 \mathrm{a}$ & $6134 \mathrm{a}$ & $1398 \mathrm{a}$ & 2883 & a \\
\hline 3 & $2381 a$ & $8334 \mathrm{~b}$ & $3708 \mathrm{~b}$ & 3857 & $a b$ \\
\hline 6 & $3169 \mathrm{~b}$ & $9402 \mathrm{~b}$ & $4778 \mathrm{c}$ & 4808 & $\mathrm{~b}$ \\
\hline
\end{tabular}

(1) Médias seguidas da mesma letra, nao diferen estatisticamente pelo Teste de Tukey a 5\% de probabilidade.

resultados. Nesse trabalho, os autores compararam cinco métodos para avaliar o sistema radicular da soja: a) de absorção de água; b) do monolito; c) do trado; d) do perfil, e e) do mini-rizotron, descrevendo as vantagens e as desvantagens de todos os métodos, sem no entanto apontar - melhor dentre eles, enfatizando a necessidade de se escolher de acordo com o interesse do estudo e as condições locais. 
A maior parte dos métodos de estudo das raízes em condições de campo, baseiam-se na retirada de amostras volumétricas de solo-raiz, o que exige lavagem e limpeza das raízes para posterior determinaçao, principalmente, de peso e ou seu comprimento, 0 que freqüentemente consome muito tempo e contribui para o desinteresse da realizaçao desse tipo de trabalho.

o método do monolito, por exemplo, em certas circunstâncias considerado como padrão para servir de comparaçao da eficiência de outros métodos, é muito trabalhoso, e apesar de apresentar grande exatidão é pouco preciso (KOPKE, 1981). Ele foi usado na maioria dos trabalhos executados pelo IAC, com bons resultados, na avaliação do desenvolvimento do sistema radicular de diversas culturas.

O método do trado que, para as condições do presente estudo demandou maior tempo, pode ser, com uma boa estrutura de apoio para trabalhos dessa natureza, sxecutado com certa facilidade (FEHRENBACKER \& ALEXANDER, 1955; CAHOON \& MORTON, 1961), e possibilita, se retirado um grande número de amostras, avaliar as diferenças entre tratamentos com maior precisão estatística.

O método do perfil elimina a necessidade da lavagem do solo para a separação. das raizes, o que é uma vantagem, mas acrescenta a necessidade da realização de um trabalho muito cuidadoso na contagem de raízes e ou 
avaliação do seu comprimento na parede do perfil, que exige paciência, além de uma certa prática.

KOPKE (1981), analisando as características e as vantagens ou desvantagens dos diversos métodos, salienta que a densidade de comprimento de raízes é uma medida recomendada, e que os métodos que permitem a sua avaliação direta devem ser portanto preferidos, como é o caso do método do perfil. Considerando esses aspectos, ele acrescenta que esse método é mais viável para muitas investigações ecológicas, além de apresentar a relação mais favorável entre o trabalho dispendido e a informação obtida.

BOHM (1976), admite que, cada vez mais, a avaliação do comprimento tem se tornado a medida preferida por muitos pesquisadores, nos estudos de raízes que envolvem a absorção de água e de nutrientes, e apresenta um aperfeiçoamento do método do perfil que permite estimar o comprimento de raízes em um volume de solo.

Oe resultados que foram obtidos no presente trabalho mostraram que os dois métodos utilizados, o do perfil e o do trado, foram complementares, especialmente na avaliação do provável efeito, do alumínio trocável, sobre o espessamento das raízes. 


\section{CONCLUSÕES}

- Os sistemas de rotação e ou sucessão com amendoim e mucuna-preta, nao causaram modificações nas caracteristicas físicas e quimicas do solo, no desenvolvimento do sistema radicular e na produção de milho, quando comparados com seu comportamento no cultivo contínuo.

- O efeito residual do calcário, quatro anos e meio após a última aplicação, ainda foi observado, principalmente através da neutralização do aluminio trocável e dos maiores teores de cálcio e magnésio, o que o torna responsável pelo maior desenvolvimento do sistema radicular e produção de milho, não alterando, no entanto, as caracteristicas físicas do solo.

- O desenvolvimento do sistema radicular, que em geral se concentrou na camada de $\theta$ a $20 \mathrm{~cm}$, apresentou uma relação direta com a produção de grãos e com os efeitos da ação dos fatores em estudo.

- A ação do calcário se fez sentir também em profundidade, mas apesar disto, as caracteristicas químicas do solo, quando afetadas, apresentaram maior variação na camada de $\theta$ a $20 \mathrm{~cm}$. 
- O método do perfil, para o estudo do sistema radicular, se mostrou mais adequado que o método do trado. 


\title{
REFERENCIAS BIBLIDGRÁFICAS
}

\author{
ALLMARAS, R.R. \& NELSON, W.W. Corn (Zea mays L.) root \\ configuration as influenced by some row-interow variants \\ of tillage and straw mulch management. Soil Science \\ Society of American Proceedings, Madison, 35: 974-80, \\ 1971.
}

BACCHI, O.O.S. Efeitos da compactação sobre o sistema solo -planta em cultura de cana-de-açucar. Piracicaba, 1976. 67p. (Mestrado - Escola Superior de Agricultura "Luiz de Queiroz"/USP).

BAEUMER, K. Tillage effects on root growth and crop yield. In: COLLOQUIUM OF THE INTERNATIONAL POTASH INSTITUTE, 16., Warsaw, 1981. Proceedings. Berne, International Potash Institute, 1981. P.57-75.

BALDOCK, J.O.; HIGGS, R.L.; PAULSON, W.H.; JACKOBS, J.A.; SCHRADER, W.D. Legume and mineral $N$ effects on crop yields in several crop sequences in the Upper Mississipi Valley. Agronomy Journal, Madison, 73: 885-99, 1981. 
BARBER, S.A. A diffusion and mass flow concept of soil nutrient availability. Soil Science, Baltimore, 93: 39$49,1962$.

BARBER, S.A. Liming materials and practices. In: PEARSON, R.W. \& ADAMS, F., ed. Soil acidity and liming. Madison, American Society of Agronomy, 1967. p.125-60. (Agronomy, 12).

BARBER, S.A. Effect of tillage practice or corn (Zea mavs L.) root distribution and morphology. Agronomy Journal, Madison, 63(5): 724-6, 1971.

BARBER, S.A. Influence of the plant root on ion movement in soil. In: CARSON, E.W., ed. The plant root and its environment. Charlottesville, University Press of Virginia, 1974. p.525-64.

JARBER, S.A. ; WALLER, J.W.; NASEY, E.H. Mechanisms for the movement of plant nutrients from the soil and fertilizer to the plant root. Journal Agricultural Food Chemistry, Washington, 11: 284-7, 1963.

BARBER, S.A.; MACKAY, A.D.; KUCHENBUCH, R.O.; BARRACLOUGH, P.B. Effects of soil temperature and water on maize root growth. Plant Soil, The Hague, 111: 267-9, 1988. 
BATAGLIA, O.C.; FURLANI, A.M.C.; TEIXEIRA, J.P.F.; FURLANI, P.R.; GALLO, J.R. Métodos de análise química de plantas. Campinas, Instituto Agronômico, 1983. 48p (IAC. Boletim Técnico, 78).

BAVER, L.D.; GARDNER, W.H.; GARDNER, W.R. Soil physics. 4.ed. New York, John Wiley, 1972. 529p.

BERTONI, J. \& LOMBARDI NETO, F. Conservação do solo. Sao Paulo, 'Ícone, 1990. 355p.

BERTONI, J.; PASTANA, R.I.; LOMBARDI NETO, F.; BENATTI

JUNIOR, R. Conclusões gerais das pesquisas sobre conservação do solo no Instituto Agronômico. Campinas, Instituto Agronômico, 1972. 56p. (IAC. Circular, 20).

BLACK, C.A. Relaciones suelo-planta. Buenos Aires, Hemisferio Sur, 1975. 444p.

BOHM, W. In situ estimation of root lenght at natural soil profiles. Journal Agricultural Science, Cambridge, 87: $365-8,1976$.

BOHM, W. Methods of studying root systems. New York, Springer-Verlag, 1979. 189p. 
BOHM, W.; MADUAKOR, H.; TAYLOR, H.M. Compariscin of five methods for characterizing soybean rootine density and development. Agronomy Journal, Madison, 69: 415-9, 1977 .

BOLTON, E.F.; DIRKS, V.A.; FINDLAY, W.I. Effect of lime and corn yield, soil tilth, and leaf nutrient for five cropping systems on Brookston clay soil. Canadian Journal of Soil Science, Ottawa, 59(3): 225-30, Aug. 1979a.

BOLTON, E.F. ; DIRKS, V.A.; FINDLAY, W.I. Some relationship between soil porosity, leaf nutrient composition, and yield for certain corn rotation at two fertility levels on Brookston clay: Canadian Journal of Soil Science, Ottawa, 59: 1-9, $1979 \mathrm{~b}$.

BRAGA, N.R. Avaliação crítica e perspectivas de experiências de adubação verde no estado de São Paulo. In: FUNDAÇÃO CARGILL. Adubação verde no Brasil. Campinas, 1984. P. 328-9. 
BROWN, D.A. \& SCOTT, H. don. Dependence of crop growth and yield on root development and activity. In: BARBER, S.A. \& BOULDIN, D.R., ed. Roots, nutrient and pater influx, and plant growth. Madison, Soil Science Society of America, 1984. cap. 6, p.101-36.

CAHOON, G.A. \& MORTON, E.S. An apparatus for the quantitative separation of plant roots from soil. American Society of Horticultural Science, Madison, 78: 593-6, 1961.

CAMARGO, O.A. \& FURLANI, P.R. Alumínio no solo: concentração, especiação e efeito no desenvolvimento radicular. In: SIMPÓSIO AVANÇADO DE SOLOS E NUTRIÇÃO DE PLANTAS, 2., Piracicaba, 1989. Anais. Campinas, Fundação Cargill, 1989. p.45-69.

CANNELL, R.Q. Soil cultural practices related to root development. In: SYMPOSIUM ON THE SOIL/ROOT SYSTE⿰氵, IN RELATION TO BRASILIAN AGRICULTURE, Londrina, 1980. Proceedings, Edited by R.S. Russell and others. Londrina, IAPAR, 1981. P.61-80. 
CATANI, R.A.; GALLO, J.R.; GARGANTINI, H. Amostragem de 80lo, métodos de análise, interpretação e indicações gerais para fins de fertilidade. Campinas, Instituto Agronômico, 1955. 22p. (IAC. Boletim, 69 ).

CAVALERI, P.A.; FUZZATO, M.F.; FREIRE, E.S. Adubação do algodoeiro. XIV. Experiência com mucuna e adubos minerais. Bragantia, Campinas, 22(26): 331-50, 1963.

CINTRA, F.L.D. \& MIELNICZUK, J. Potencial de algumas espécies vegetais para a recuperaçăo de solos com propriedades fisicas degradadas. Revista Brasileira de Ciência do Solo, Campinas, 7(2): 197--201, 1983.

CORRÊA, D.M.; PETINELLI, A.; VENTURINI, W.R.; FREIRE, E.S. Adubação do algodoeiro. XI. Ensaio com calcário, adubação verde e adubação mineral. Bragantia, Campinas, $20(22): 617-33,1961$.

CRUZ, J.C. Effect of crop rotation and tillage systems on properties, root distribuition and crop production. West Lafayet, 1982. 220 p. (PhD - Purdue University). 
DECHEN, A.R. Análises químicas de solo e de folhas, e produção de amendoim (Arachis hipogaea L.) e de milho (Zea mavs L.) em função de sistemas de produção e de doses de calcário. Resultados de sete anos em um Latossolo Vermelho-escuro de Campinas, SP. Piracicaba, 1990. 153p. (Livre-docência - Escola Superior de Agricultura "Luiz de Queiroz"/US?.

DECHEN, S.C.F.; LOMBARDI NETO, F.; CASTRO, O.M. de Gramineas e leguminosas e seus restos culturais no controle da erosão em latossolo roxo. Revista Brasileira de Ciência do Solo, Campinas, 5: 133-7, 1981.

DECHEN, S.C.F.; VIEIRA, S.R.; LOMBARDI NETO, F.; CASTRO, O.M. de; QUAGGIO, J.A.; MARIA, I.C. de. Physical characterization of a dark-red latosol under crop rotation with peanut and maize. In: INTERNATION CONFERENCE ON DRYLAND FARMING, Amarillo, 1988. Proceedings . Amarillo, 1990. p.581-3.

DE-POLLI, H. \& CHADA, S.S. Adubação verde incorporada ou em cobertura na produção de milho em solo de baixo potencial de produtividade. Revista Brasileira de Ciência do Solo, Campinas, 13: 287-93, 1989. 
DORAN, J.W. \& SMITH, M.S. Organic matter marisement and utilization of soil and fertilizer nutrients. In: FOLLEIT, R.F.; STEWART, J.W.B.; COLE, C.:. Soil fertility and organic matter as critical components of production systems. Madison, Soil Science Dociety of America, 1987 . cap.4, p.53-72.

EVANS, L.T. \& WARDLAW, I.F. Aspects of the comparative phisiology of grain yield in cereals. Advances in Agronomy, New York, 28: 301-59, 1976.

FEHRENBACKER, J.B. \& ALEXANDER, J.D. A method for studying corn root distribution using a soil-core sampling machine and shakertype washer. Agronomy Journal, Madison, 47(10): 468-71, 1955.

FERRAZ, C.A.M.; CIA, E.; SABINO, N.P. Efeito da mucuna e e amendoim em rotação com o algodoeiro. Bragantia, Campinas, 36(1): 1-9, 1977.

FOTH, H.D. Root and top growth of corn. Agronomy Journal, Madison, 54(1): 49-52, 1962 . 
FOY, C.D. Physiological effects of hidrogen, aluminum, and manganese toxicities in acid soil. In: PEARSON, R.W. \& ADAMS, F., ed. Soil acidity and liming, 2.ed. Madison, Soil Science Society American, 1984. p.57-97. (Agronomy, 12 ).

FRIED, M. \& BROESHART, H. The soil plant system: in relation to inorganic nutrition. New York, Academic Press, 1967. 358p.

FUNDAÇÃO CARGILL. Adubação verde no Brasil. Campinas, 1984. 363p.

FUNDAÇÃO INSTITUTO BRASILEIRO DE GEOGRAFIA E ESTATÍSTICA. Campinas. In:__ Enciclopédia dos municípios brasileiros. Rio de Janeiro, I.B.G.E., 1957. v.28, p. 199-209.

FURLANI, P.R. Efeitos fisiolúgicos do alumínio em plantas. In: SIMPÓSIO AVANÇADO DE SOLOS E NUTRIÇÃO DE PLANTAS, 2., Piracicaba, 1989. Anais. Campinas, Fundaçăo Cargill, 1989. p.73-90. 
GALLO, P.B.; LAVORENTI, A.; SAWASAKI, E.; HIROCE, R.; MASCARENHAS, H.A.A. Efeito de cultivos anteriores de soja na produção e no teor de nitrogênio das folhas e dos grãos de milho. Revista Brasileira de Ciência do Solo, Campinas, 5: 64-7, 1981 .

GERMEK, E.B.; INFORZATO, R.; FRANCO, C.M. Estudo do sistema radicular do arroz. Bragantia, Campinas, 10: 89-92, 1950.

GOEDERT, W.J.; RITCHEY, K.D.; SANZONOWICZ, C. Desenvolvimento radicular do capim-andropogon e sua relação com o teor de cálcio no perfil do solo. Revista Brasileira de Ciência do Solo, Campinas, 9: 89-91, 1985.

GRABLE, A.R. Soil aeration and plant growth. Advances in Agronomy, New York, 18: 57-106, 1966.

GROHMMANN, F. \& QUEIROZ NETO, J.P. Efeito de compactação artificial de dois solos limo argilosos sobre a penetração das raizes do arroz. Bragantia, Campinas, $25(38): 421-31,1966$. 
HAAS, H.J. Effects of fertilization age of stand, and decomposition on weight of grass roots and of grass and alfalfa on soil nitrogen and carbon. Agronomy Journal, Madison, 50: 5-9, 1958 .

HALLAN, M.J. \& BARTHOLOMEU, W.V. Influence of rate of plant plant residue addition in accelarating the decomposition of soil organic matter. Soil Science Society Proceeding, Madison, 18: 365-8, 1953.

HAMBLIN, A. The influence of soil structure on water movement, crop root growth, and water uptake. Advances in Agronomy, New York, 38: 95-158, 1985.

HARRIS, R.F.; CHESTERS, G.; ALLEN, O.N. Dynamic of soil aggregation. Advances in Agronomy, New York, 18: 107-69, 1966 .

HATANO, R.; IWANAGA, K.; OKAJIMA, H.; SAKUMA, T. Relationship between the distribution of soil macropores and root elongation. Soil Science Plant Nutrition, Tokyo, $34(4): 535-46,1988$. 
HAYNES, R.J. \& LUDECKE, T.E. Yield, root morphology and chemical composition of two pasture legumes as affected by lime and phosphorus applications to an acid soil. Plant and Soil, The Hague, 62, 241-54, 1981.

HURD, E.A. Growth of roots of seven varieties of spring wheat at high and low moisture levels. Agronomy Journal, Madison, 60: 201-5, 1968 .

HURD, E.A. \& SPRATT, E.D. Root patterns in crops as related to water and nutrient uptake. In: GUPTA, U.S., ed. Phisiological aspects of dryland farming. New Delhi, Oxford \& Ibh, 1982. cap.3, p.167-235.

IGUE, K. Dinâmica da matéria orgânica e seus efeitos nas propriedades do solo. In: FUNDAÇÃO CARGILL. Adubação verde no Brasil. Campinas, 1984. p.232-67.

INFORZATO, R. \& CAMARGO, L.S. Sistema radicular do morangueiro (Eragaria hibridos) em duas fases do ciclo vegetativo. Bragantia, Campinas, 32(8): 185-91, 1973.

INFORZATO, R. \& CARVALHO, A.M. de. Estudo do sistema radicular do mamoeiro (Carica papaya L.) em solo podzolizado variação Marilia. Bragantia, Campinas, $26(11): 155-9,1967$. 
INFORZATO, R. \& CASTRO, G.A.P. Estudo comparativo do sistema radicular de duas variedades de rami. Bragantia, Campinas, 35: XIX-XXI, 1976.

INFORZATO, R. \& MASCARENHAS, H.A.A. Sistema racicular do Dolichos lablab em um solo massapê-salmourao. Bragantia, Campinas, 26(16): 213-7, 1967.

INFORZATO, R. \& MASCARENHAS, H.A.A. Estudo do sistema radicular da soja (Glvcine max (L.) Merril) em solo Latossolo Roxo adubado ou sem adubo. Bragantia, Campinas, 28: 175-80,1969.

INFORZATO, R. \& MIYASAKA, S. Sistema radicular do feijoeiro em dois tipos de solos do estado de São Paulo. Bragantia, Campinas, 22(38): 477-81, 1963.

INFORZATO, R. \& TELLA, R. de. Sistema radicular do amendeim. Bragantia, Campinas, 19: CXIX-CXXIII, 1950.

INFORZATO, R.; CAMPOS, H.R.; CAMARGO, L.S. Desenvolvimento do sistema radicular de tomateiro (Livcopersicum esculentun Mill) em plantas com diferentes idades. Bragantia, Campinas, 29(10): 105-13, 1970. 
INFORZATO, R.; GIACOMELLI, E.J.; ROCHELLE, L.A. Sistema radicular do abacaxizeiro, aos 4,8 e 12 meses, plantado no início da estaçao seca, em solo Latossol Vermelhoescuro orto. Bragantia, Campinas, 27(11): 135-41,1968.

JACKSON, W.A. Phisiological effects of soil acidity. In: PEARSON, R.W. \& ADAMS, F., ed. Soil acidity and liming. Madison, American Society o gronomy, 1967. cap.2., p.43-124. (Agronomy, 12).

JOFRE, J.S. Green manuring viewed by a pedologist. Advances in Agronomy, New York 7: 141-87, 1955.

KIEHL, E.J. Manual de edafologia; relações solo-planta. Sao Paulo, Ceres, 1979. 262p.

KIEHL, E.J. \& GALLI, F. Adubação verde com tremoço. O Solo, Piracicaba, 43: 19-23, 1951.

KLEPPER, B.; TAYLOR, H.M.; HUCK, M.G.; FISCUS, E.L. Water relations and growth of cotton in drying soil. Agronomy Journal, Madison, 65: 307-10, 1973. 
KOPKE, U. Methods for studying root growth. In:SYMPOSIUM ON THE SOIL/ROOT OYYSTEM IN RELATION TO BRASIL AGRICULTURE, Londrina, 1980. Proceedings, edited by R.S. and others. Londrina, RUSSELL, Fundaçao Instituto Agronômico do Paraná, 1981. p.303-18.

LINDSAY, W.L. Inorganic phase equilibria of micronutrients in soils. In: MORTVEDT, J.J.; GIORDANO, P.M.; LINDSAY, W.L., ed. Micronutrients in agriculture. Madison, Soil Science Society of America, 1972. p.41-57.

LOPES, A.S. \& COX, F.R. A survey of the fertility status of surface soils under "cerrado" vegetation in Brazil. Soil Science Society American Journal, Madison, 41: 7427,1977 .

LUND, Z.F. The effect of calcium and its relation to several cations in soybean root growth. Soil Science Society American Proceedinds, Madison, 34, 456-9, 1970.

MACKAY, A.D. \& BARBER, S.A. Soil moisture effects on root growth and phosphorus uptake by corn. Agronomy Journal, Madison, $77(4)$ : 519-23, 1985 . 
MCCLURE, J.W. \& HARVEY, C. Use of radiophosphorue in measuring root growth of sorghums. Agronomy Journal, Madison, 54: 457-9, 1962 .

MALTONI, K.L. Alteraçoes físicas e quimicas decorrentes do manejo, ocorridas em Latossolo Vermelho-Amarelo do municipio de Diamantino, M.T. Viçosa, 1988. 102 p. (M.S. - Universidade Federal de Viçosa).

MARSCHNER, H. Mineral nutrition of higher plants. London, Academic Press, 1986, 674p.

MASCARENHAS, H.A.A.; HIROCE, R.; BRAGA, N.R.; MIRANDA, M.A. C. de; POMMER, C.V.; SAWASAKI, E. Efeito do nitrogênio residual de soja na produção do milho. Campinas, Instituto Agronômico, 1978. 16p. (IAC. Boletim Técnico, 58 ).

MEDINA, J.C.; INFORZATO, R.; PETTINELLI, A.; PINTO, L.C. de T. Sistema radicular do fórmio, sisal e bambu imperial. Bragantia, Campinas, 22(6): 59-71, 1963.

MENGEL, D.B. \& BARBER, S.A. Development and distribution of the corn root system under field conditions. Agronomy Journal, Madison, 66: 341-4, 1974. 
MIELNICZUK, J. O potássio no solo. 5.ed. Pirấricaba, Potafos, 1984. 79p.

MIYASAKA, S. Histórico de estudos de adubação rerde, leguminosas viáveis e suas caracteristicas. Ir: FUNDAÇÃO CARGILL. Adubação verde no Brasil. Campinas, Fundação Cargill, 1984. p.64-123.

MIYASAKA, S.; CAMARGO, O.A. de; CAVALERI, P.A.; GODOY, I.J. de; CURI, S.M.; LOMBARDI NETO, F.; MEDINA; J.C.; CERVELINI, G.S.; BULISANI, E.A. Adubação orgânica, adubação verde e rotação de culturas no Estado de São Paulo. Campinas, Fundação Cargill, 1983. 138p.

MUZILLI, O. Influência do sistema de plantio direto, comparado ao convencional, sobre a fertilidade da camada arável do solo. Revista Brasileira de Ciência do Solo, Campinas, 7: 95-102, 1983.

NASCIMENTO, V.M. do; MELO, W.J. de; NEPTUNE, A.M.L. Efeitos da rotação de culturas sobre frações da matéria orgânica de um latossolo sob vegetação de cerrado. Científica, Sao Paulo, 16(1): 13-9, 1988. 
NEME, N.A. Leguminosas para adubos verdes e forragens. São Paulo, Divisão de Fomento Agricola, 1934. 5p. (Boletim, 3).

PEARSON, R.W. Significance of rooting pattern to crop production and some problems of root research. In: CARSON, E.W., ed. The plant root and its envinonment. Virginia, University Press, 1974. cap.10, p.247-70.

PEEVY, W.J. \& NORMAN, A.G. Influence of decomposition of plant materials on properties of the decomposed residues. Soil Science, Baltimore, 65: 209-26, 1948.

PRIMAVESI, A. O manejo ecológico do solo. 2.ed. São Paulo, Nobel, 1979. 541p.

QUAGGIO, J.A. Reação do solo e seu controle. In: SIMPÓSIO AVANÇADO DE QUÍMICA E FERTILIDADE DO SOLO, 1., Piracicaba, 1986. Anais. Campinas, Fundação Cargill, 1986. p. 53-89.

QUAGGIO, J.A.; MASCARENHAS, H.A.A.; BATAGLIA, O.C. Resposta da soja à aplicação de doses crescentes de calcário em Latossolo Roxo Distrófico de cerrado. II Efeito residual. Revista Brasileira de Ciência do Solo, Campinas, 6: 113-8, 1982. 
RAIJ, B. van. Avaliação da fertilidade do solo. 2.ed. Piracicaba, Instituto da Potassa \& Fosfato, 1983. 142p.

RAIJ, B. van \& QUAGGIO, J.A. Métodos de análises de solo para fins de fertilidade, Campinas, Instituto Agronômico, 1983, 31p. (Boletim Técnico, 81 ).

RAIJ, B. van \& ZULLO, M.A.T. Métodos de análise de solo. Campinas, Instituto Agronômico, 1977. 16p. (IAC. Circular, 63).

REICHARDT, $K$. Soil physico-chemical conditions and the development of roots. In: SYMPOSIUM ON THE SOIL/ROOT SYSTEM IN RELATION TO BRASILIAN AGRICULTURE,; Londrina, 1980. Proceedings, Edited by R.S. Russell end others. Londrina, IAPAR, 1981. p. 103-14.

RILEY, D. \& BARBER, S.A. Bicarbonate accumulation and pH changes at tire soybean (GIicine max (L.) Merr.) rootsoil interface. Soil Science Society American Proceedings, Madison, 33: 905-8, 1969.

RITCHEY, K.D.; SILVA, J.E.; SOUZA, D.M.G. Relação entre teor de cálcio no solo e desenvolvimento de raizes avaliado por um método biológico. Revista Brasileira de Ciência do Solo, Campinas, 7: 269-75, 1983. 
RODRIGUEZ, O.; INFORZATO, R.; TÉOFILO SOBRINHO, J. Estudo do sistema radicular de três porta-enxertos para citros em viveiro. Revista Brasileira de Fruticultura, Cruz das Almas, 1(1): 23-30, 1978.

ROSSI, G. \& MUNDSTOCK, C.M. Desenvolvimento do sistema radicular, rendimento e componentes do rendimento do milho (Zea mavs L.) sob diferentes niveis de drenagem do solo. Revista Brasileira de Ciência do Solo, Campinas, 4(1): $1-4,1980$.

RUSSELL,E.J. \& RUSSELL, E.W.. Las condiciones del suelo y el crecimiento de las plantas. 9.ed.. Madrid, Aguilar, 1968. 801p.

RUSSELL, R.S. Plant root systems - their function and interaction with the soil. In: SYMPOSIUM ON THE SOIL/ROOT SYSTEM IN RELATION TO BRASILIAN AGRICULTURE, Londrina, 1980. Proceedings; edited by R.S. Russell and others. Londrina, IAPAR, 1981. P.3-19. 
SANTOS, H.P. dos \& ROMAN, E.S. Rotação de cuľturas. XIV. Efeito de culturas de inverno e de rerão na disponibilidade de nutrientes e matéria oweânica do solo, no período agrícola de 1980 a 1996. Revista Brasileira de Ciência do Solo, Campinas, 13: 303-10, 1989 .

SARRUGE, J.R. \& HAAG, H.P. Análises químicas ea plantas. Piracicaba, ESALQ, 1974. 55p.

SCHUURMANN, J.J. Influence of soil density on root development and growth of oats. Plant and Soil, The Hague, 22, (3): $352-74,1965$.

SCHUURMANN, J.J. \& GOEDEWAAGEN, M.A.J. Methods for the examination of root systems and roots. 2.ed.Wageningen, Pudoc, : 1971, 86p.

SETZER, J. Átlas climático e ecológico do Estaao de São Paulo. São Paulo, Instituto Geológico e Grográfico, 1966. 61p. 
SHOEMAKER, H.E.; McLEAN,E.O.; PRATT, P.F. Buffer methods for determining lime requirement of soils with appreciable amount of exchangeable aluminum. Soil Science Society American Proceedings, Madison, 25: $274-7,1961$

SIIVA, N.M. da. Efeitos da rotação de culturas em algodão no Estado de São Paulo. In: FUNDAÇÃO CARGILL. Adubação verde no Brasil. Campinas, 1984. p.124-8.

SPRATT, E.D. Fertility of a chernozemic clay soil after 50 years of cropping with and without forage crops in rotation. Canadian Journal Soil Science, Ottawa, 46: $207-12, \quad 1966$

SPRATT, E.D. \& McCURDY, E.V. The effect of various longterm soil fertility treatements on the phosphorus status of a clay chernozem. Canadian Journal Soil Science., Ottawa, 46: 29-36, 1966.

STYPA, M.; NUNEZ-BARRIOS, A.; BARRY, D.A.; MILLER, M.H.; MITCHELL, W.A. Effects of subsoil bulk density, nutrient availability and soil moisture on corn root growth in the field. Canadian Journal Soil Science, Ottawa, 67: 293-308, 1987 . 
SUMNER, M.E. \& BOSWELL, F.C. Alleviating nutrient stress. In: ARKIN, G.F. \& TAYLOR, H.M., ed. Modifying the root environment to reduce crop stress., Michigan, American Society of Agricultural Engineers, 1981. cap.4, p.99137.

SUTHERLAND, W.N.; SHRADER, W.D.; PESEK, J.T. Efficiency of legume residue nitrogen and inorganic nitrogen in corn production. Agronomy Journal, Madison, 53: 339-42, 1961.

TACKETT, J.L. \& PEARSON, R.W. Oxigen requirements of cotton seedling roots for penetration of compacted soil cores. Soil Science Society American Proceedings, Madison, 28: 600-5, 1964.

TAYLOR, H.M. \& KLEPPER, B. Water relations of cotton. I. Root growth and water use as related to top growth and soil water content. Agronomy Journal, Madison, 66: 5848,1974 .

TENNANT, D.A. A test of a modified line intersect method of estimating root length. Journal of Ecology, London, 63: $995-1001,1975$. 
TIESSEN, H. Evaluation of soil $\mathrm{N}$ under intercropping and crop rotations on a highly heterogeneous soil. Communications in Soil Science and Plant Analysis, New York, 19(4): 461-70, 1988 .

TISDALL, J.M. \& OADES, J.M. The management of ryegrass to stabilize aggregates of a red-brown earth. Australian Journal of Soil Research, Vctoria, 18: 415-22, 1980.

UCHIKAWA, F.J. Efeito de cultivos continuos de milho (Zea mays L), soja (Glicine max (L) Merrill) e de rotacão milho-soja, sobre algumas propriedades fisicas e químicas de um Latossolo Roxo Eutrófico. Vicosa, 1989. 63p. (M.S. - Universidade Federal de Viçosa).

UNGER, P.W.; ECK, H.V.; MUSICK, J.T. Alleviating plant water stress. In: ARKIN, G.F. \& TAYLOR, H.M. ed. Modifying the root environment to reduce crop stress. Michisan, American Society of Agricultural Engineers, 1981, cap.3, p.61-95.

VASCONCELLOS, C.A. \& PACHECO, E.B. Adubação verde e rotação de culturas. Informe Agropecuário, Belo Horizonte, $13(147): 37-40,1987$. 
VASCONCELLOS, C.A. ; SANS, L.M.A. ; PACHECO, E.E. Influência da rotação de culturas no sistema radicular do milho e em algumas características químicas de un Latossolo Vermelho-escuro Distrófico da regiâc de Sete Lagoas. In: CONGRESSO NACIOMAL DE MILHO E SORGO, 18., Belo Horizonte, 1986. Resumo. Sete Lagoas, EMERAPA/CNPMS, 1986. P.99.

VASCONCELLOS, C.A. ; PACHECO, E.B. ; CRUZ, J.C.; ERANÇA, G.E. de. Adubação verde nas culturas do milho e do sorgo. In: FUNDAÇÃo CARGILL . Adubação verde no Brasil. Campinas, Fundação Cargill, 1984. p.18-29.

VEIHMEYER, F.J. \& HENDRICKSON, A.H. Soil density and root penetration. Soil Science, Baltimore, 65: 487-95, 1948 .

VIDOR, C. \& FREIRE, J.R.J. Relação de substituìção entre calcário e fósforo aplicados ao solo na cultura da soja. Agronomia Sulriograndense, Porto Alegre, 8: 187-93, 1972 .

VIEGAS, G.P.; GARGANTINI, H.; FREIRE, E.S. Adubação do milho. XIII. Efeitos da mucuna, do calcário e de outros adubos sobre as propriedades químicas do solo. Bragantia, Campinas, 19: 91-100, 1960. 
VIEIRA, C. Efeito da adubação verde intercalar sobre o rendimento do milho. Experientiae, Viçosa, 1(1): 1-24, 1961 .

WIERSMA, D. The soil environment and root development. Advances in Agronomy, New York, 11: 43-51, 1959.

WIERSUM, L.K. The relationship of the size and structural rigidity of pores to their penetration by roots. Plant and Soil, The Hague, 9:75-85, 1957.

YAALON, D.H. \& YARON, B. Framework for man-made soil changes an outline of metapedogenesis. Soil Science, Baltimore, 102: 272-7, 1966.

YATES, F. Análise de uma experiência de rotação. Bragantia, Campinas, 12(7/9): 213-28, 1952.

ZONTA, E.P.; MACHADO, A.A.; SILVEIRA, JR., P. Sistema de análise estatistica para microcomputadores: manual de utilização. Pelotas, s.d. 84p. 